\title{
AGR-3/4 Final Data Qualification Report for ATR Cycles 151A through 155B-1
}

\author{
Binh T. Pham
}

INL is a

U.S. Department of Energy

National Laboratory

operated by

Battelle Energy Alliance

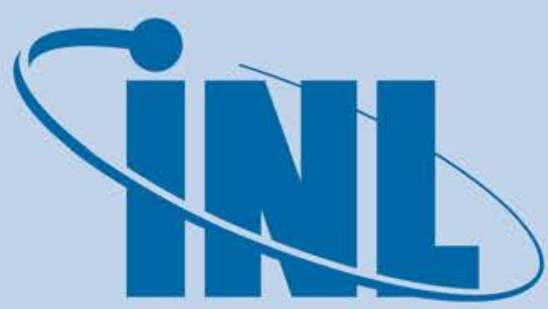

Idaho National Laboratory
March 2015

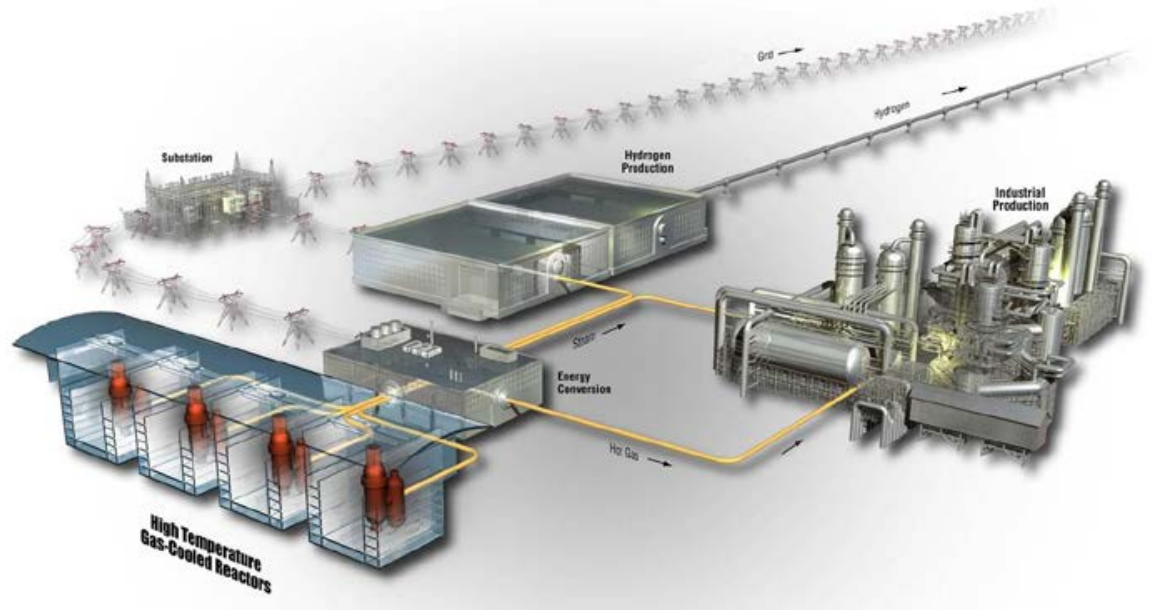




\section{DISCLAIMER}

This information was prepared as an account of work sponsored by an agency of the U.S. Government. Neither the U.S. Government nor any agency thereof, nor any of their employees, makes any warranty, expressed or implied, or assumes any legal liability or responsibility for the accuracy, completeness, or usefulness, of any information, apparatus, product, or process disclosed, or represents that its use would not infringe privately owned rights. References herein to any specific commercial product, process, or service by trade name, trade mark, manufacturer, or otherwise, does not necessarily constitute or imply its endorsement, recommendation, or favoring by the U.S. Government or any agency thereof. The views and opinions of authors expressed herein do not necessarily state or reflect those of the U.S. Government or any agency thereof. 
INL/EXT-14-33780

Revision 0

\title{
AGR-3/4 Final Data Qualification Report for ATR Cycles 151A through 155B-1
}

\author{
Binh T. Pham
}

March 2015

\begin{abstract}
Idaho National Laboratory
Advanced Reactor Technologies Technology Development Office Idaho Falls, Idaho 83415
\end{abstract}

http://www.inl.gov

Prepared for the

U.S. Department of Energy

Office of Nuclear Energy

Under DOE Idaho Operations Office

Contract DE-AC07-05ID14517 



\title{
INL ART TDO
}

\section{AGR 3/4 Final Data Qualification Report for ATR Cycles 151A through 155B-1}

\author{
INLEXT 1433780
}

Revision 0

March 2015

Approved by:

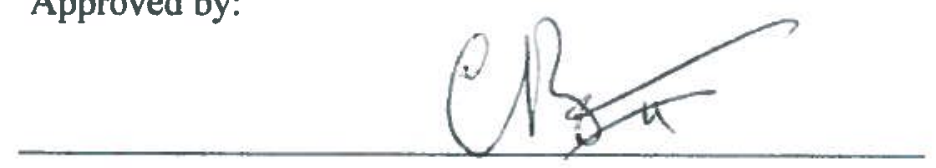

Binh T. Pham

$3 / 17 / 20 / 5$

Author
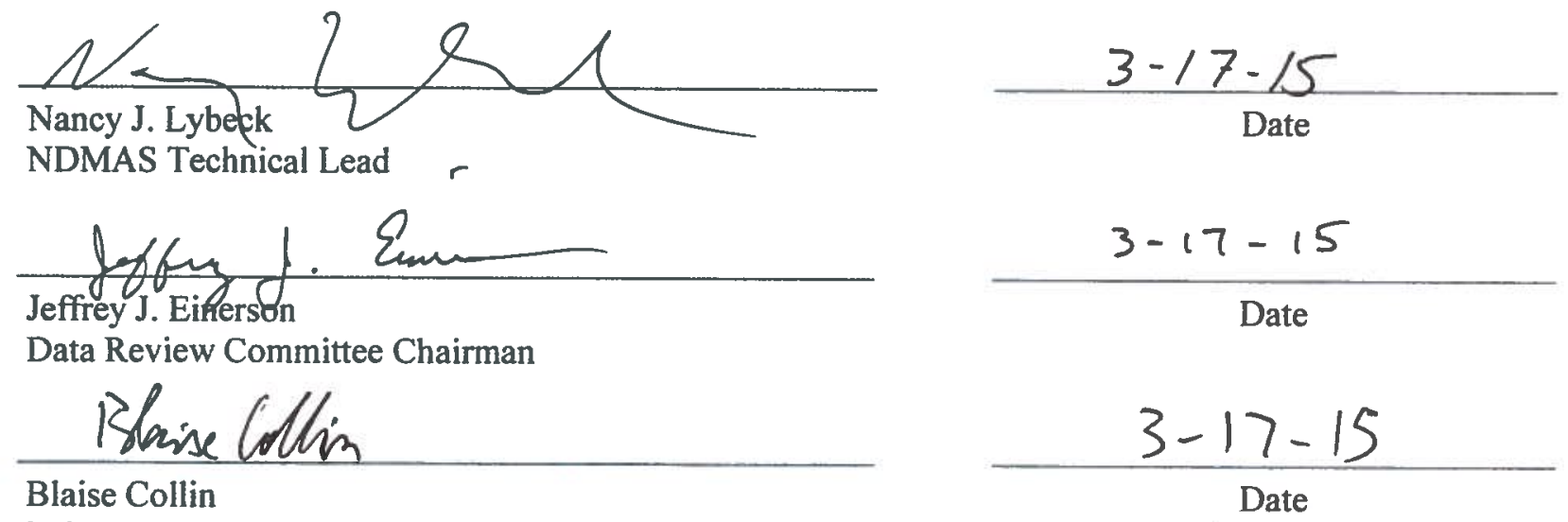

Blaise Collin

Independent Technical Reviewer

Date

Blasise Collin
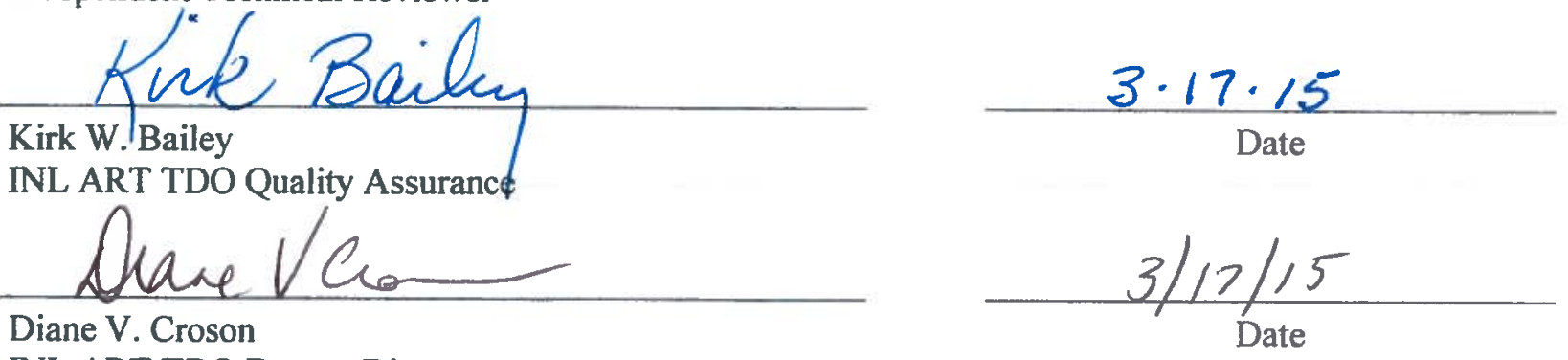

Diane V. Croson

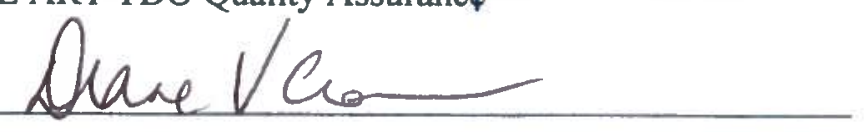

INL ART TDO Deputy Director 



\section{SUMMARY}

This report provides the qualification status of experimental data for the entire Advanced Gas Reactor-3/4 (AGR-3/4) fuel irradiation. AGR-3/4 is the third in a series of planned irradiation experiments conducted in the Advanced Test Reactor (ATR) at Idaho National Laboratory (INL) for the AGR Fuel Development and Qualification Program, which supports development of the High Temperature Gas-Cooled Reactor (HTGR) under the INL Advanced Reactor Technologies Technology Development Office (TDO). The main objective of the AGR-3/4 irradiation experiment is to provide a known source of fission products for subsequent transport through the compact matrix and structural graphite materials from designed-to-fail fuel particles.

Full power irradiation of the AGR-3/4 experiment began on December 14, 2011 (ATR Cycle 151A), and was completed on April 12, 2014 (end of ATR Cycle 155B-1) after 369.1 effective full power days (EFPDs) of irradiation. In the NDMAS database Cycle 155B actually includes 155B and 155B-1 cycles. Thus, the AGR-3/4 experiment was in the reactor core for eight of the ten ATR cycles between 151A and 155B-1. During the unplanned outage cycle, 153A, the experiment was removed from the ATR northeast flux trap (NEFT) location and stored in the ATR canal. This was to prevent overheating of fuel compacts due to higher than normal ATR power during the subsequent Powered Axial Locator Mechanism (PALM) cycle, 153B. The AGR-3/4 experiment was inserted back into the ATR NEFT location during the outage of ATR Cycle 154A on April 26, 2013. Therefore, the AGR-3/4 irradiation data received during these two cycles (153A and 153B) are irrelevant and their qualification status is not included in this report. Additionally, during ATR Cycle 152A the ATR core ran at low power for a short enough duration that the irradiation data are not used for physics and thermal calculations. However, the qualification status of irradiation data for this cycle is still covered in this report. As a result, this report includes data from eight ATR Cycles: 151A, 151B, 152A, 152B, 154A, 154B, 155A, and 155B, as recorded in the Nuclear Data Management and Analysis System (NDMAS).

The AGR-3/4 data streams addressed in this report include thermocouple (TC) temperatures, sweep gas data (flow rates, pressure, and moisture content), and Fission Product Monitoring System (FPMS) data (release rates, release-to-birth rate ratios [R/Bs], and particle failure counts) for each of the twelve capsules in the AGR-3/4 experiment. During Outage Cycle 155A, fourteen flow meters were installed downstream from fourteen FPMS monitors to measure flows from the monitors; qualification status of these data are also included in the report. The final data qualification status for these data streams is determined by a Data Review Committee (DRC) composed of AGR technical leads, Sitewide Quality Assurance (QA), and NDMAS analysts. For ATR Cycles 151A through 154B, the DRC convened on February 12, 2014, reviewed the data acquisition process, and considered whether the data met the requirements for data collection as specified in QA-approved INL ART TDO data collection plans. The DRC also examined the results of NDMAS data testing and statistical analyses, and confirmed the qualification status of the data as given in this report. The qualification status of AGR-3/4 irradiation data during the first six cycles were previously reported in INL/EXT-14-31186. This report presents data qualification status for the entire AGR-3/4 irradiation.

A total of 53,608,130 TC temperature and sweep gas data records were received and processed by NDMAS for AGR-3/4 irradiation. Of these records, 49,051,891 (91.5\% of the total) met data collection and accuracy requirements and are labeled as Qualified. For the first two cycles, ATR Cycles 151A to 151B, data records are 5-minute averaged 
values provided on a weekly basis in EXCEL spreadsheets. For remaining cycles, ATR Cycle 152A through 155B, data records are instantaneous measurements recorded every minute and provided by .csv text files automatically every 2 hours. Therefore, the number of processed irradiation data increased substantially from ATR Cycle 152A on.

For TC readings, 1,498,841 TC records (7.7\% of the total of 19,398,074 TC records) were Failed, mostly because of instrument failures (TC2 in Capsule 2, TC1/2 in Capsule 3, TC1 in Capsule 5, and TC1 in Capsule 6). There are also 305,742 TC records (1.6\% of the total TC records) that were categorized as Trend data because of TC3 drift in Capsule 10 starting from the middle of ATR Cycle 154B. For sweep gas flow rates, 2,751,656 gas flow records ( $8.0 \%$ of the total of 34,210,056 gas flow records) were Failed mostly due to missing capsule flow rate values during low power cycle, $152 \mathrm{~A}$, and negative downstream flow rates during the last cycle, ATR Cycle 155B. The number of Failed gas flow rates is reduced because $1,674,344$ slightly negative capsule flow rate records were reexamined and found to be valid measurements. These data records were replaced with 0 standard cubic centimeters per minute in the database and labeled as Qualified data.

For FPMS data, NDMAS received and processed release and $\mathrm{R} / \mathrm{B}$ data for seven ATR cycles (151A, 151B, 152B, 154A, 154B, 155A, and 155B), when ATR core reached full power during AGR-3/4 irradiation. These data consist of 259,896 release rate records and 259,896 R/B records for the twelve radionuclides (Kr-85m, Kr-87, Kr-88, Kr-89, Kr-90, Xe-131m, Xe-133, Xe-135, Xe-135m, Xe-137, Xe-138, and Xe-139) reported for twelve capsules. There are equivalent numbers of uncertainty (in \%) records associated with release and R/B records. NDMAS also received 732 records of weekly particle failure counts for each of the twelve capsules throughout AGR-3/4 irradiation. Each particle failure count record includes three values: best-estimate, maximum and minimum counts. To date, the FPMS data stored in NDMAS database are preliminary data and their qualification statuses are set to In-process. Detailed documentation of the release rate and $\mathrm{R} / \mathrm{B}$ data for the AGR-3/4 experiment is being issued by the FPMS team. This ECAR will provide the basis for qualification of the AGR-3/4 FPMS data and qualification statuses will be updated accordingly. All the above data have been processed and tested using a SAS-based enterprise application software system, stored in a secure Structured Query Language database, made available on the NDMAS Web portal (https://ndmas.inl.gov), and approved by the INL Scientific and Technical Information Management System for release to both internal and external INL ART TDO program participants. 


\section{CONTENTS}

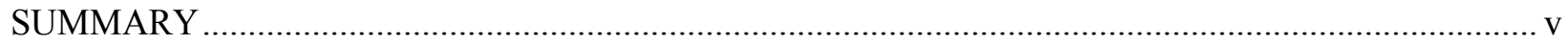

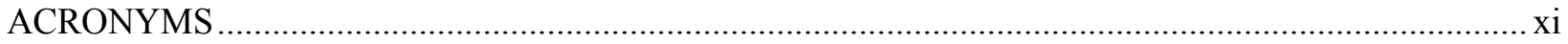

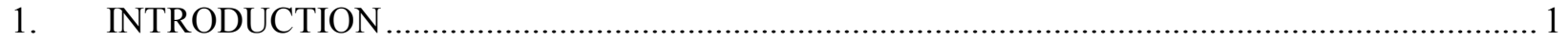

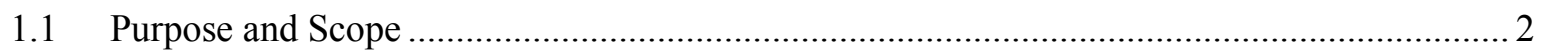

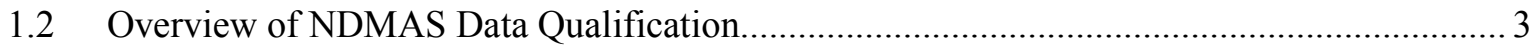

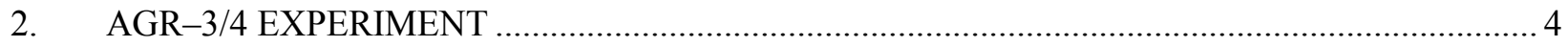

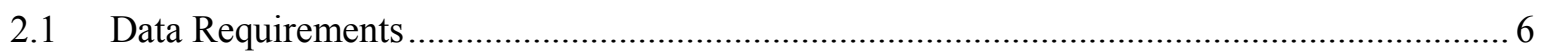

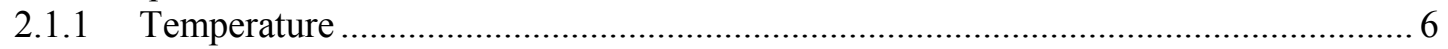

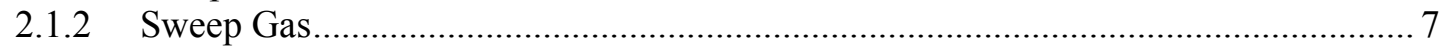

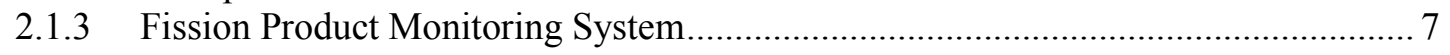

2.2 Qualification Requirements and NQA-1 Conformance …............................................... 8

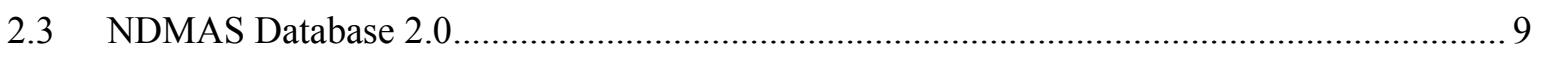

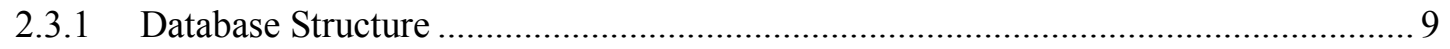

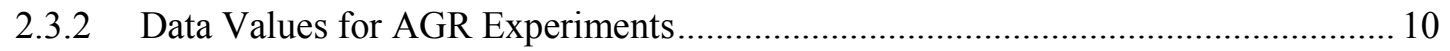

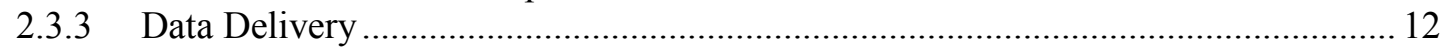

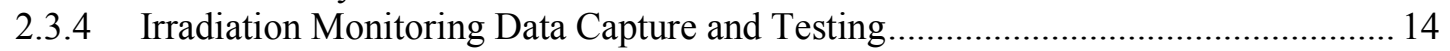

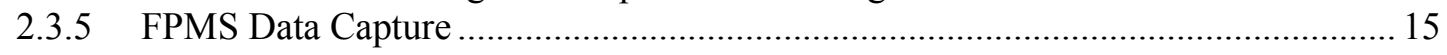

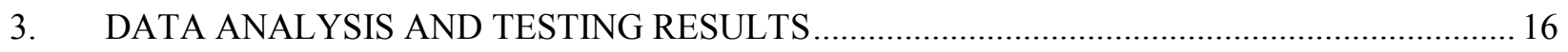

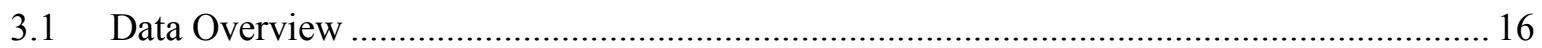

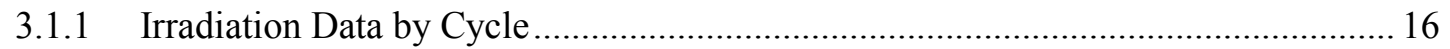

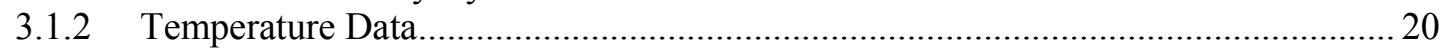

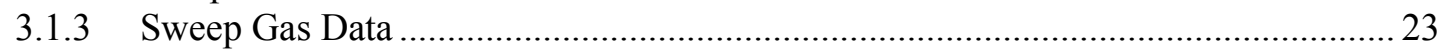

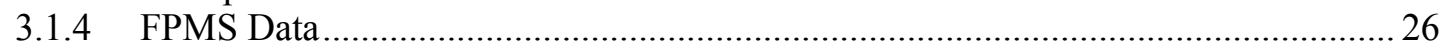

3.2 Testing for Data Anomalies of TC Temperatures.......................................................... 32

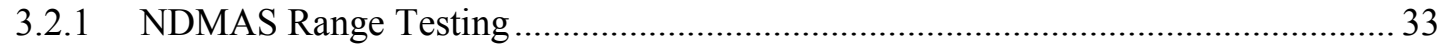

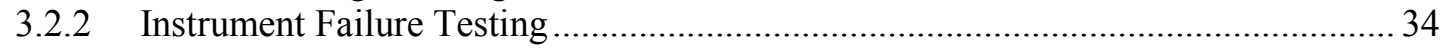

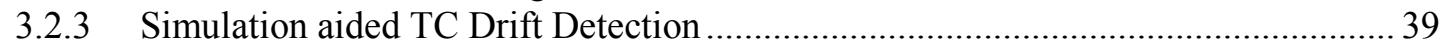

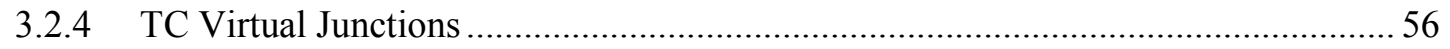

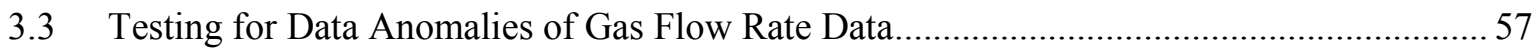

3.3.1 NDMAS Range Testing for Capsule Gas Flow Rates ........................................... 57

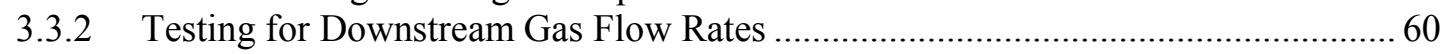

3.3.3 Sweep Gas Flow Data Analysis for Neon Fraction Calculation ................................ 63

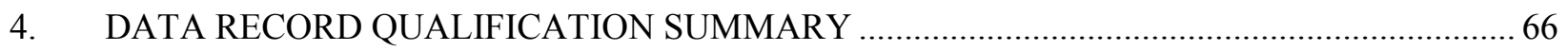

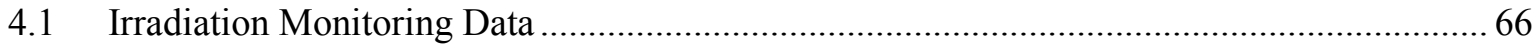

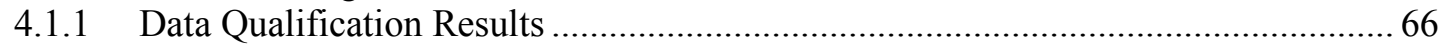

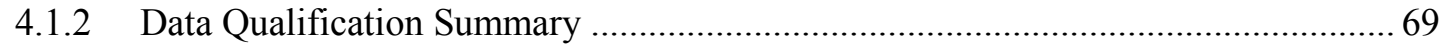

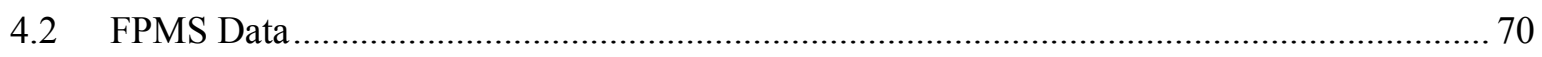

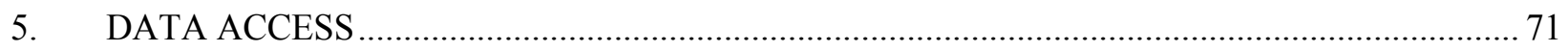

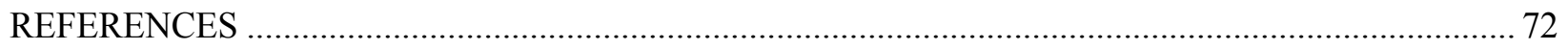




\section{FIGURES}

Figure 1. AGR-3/4 NEFT location in ATR core cross section......................................................... 4

Figure 2. Axial (left) and radial (right) cross-section view of AGR-3/4 capsules..................................... 5

Figure 3. Simplified flow path for AGR-3/4 sweep gas. ...................................................................... 5

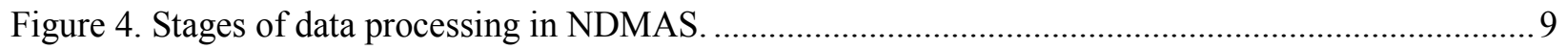

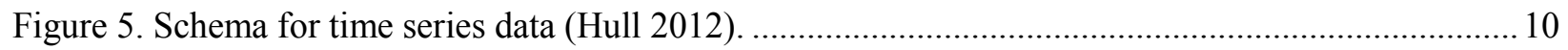

Figure 6. Diagram of TC temperature values used for AGR experiment. .............................................. 11

Figure 7. Diagram of gas flow rate values used for AGR experiment................................................... 12

Figure 8. ATR operating parameters during AGR-3/4 irradiation...................................................... 17

Figure 9. Capsule 10 TC readings around the time when AGR-3/4 was reinserted into the ATR

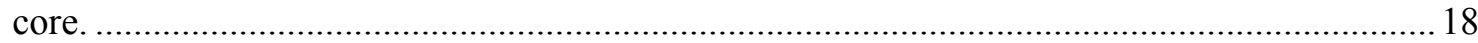

Figure 10. Gas flow rates for Capsules 7-12 around the time when AGR-3/4 was reinserted into the ATR core.

Figure 11. Capsules 7-12 TC temperature data for Cycles 151A-155B ............................................21

Figure 12. Capsules 1-6 TC temperature data for Cycles 151A-155B .............................................22

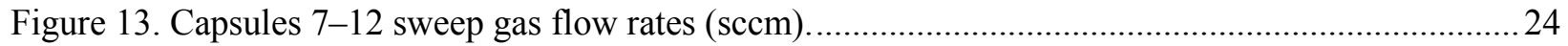

Figure 14. Capsules 1-6 and the Leadout sweep gas flow rates ( $\mathrm{sccm})$............................................25

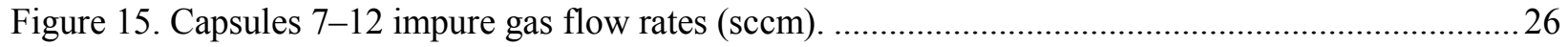

Figure 16. Fission product release rates for Kr-85m, Kr-88, and $\mathrm{Xe}-138$ for Capsules 7-12 ..................22

Figure 17. Fission product release rates for $\mathrm{Kr}-85 \mathrm{~m}, \mathrm{Kr}-88$, and $\mathrm{Xe}-138$ for Capsules $1-6 \ldots \ldots \ldots \ldots \ldots \ldots \ldots . .28$

Figure 18. Fission product R/B ratios for $\mathrm{Kr}-85 \mathrm{~m}, \mathrm{Kr}-88$, and $\mathrm{Xe}-138$ for Capsules $7-12 \ldots \ldots \ldots \ldots \ldots \ldots \ldots . . .29$

Figure 19. Fission product R/B ratios for $\mathrm{Kr}-85 \mathrm{~m}, \mathrm{Kr}-88$, and $\mathrm{Xe}-138$ for Capsules $1-6 \ldots \ldots \ldots \ldots \ldots \ldots \ldots \ldots . . . . . . . . .30$

Figure 20. Particle failure counts for Capsule 1 (left plots) and Capsule 9 (right plots)..........................31

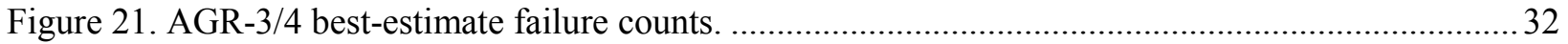

Figure 22. TC2 in Capsule 2 failed right at the beginning of Cycle 154A on 29 April, 2013 at

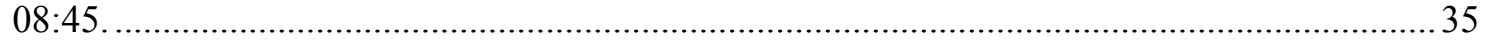

Figure 23. TC1 in Capsule 3 failed on May 17, 2013, at 03:15 (based on actual data)........................... 36

Figure 24. TC2 in Capsule 3 failed on October 9, 2013 at 12:15 (based on actual data). ........................37

Figure 25. TC1 in Capsule 5 failed on January 11, 2014 at 08:30 (based on actual data).........................38

Figure 26. TC1 in Capsule 6 failed on February 13, 2014 at 14:00 (based on actual data).......................39

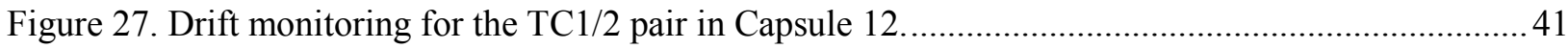

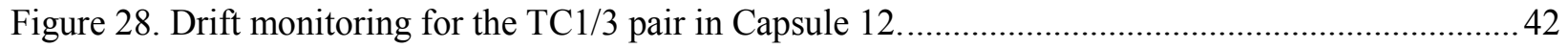

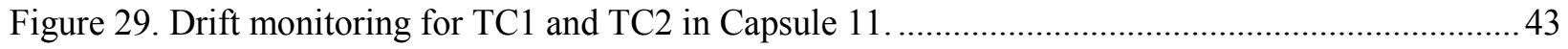




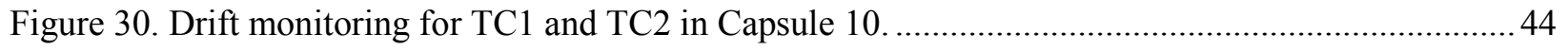

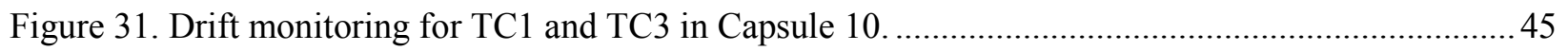

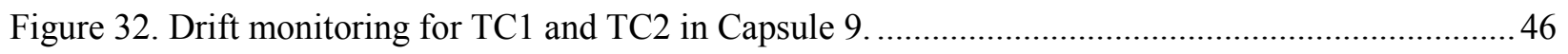

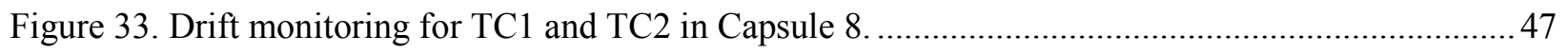

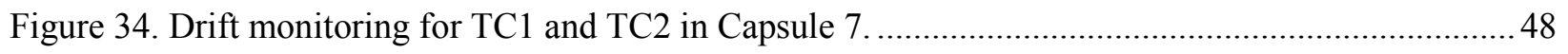

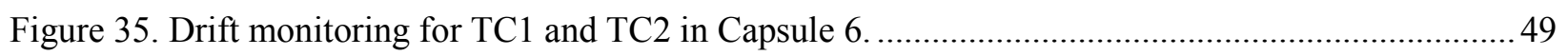

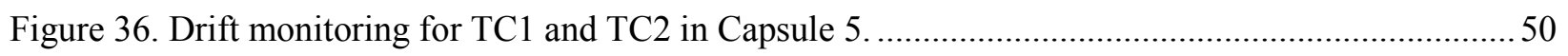

Figure 37. Drift monitoring for TC1 and TC3 in Capsule 5 ................................................................. 51

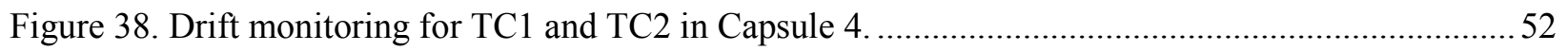

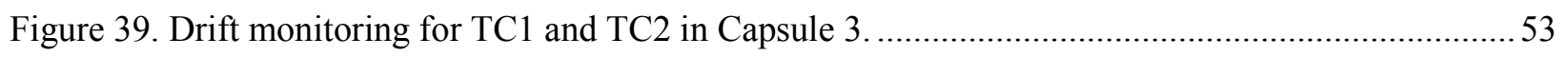

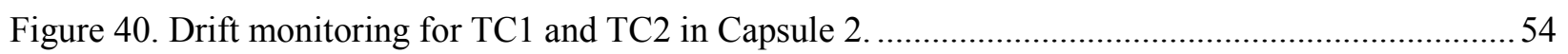

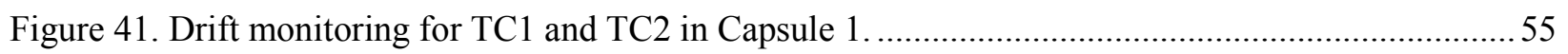

Figure 42. Example of a correlation plot for the TC1, TC2, and TC3 installed in Capsule 12................56

Figure 43. Example of a correlation plot for the TC1 and TC2 installed in Capsule 9............................5 57

Figure 44. Gas flow rates for Capsules 7-12 during the period November 27, 2013 12:00 to

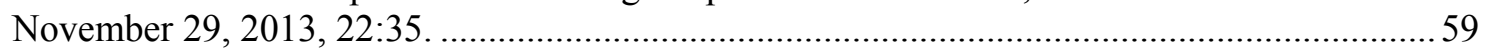

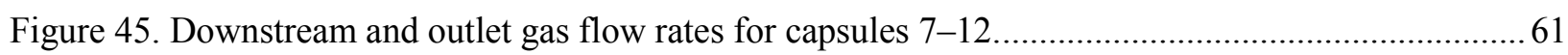

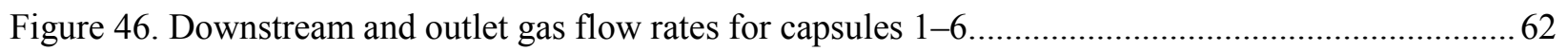

Figure 47. Total inlet and outlet gas flows of the whole AGR-3/4 test train.......................................... 63

Figure 48. Differences between outlet and inlet flows increased in response to the leadout flow increase.

Figure 49. Example of Fuel development and qualification web pages on the NDMAS SharePoint site.

\section{TABLES}

Table 1. Irradiation monitoring data transferred from CDCS to NDMAS. .............................................. 13

Table 2. NDMAS data values for the AGR-3/4 irradiation monitoring and FPMS data.......................... 13

Table 3. Range test limits applied to AGR-3/4 irradiation monitoring data (see Section 2.1)................. 15

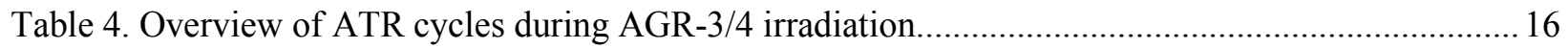

Table 5. Overview of TC temperature data captured during AGR-3/4 irradiation..................................20

Table 6. Overview of gas flow rate data captured during AGR-3/4 irradiation....................................... 23

Table 7. NDMAS tests performed for AGR-3/4 irradiation monitoring data......................................... 33

Table 8. Results of range tests for TC readings during AGR-3/4 irradiation. .......................................... 33

Table 9. TC failures during AGR-3/4 irradiation................................................................................. 34

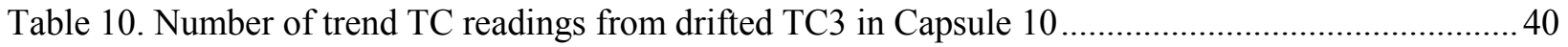


Table 12. Summary of FPM gas flow rates during AGR-3/4 irradiation.

Table 13. Summary of the leadout flow portions and the outlet flow measurement biases for all capsules. 64

Table 14. Summary of TC temperature failures during AGR-3/4 irradiation............................................... 67

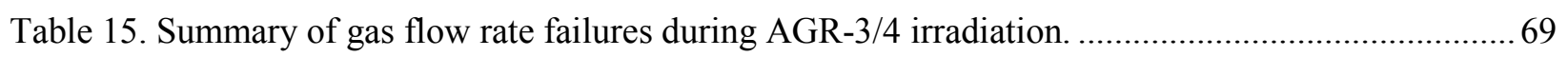

Table 16. Qualification status of TC temperatures and sweep gas flow rates for AGR-3/4 experiment. 


\section{ACRONYMS}

AGC Advanced Graphite Creep

AGR Advanced Gas Reactor

ART Advanced Reactor Technologies

ASME American Society of Mechanical Engineers

ATR Advanced Test Reactor

CDCS Capsule Distributed Control System

DRC Data Review Committee

DTF design to fail

ECAR Engineering Calculations and Analysis Report

EFPD effective full power day

FPM Fission Production Monitoring

FPMS Fission Production Monitoring System

INL Idaho National Laboratory

NDMAS Nuclear Data Management and Analysis System

NEFT northeast flux trap

PALM Powered Axial Locator Mechanism

PIE post-irradiation examination

QA Quality Assurance

$\mathrm{R} / \mathrm{B}$ release rate to birth rate ratio

RDAS Reactor Data Acquisition System

sccm standard cubic centimeters per minute

SQL Structured Query Language

TC thermocouple

TDO Technology Development Office

TFR Technical and Functional Requirements

TRISO tristructural isotropic 


\section{AGR-3/4 Final Data Qualification Report for ATR Cycles 151A through 155B-1}

\section{INTRODUCTION}

This report presents the data qualification status of fuel irradiation monitoring data from eight Advanced Test Reactor (ATR) cycles (151A, 151B, 152A, 152B, 154A, 154B, 155A, and 155B) covering the entire Advanced Gas Reactor -3/4 (AGR-3/4) experiment irradiation. The ATR Cycle 155B-1 data was combined with the ATR Cycle 155B. AGR-3/4 is the third in a series of planned irradiation experiments conducted in the ATR at Idaho National Laboratory (INL) for the AGR Fuel Development and Qualification Program, which supports development of Advanced Reactor Technologies (ART) under the INL ART Technology Development Office (TDO). The primary experimental objectives are: (1) irradiate tristructural isotropic (TRISO) UCO (uranium oxycarbide) fuel particles, including designed to fail (DTF) fuel particles that will provide a known source of fission products for subsequent transport through compact matrix and structural graphite materials; and (2) assess the effects of sweep gas impurities typically found in the primary circuit of high temperature gas-cooled reactors (HTGRs), such as $\mathrm{CO}, \mathrm{H}_{2} \mathrm{O}$, and $\mathrm{H}_{2}$, on fuel performance and subsequent fission product transport (PLN-3636, SPC-1345, and PLN-3867).

The AGR-3/4 experiment was first at full power on December 14, 2011 (ATR Cycle 151A); irradiation was completed on April 12, 2014 (end of ATR Cycle 155B-1) after 369.1 effective full power days (EFPDs) of irradiation. During this time, there are only eight cycles when the AGR-3/4 experiment was in the reactor core. During the ATR unplanned outage cycle, $153 \mathrm{~A}$, the experiment was removed from the ATR northeast flux trap (NEFT) location and stored in the ATR canal. This was to prevent overheating of fuel compacts due to higher than normal ATR power during the subsequent Powered Axial Locator Mechanism (PALM) Cycle 153B. The AGR-3/4 test train was reinserted into the ATR NEFT location on April 26, 2013, during the outage of ATR Cycle 154A. As a result, the AGR-3/4 irradiation data received during these two cycles (153A and 153B) are irrelevant, and therefore were excluded from this report. During the low power Cycle 152A, the ATR ran at very low power for a few short periods of time, resulting in an average effective power of $0.209 \mathrm{MW}$ for 89.6 hours. The physics modelers assume negligible burn-up was accumulated for AGR-3/4 experiment fuel, and thus this cycle can be considered as an extended power outage for the experiment fuel depletion calculation. However, irradiation data during this cycle are included in this report because they are valid measurements.

All experimental data from the AGR-3/4 experiment are captured and processed by the Nuclear Data Management and Analysis System (NDMAS). NDMAS processes AGR data into a secure Structured Query Language (SQL) Server database, performs testing on and analysis of the data for anomalies identification, presents the data via an access-controlled Web portal, and documents the qualification status of the data. The AGR-3/4 data streams addressed in this report include thermocouple (TC) temperatures, sweep gas flow rates, and fission product monitoring system (FPMS) data (release rates, release-rate-to-birth rate ratios [R/Bs], and particle failure counts) for each of the 12 capsules in the AGR-3/4 experiment. For the first two cycles, 151A and 151B, irradiation data are five average values delivered weekly in .csv files. For NDMAS to reach its maximum utility in support of the temperature control of experiments, from ATR Cycle 152A on, irradiation data were delivered to NDMAS automatically every 2 hours. Each batch of data received contains ATR operating condition data and irradiation monitoring data for both AGR and Advanced Graphite Creep (AGC) current experiments. The automatic data transfer includes instantaneous values at 1-minute intervals, resulting in a much larger number of data records.

Ultimately, the Data Review Committee (DRC) determines the final data qualification status of AGR-3/4 irradiation data. The DRC is comprised of project technical leads, Quality Assurance (QA), NDMAS analysts, and an independent technical reviewer (Appendix A). This report documents the data 
qualification process and data status covering the period from December 12, 2011 (when records started), through April 22, 2014 at 13:45, 10 days after the power-down of ATR Cycle 155B (April 12, 2014) in order to include gas flow rate data used in calculation of FPMS data.

\subsection{Purpose and Scope}

The AGR-3/4 fuel irradiation monitoring data streams examined in this report include TC temperatures, sweep gas measurements (gas flows, pressure, and moisture), and fission product monitoring data. All anomalous data flagged by NDMAS analysts were presented to the DRC. Final data qualification status for these data streams is determined by the DRC. The DRC considers: (1) whether the data meet the requirements for data collection as specified in Test Plans, Test Specifications, Technical and Functional Requirements (TFR), and QA plans; (2) the results of data testing and statistical analyses as performed by the NDMAS; (3) other QA-approved data reports submitted by data generators such as Engineering Calculations and Analysis Reports (ECARs); and (4) whether the data support application to the defined intended use (MCP-2691, "Data Qualification"). All of the above information is summarized in this report. The final DRC findings on data qualification status are documented using the Data Evaluation Report, FRM-1073, which is stored as a record in the INL Electronic Document Management System (EDMS).

This report describes: (1) data handling procedures within NDMAS after receipt of the data from data generators; (2) the data structure, including data packages, components, attributes, and response variables; (3) NDMAS testing and statistical methods used to help identify possible data anomalies; (4) summarized information on test results and resolutions; and (5) the qualification status of the AGR-3/4 data records received by NDMAS during AGR-3/4 irradiation.

Fuel irradiation monitoring data reported herein include the following for each of 12 independently controlled and monitored capsules in the AGR-3/4 experiment:

- TC temperatures (three TCs each in Capsules 5, 10, and 12; and two TCs in each remaining capsule)

- Sweep gas (helium, neon, impure, outlet) measurements (mass flow rates, pressure, and moisture content) and flow rates from additional flow meters were installed downstream from the FPMS detectors

- Krypton and xenon radionuclide (12 isotopes) release rates measured by the FPMS detectors and subsequently calculated krypton and xenon radionuclide R/Bs. The FPMS data also includes weekly particle failure counts.

The basis for the qualification status of FPMS data will be contained in QA-approved ECARs submitted by the FPMS technical staff. These ECARs will provide independent verification that the FPMS data submitted to NDMAS meet data collection requirements and conform to NQA-1 (ASME NQA-1-2008 with 1a 2009 addenda) requirements. No similar ECARs exist for the TC and sweep gas data, so the basis for their data qualification is the DRC review of the data, data testing and analysis results, and data collection documentation as presented in this report.

This document does not address the qualification status of three additional AGR-3/4 data streams stored in the NDMAS database: fuel fabrication data, thermal/neutronics simulation data, and post-irradiation examination (PIE) data. All AGR-3/4 fuel fabrication data were qualified based on INL receipt and review of hard-copy vendor Data Certification Packages. These data have been stored in the NDMAS database and made available on the NDMAS Web portal (https://ndmas.inl.gov). AGR-3/4 thermal/neutronics simulations are generated by the program modelers. The thermal/neutronics data will be entered into the NDMAS database after ECARs are issued by the modelers. AGR-3/4 PIE has not yet begun.

ATR operating condition data, including lobe powers, outer shim control cylinder positions, neck shim positions, and control rod positions, are stored in the NDMAS database and presented with AGR 
irradiation data on the NDMAS Web portal to help experimental interpretation and to provide input for physics calculations. Because ATR data are generated outside of the INL ART TDO program, NDMAS does not formally qualify these data on a routine basis. However, to verify QA program execution for use as an NDMAS data stream, the Sitewide QA organization performed an inspection of the ATR data acquisition systems and data collection processes (IAS121679 2012). This inspection confirmed implementation of the INL QA program (PDD-13000, "Quality Assurance Program Description") for the ATR data used by NDMAS in the INL ART TDO program. In addition, NDMAS also performed several simple tests to exclude obvious failed lobe power data, preventing their use in physics calculations.

\subsection{Overview of NDMAS Data Qualification}

NDMAS roles and responsibilities regarding data qualification are detailed in PLN-2709, "Nuclear Data Management and Analysis System Plan," and MCP-2691.

Some of the primary tasks performed by NDMAS related to data qualification are:

- Archiving submitted data in native file format on a secure network server under version control.

- Processing the data into standardized electronic data sets, storing the data in a secure electronic database compliant with the INL ART TDO quality assurance program plan (PLN-2690) and the records management plan (PLN-3319), and testing the data to ensure accuracy. NDMAS is currently using SAS ${ }^{\circledR}$ Enterprise Guide and a secure Microsoft SQL server (the "Vault") for these purposes.

- Analyzing irradiation-monitoring data to identify possible data anomalies and trends using various $\mathrm{SAS} \circledast$ statistical tools such as range testing, control charts, correlation analyses, and regression analyses. These results are included in data qualification reports (such as this one), and are considered by the DRC in their determination of final data Qualification State.

- Documenting the receipt of QA-approved data reports (e.g., ECARs) for FPMS and fuel fabrication data, which provide the basis for their data qualification status.

- Providing secure and appropriate Web access to the data (https://ndmas.inl.gov), information on the data qualification status, and requested data analyses to end users, including external research partners.

All the AGR-3/4 data currently being collected at INL are considered to be Type $A$ - data obtained within an NQA-1 QA program that must meet specific requirements for data collection with independent verification that those requirements were met (MCP-2691). The results of this process are one of three data Qualification States applied to each data record:

- Qualified. Independent verification documenting that the data meet the requirements for a specific end use as defined in a data collection plan and were collected within an NQA-1 or equivalent QA program. Any nonconformances are concluded to not affect the usability of the data.

- Trend. Independent verification identifying minor flaws or gaps in meeting requirements for data use. Even so, the data still provide information that can be used by the program. Data were collected within an NQA-1 or equivalent QA program.

- Failed. Independent verification identifies major flaws in meeting data collection requirements. Data do not provide information about the system or object. Data are not useable by the program as intended. 
Prior to the data receiving a final Qualification State, NDMAS sets the data Qualification State to In Process for data that have already been stored in NDMAS. Time-critical data, such as the fuel irradiation data, are made available on the NDMAS Web portal while data qualification is In Process to facilitate near real-time monitoring of experimental results by project staff to improve control of the test conditions predefined in the test specification plan (SPC-1345, "AGR-3/4 Irradiation Test Specification").

\section{AGR-3/4 EXPERIMENT}

The primary objectives of the AGR-3/4 experiment are defined in PLN-3636, "Technical Program Plan for the Advanced Reactor Technologies Technology Development Office/Advanced Gas Reactor Fuel Development and Qualification Program." A detailed description of the experiment is provided in PLN-3867, "AGR-3/4 Irradiation Experiment Test Plan.” The fuel to be irradiated in AGR-3/4 contains conventional TRISO fuel particles with UCO kernels similar to the baseline fuel used in the AGR-1 experiment, and DTF fuel particles whose kernels are identical to the driver fuel kernels but whose coatings are designed to fail under irradiation, leaving fission products to migrate through the surrounding materials (PLN-3867). The AGR-3/4 test train was inserted in the NEFT location of the ATR core as shown in Figure 1 during the outage portion of ATR Cycle 151A in December 2011.

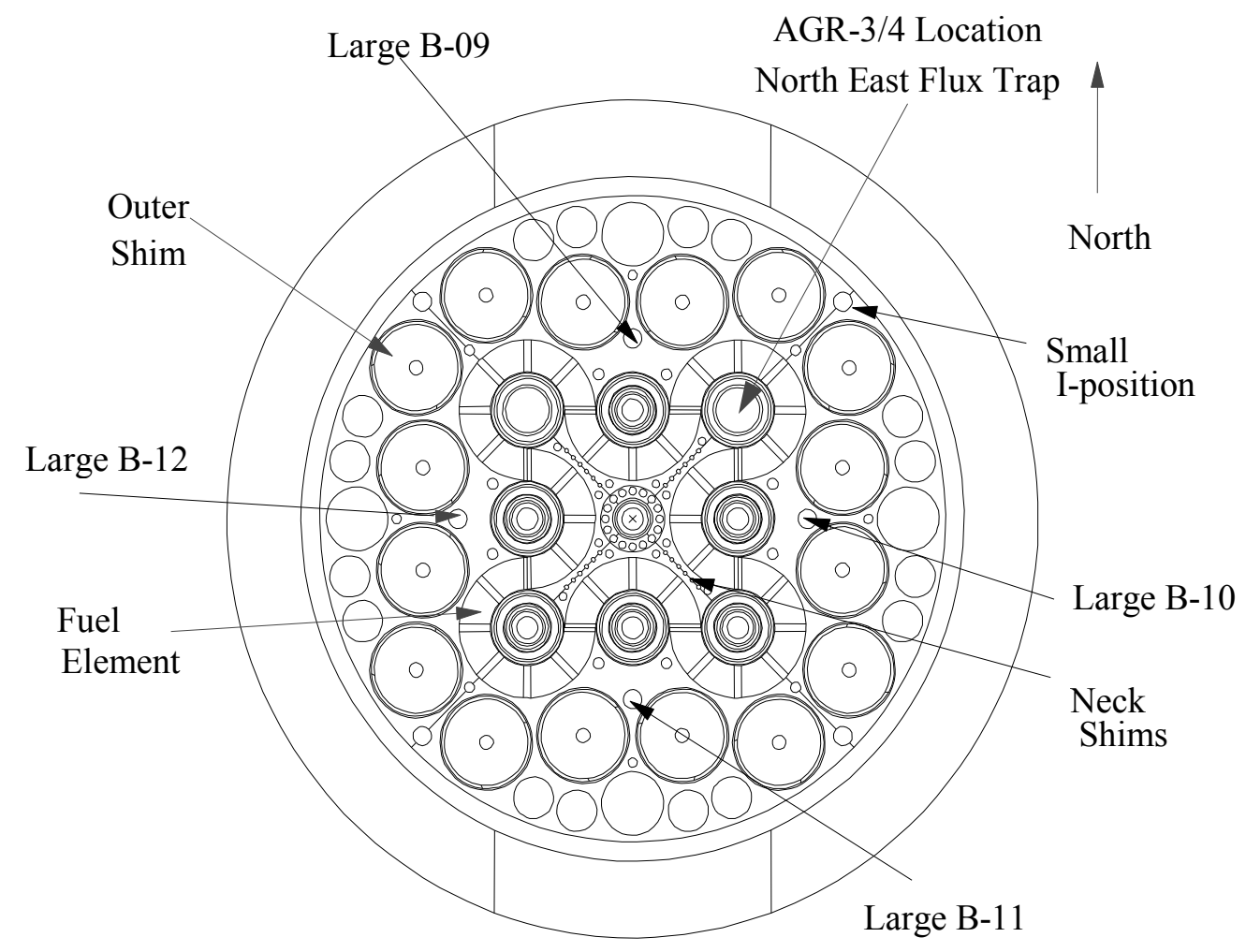

Figure 1. AGR-3/4 NEFT location in ATR core cross section.

AGR-3/4 test train is comprised of 12 independently controlled and monitored capsules stacked on top of each other to form a test train using the full 1.22-m active core height. Each capsule contains four 1.27 -cm-long compacts $(0.5$ inch). A leadout tube holds the experiment in position and contains and protects the gas lines and TC wiring extending from the test train to the reactor penetration. Three TCs are located in each of Capsules 5, 10 and 12; and two TCs are located in each remaining capsule, as shown in the right side of Figure 2. By the end of irradiation, five out of the 27 total installed TCs in the AGR-3/4 experiment failed: TC2 in Capsule 2, TC1 and TC2 in Capsule 3, TC1 in Capsule 5, and TC1 in Capsule 6 (TC failures are listed according to their failure time from earliest to latest). Each capsule has an independent gas line to route a helium/neon gas mixture that is adjusted for the purpose of controlling 
experiment fuel temperatures during irradiation and transporting any fission products released from the capsules to the corresponding FPMS detector by the gas outlet line (Figure 3). Irradiation data including TC temperatures and sweep gas flow rates received in NDMAS from ATR Cycles 151A and 151B are 5-minute average values; all later data are instantaneous measurements at 1-minute intervals.

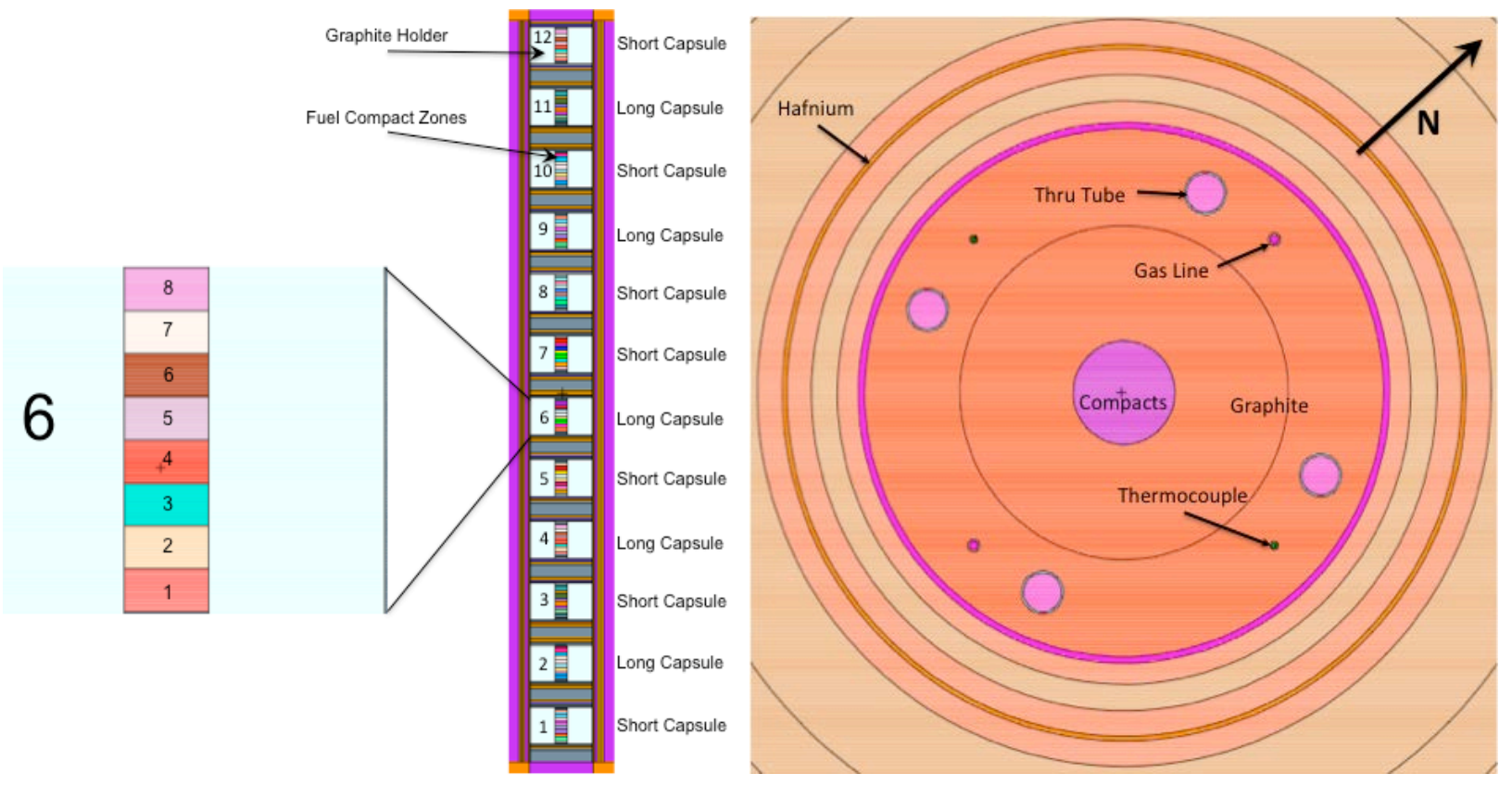

Figure 2. Axial (left) and radial (right) cross-section view of AGR-3/4 capsules.

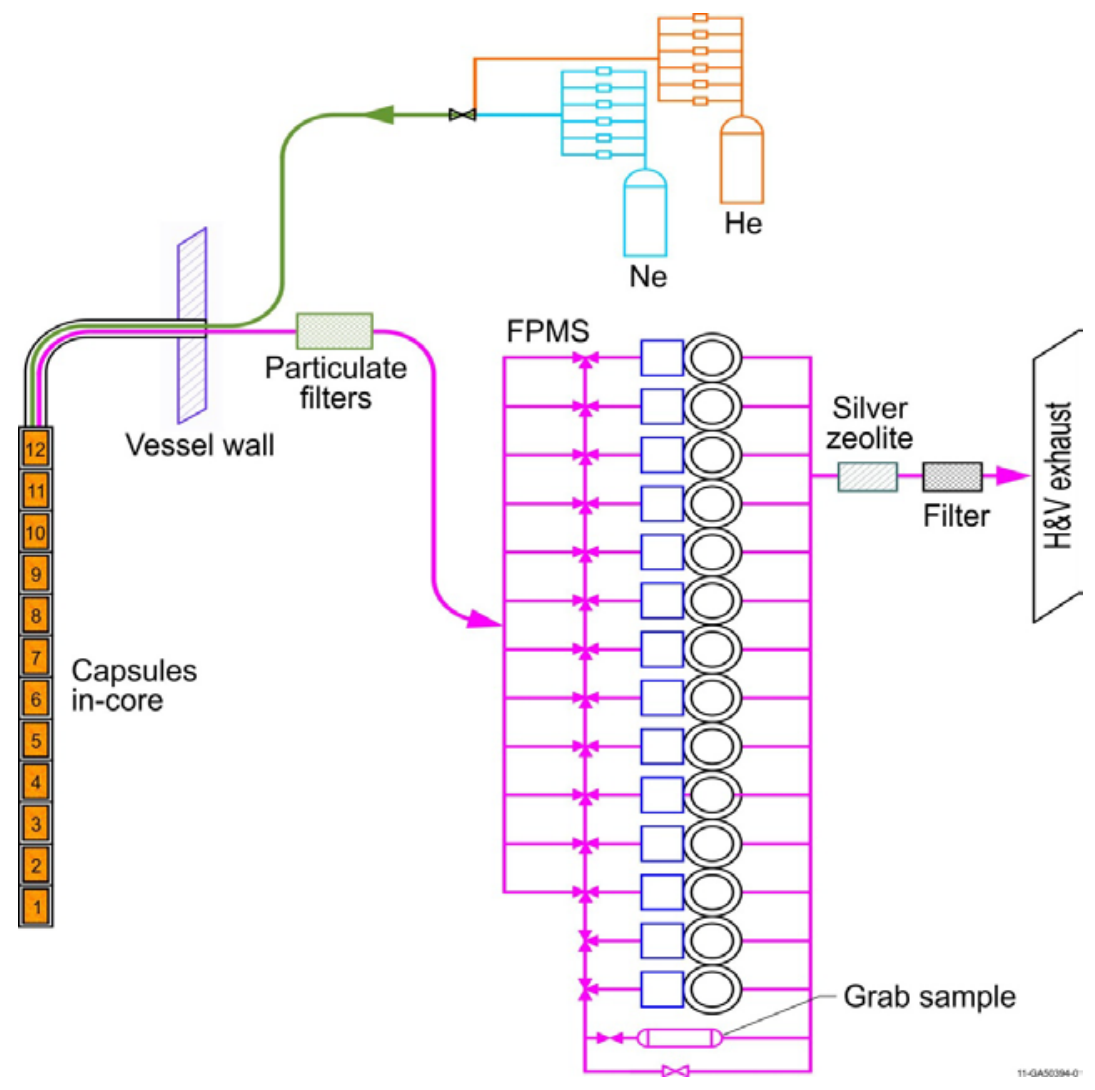

Figure 3. Simplified flow path for AGR-3/4 sweep gas. 
The FPMS detector for each capsule is capable of detecting individual fuel particle failures and providing fission product release rates for the 12 radionuclides as specified in SPC-1345. To assess the effects of sweep gas impurities on fuel performance and subsequent fission product transport, the impure gas was injected into any of Capsules 7-12 using additional flow controllers. This impure gas consists of $98 \%$ or $99 \%$ helium contaminated with $\mathrm{CO}, \mathrm{H}_{2} \mathrm{O}$, and $\mathrm{H}_{2}$, which are typically found in the primary circuit of high temperature gas-cooled reactors. Thus, each capsule would have combined helium/neon flow from a mass flow controller and any additional impure gas flow. During the outage phase of ATR Cycle 155A, 14 flow meters were installed downstream from fourteen fission product monitoring system (FPMS) monitors to measure flows from the monitors. These flows are referred as "FPM" flows to differentiate them from gas flows to/from capsules; the qualification statuses of these data are also included in this report.

\subsection{Data Requirements}

Requirements and specifications for the AGR-3/4 irradiation experiment are contained in SPC-1345 and TFR-656, "Temperature Control and Off Gas Monitoring Systems for Advanced Gas Reactor Experiment AGR-3/4." Significant features of the test train are presented in the Technical and Functional Requirements documents (TFR-630 2011 and TFR-729 2011). In addition, beginning at the start of Cycle 152A, an automated feed was implemented to transfer to NDMAS both ATR operating data (Reactor Data Acquisition System [RDAS]) and capsule irradiation data (Capsule Distributed Control System [CDCS] for AGC and AGR experiments) every 2 hours as described in TFR-747, "RDAS-CDCS Data Transfer to NDMAS," Revision 3.

The following requirements include only those related to the measured data provided to NDMAS during the AGR-3/4 experiment (TC temperatures; sweep gas flow rates including impure gas, pressure, and moisture content; and FPMS data). They do not include requirements related to process or instrument parameters not reported to NDMAS, requirements specifying as-installed instrument accuracy that cannot be verified during the experiment (e.g., sweep gas flow rate accuracy of $\pm 2 \%$ ), as-installed materials specifications (e.g., hafnium shield purity), or requirements that can only be evaluated by simulated modeling or PIE activities (e.g., fast neutron fluence and burnup).

The requirements given in the following sections are requirements for the irradiation test conditions. Actual data may not meet some of these requirements, but may still be flagged as Qualified data. Data are Qualified based on compliance with NQA-1, passing statistical tests, and confirmation by the Data Review Committee.

\subsubsection{Temperature}

The irradiation experiment condition requirements relating to capsule temperature are summarized in (SPC-1345). Fuel temperatures can only be evaluated using thermal simulation modeling. The requirements listed below are for reference only. TC temperature data cannot be rigorously compared to these requirements because the TCs do not directly measure the fuel temperature, but instead measure the lower temperatures of the graphite sink for all of the capsules and the graphite matrix for three capsules $(5,10$, and 12), which are outside the fuel compacts (see Figure 2). The AGR-3/4 temperature specification is listed as follows:

- The instantaneous peak fuel temperature for each capsule shall be $\leq 1800^{\circ} \mathrm{C}$.

- The time averaged peak fuel temperature shall be $900 \pm 50^{\circ} \mathrm{C}$ for one capsule, $1100 \pm 50^{\circ} \mathrm{C}$ for up to six capsules, $1200 \pm 50^{\circ} \mathrm{C}$ for up to four capsules, and $1300 \pm 50^{\circ} \mathrm{C}$ for one capsule.

- The instantaneous peak temperature for the sink material in each capsule shall be $\leq 650^{\circ} \mathrm{C}$.

- Readings from each TC shall be recorded at least every 5 minutes during irradiation, and each TC shall have an as-installed accuracy of $\pm 2 \%$ of reading irradiation (measurement requirement in SPC-1345). 


\subsubsection{Sweep Gas}

The irradiation experiment condition requirements relating to sweep gas (helium, neon, combined outlet) are summarized as follows (SPC-1345, TFR-656, and PLN-3867):

- The moisture content of inlet sweep gas on the inlet side of the capsule shall be $<5$ parts-per-million (ppm) $\mathrm{H}_{2} \mathrm{O}$, measured at least once after each gas cylinder change at a dew point of $-100 \pm 2.5^{\circ} \mathrm{C}$ (SPC-1345).

- The moisture content of the sweep gas on the outlet side of the capsule shall be measured at least every hour at a dew point of $-100 \pm 2.5^{\circ} \mathrm{C}$ and shall be indicated in volumetric water concentration in ppm (SPC-1345). There is no published ppm limit or specification for moisture content on the capsule outlet side; values are monitored to ensure they do not exceed the inlet specification $(<5 \mathrm{ppm})$, which may indicate a leak (J. Maki, personal communication).

- The flow rate of each sweep gas constituent shall be measured with an accuracy of $\pm 2 \%$ and shall be recorded at least every hour during irradiation and continuing for at least 2 days after each reactor shutdown (SPC-1345).

- Gas flow rates will be $\leq 50 \mathrm{sccm}$ (standard cubic centimeters per minute) at a pressure of approximately 15 psia or $0.103 \mathrm{MPa}$ (PLN-3867).

- Before reactor startup, the gas flow will be set at 100\% helium. One or a combination of several thermocouples in the experiment will be selected for temperature control. After the ATR reaches full power and all startup activities are complete, the control system will be initialized and will adjust the helium/neon mixture to control test temperature to meet the experiment's temperature requirement (TFR-656).

- Flow to the capsules will be monitored and controlled by the Distributed Control System using mass flow controllers with an accuracy of $\pm 2 \%$ and the system will allow flow rates from 0 to $100 \mathrm{sccm}$ (TFR-656).

\subsubsection{Fission Product Monitoring System}

The irradiation experiment condition requirements relating to the FPMS are as follows (SPC-1345):

- Able to detect every individual particle failure from each capsule, up to and including the first 250 failures, and able to identify in which capsule each failure had occurred (operational requirement in SPC-1345).

- Transit time of sweep gas $<25$ minutes from each capsule to the FPMS (operational requirement in SPC-1345).

- Continuous measurements of total radiation level of the sweep gas from each capsule (measurement requirement in SPC-1345).

- At a minimum, concentrations of Kr-85m, Kr-87, Kr-88, Xe-131m, Xe-133, and Xe-135 shall be measured in the sweep gas from each capsule and recorded at least daily during irradiation. If possible, the concentrations of Kr-89, Kr-90, Xe-135m, Xe-137, Xe-138, and Xe-139 should also be measured in the sweep gas from each capsule and recorded at least daily during irradiation (measurement requirement in SPC-1345).

- At a minimum, concentrations of Xe-133, Xe-135, and Xe-135m shall be measured in the sweep gas from each capsule and recorded daily for at least 2 days following each reactor shutdown (measurement requirement in SPC-1345). 


\subsection{Qualification Requirements and NQA-1 Conformance}

All electronically recorded Type $A$ data are to be validated and qualified to confirm conformance with data collection requirements. For the irradiation monitoring data streams, this includes the following types of data for each capsule:

- TC temperatures (three each in Capsules 5, 10, and 13; and two for each of the remaining nine capsules)

- Sweep gas measurements (mass flow rates for helium inlet, neon inlet, total outlet, and impure; pressure; and moisture content)

- FPMS krypton and xenon radionuclide release rates and associated error

- $\quad$ FPMS R/Bs and associated error for krypton and xenon radionuclides

- Weekly fuel particle failure counts.

Qualified data must be collected in accordance with data collection plans that are NQA-1 compliant. Compliance of the irradiation monitoring data addressed in this report was verified independently by a DRC comprised of AGR technical leads, Sitewide QA, an independent peer reviewer, and NDMAS analysts.

The data collection requirements are documented in the following QA-approved plans, procedures, specifications, and software user guides, which implement NQA-1 requirements for the INL ART TDO program:

- Program Documents

- MCP-2691, "Data Qualification”

- LWP-13621, "Software Quality Assurance for Research and Development Activities"

- PLN-2690, "Idaho National Laboratory Advanced Reactor Technologies Technology Development Office Quality Assurance Program Plan"

- PLN-3319, "Records Management Plan for the INL ART Technology Development Office"

- AGR Experiment Documents

- PLN-3636, "Technical Program Plan for the Advanced Reactor Technologies Technology Development Office/Advanced Gas Reactor Fuel Development and Qualification Program"

- PLN-3867, “AGR-3/4 Irradiation Experiment Test Plan"

- SPC-1345, "AGR-3/4 Irradiation Test Specification"

- TFR-630, “Advanced Gas Reactor AGR-3/4 Experiment Test Train”, Technical and Functional Requirements

- TFR-656, "Temperature Control and Off Gas Monitoring Systems for Advanced Gas Reactor Experiment AGR-3/4"

- TFR-747, "Technical and Functional Requirements: RDAS-CDCS Data Transfer to NDMAS"

- $\quad$ FPMS Documents (all approved by Sitewide QA)

- GDE-503, "Users' Guide for the Fission Product Monitoring System"

- PLN-3551, "Fission Product Monitoring System Operability Test Plan for the AGR Experiment Series." 


\subsection{NDMAS Database 2.0}

The current data structure in the Vault, NDMAS database Version 2.0 (Hull 2012), uses best database practices to accommodate the number of records and the complexity of the data. This structure allows efficient storage of large amounts of data and all aspects of associated information (Meta data). The systematic table structure in this relational database also speeds up the retrieval of a large amount of data via the predefined views and customized tables in the Vault. This section explains the data flow to NDMAS and describes data specific to the AGR-3/4 irradiation experiment. Figure 4 summarizes the stages of data processing within NDMAS.

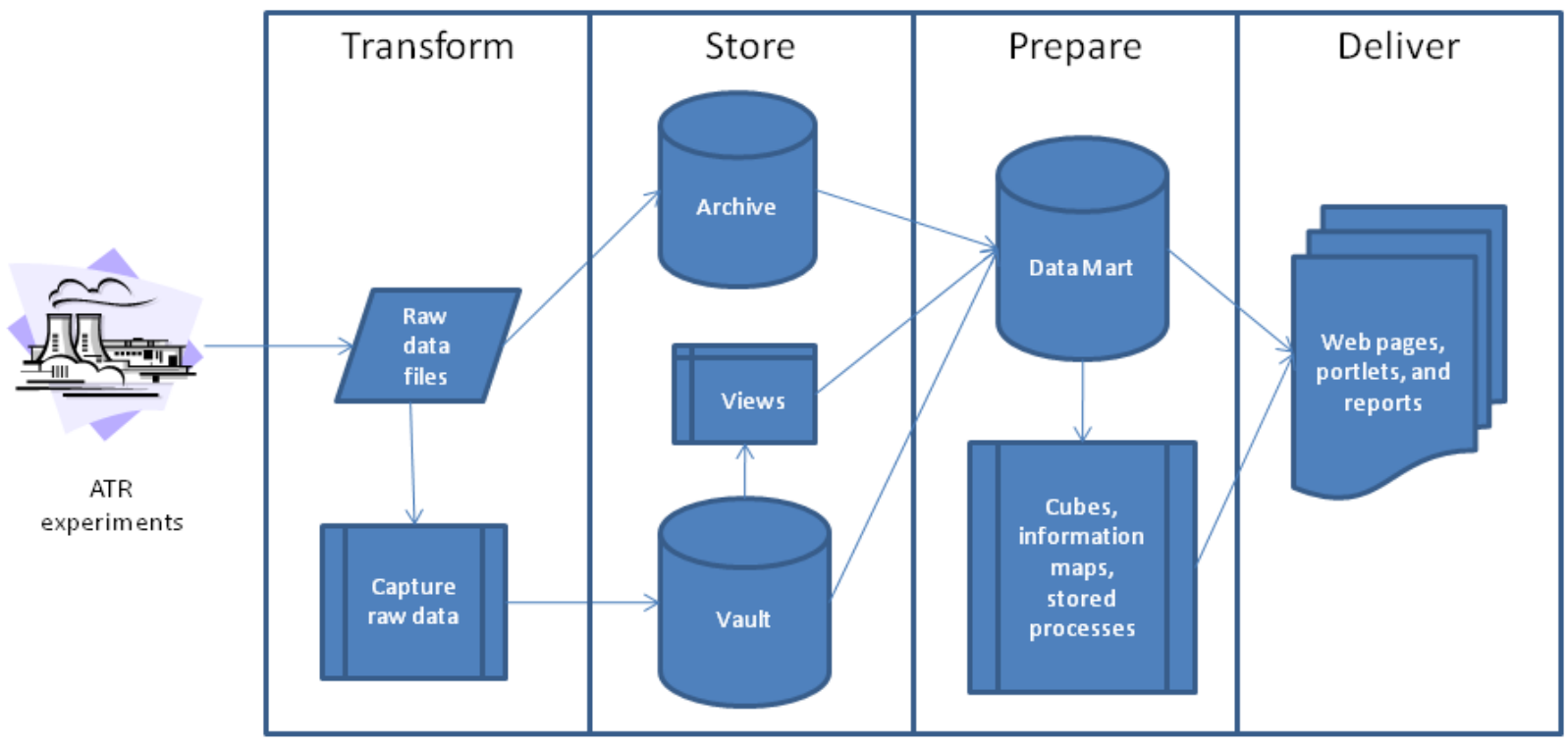

Figure 4. Stages of data processing in NDMAS.

\subsubsection{Database Structure}

The design of the NDMAS 2.0 relational database is described in detail in (Hull 2012). The data storage structure is based on a hierarchy of:

$$
\text { Project } \rightarrow \text { Experiment } \rightarrow \text { Data stream } \rightarrow \text { Data package } \rightarrow \text { Data value }
$$

The AGR-3/4 Experiment belongs to the AGR project within the INL ART program. A Data stream is a particular workflow pathway along which related data flow into NDMAS. A Data package is a batch of data provided to NDMAS from the data generator. The number of data packages ranges from one to dozens, depending on the data stream. A data value is a single variable value recorded that provides information about the system or object being measured. Data values include response elements, usually numeric values that describe the response of the object or system (e.g., pressure or temperature) and attribute elements that generally describe the object or system being measured, or provide categorical or spatial information about the object such as thermocouple composition, graphite grade, or capsule position. When applicable (e.g., NQA-1 requirements for AGR experimental data) each data value also includes data state and qualification state representing data quality. Figure 5 shows the general data schema for time series data adopted for the NDMAS database design.

The AGR-3/4 experiment has two time series data streams: irradiation monitoring and FPMS. The use of tables (Figure 5) containing common keys shared between multiple data streams increases the flexibility for storing various types of data-associated information and reduces storage space by using a unique numeric identification in place of repetitive descriptive text data. Data retrieval from the NDMAS Vault is achieved by the use of views associating data with metadata and contextual information such as 
location, instrument, measurement units, and data stream information. To further speed up the data retrieval, several customized tables were created and are automatically updated with new data as they are received using SQL store procedures on the server.

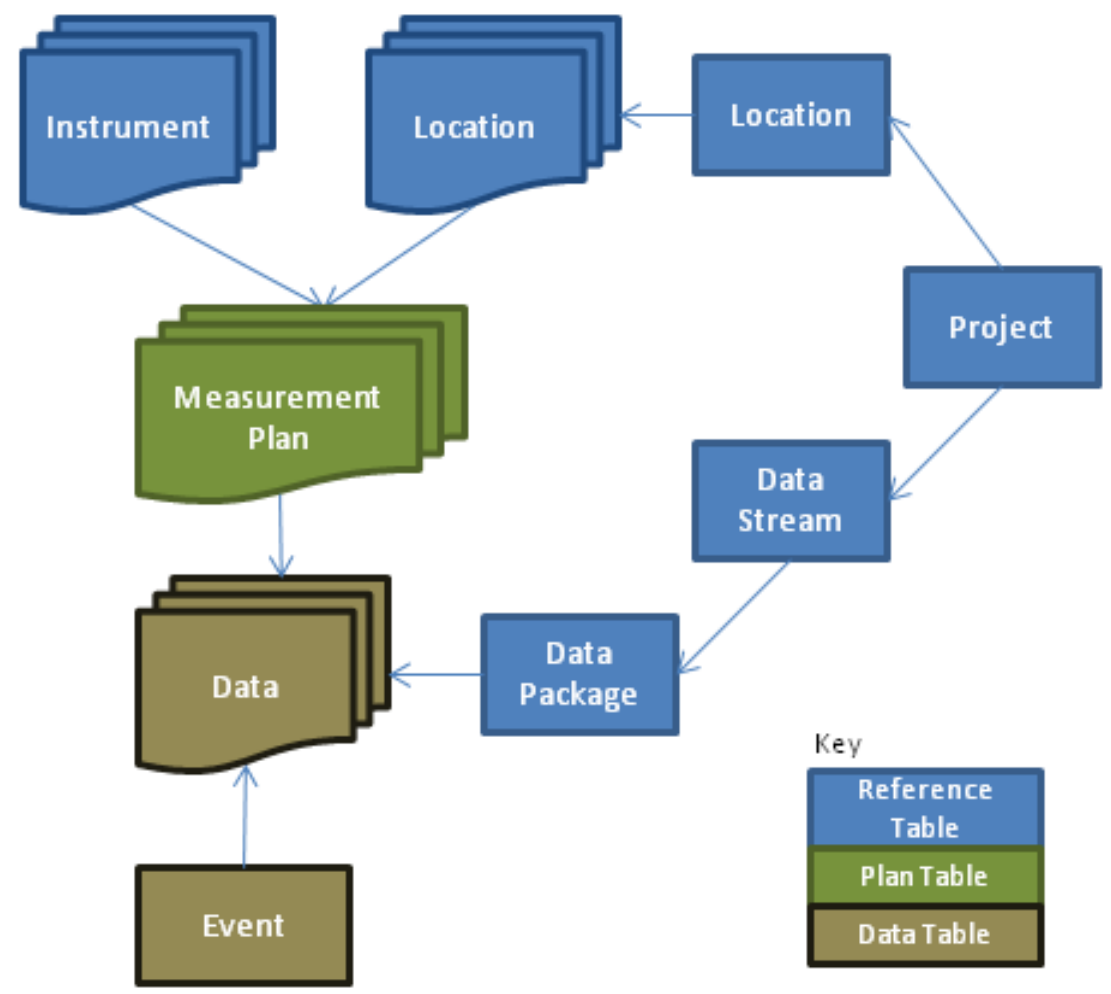

Figure 5. Schema for time series data (Hull 2012).

\subsubsection{Data Values for AGR Experiments}

The AGR-3/4 data streams addressed in this report include TC temperatures, sweep gas data (flow rates, pressure, and moisture content), and FPMS data (release rates, release-rate-to-birth-rate ratios [R/Bs], and particle failure counts) for each of the 12 capsules in the AGR-3/4 experiment. The data values in the NDMAS database include response elements and attribute elements as described in previous Section 2.3.1.

Figure 6 shows the relational diagram for TC temperature values and Figure 7 shows the diagram for gas flow rate values for AGR experiments. The reference tables contain unique hardware IDs associated with actual domain hardware components such as measurement instruments (e.g., rThermocouple on top left of Figure 6) or test train components (e.g., rAGR_Capsule in both Figure 6 and Figure 7) used in the experiments. The plan tables (e.g., bAGR_Temperature_Plan in the middle of Figure 6) contain the plan ID associated with the detailed description about the measured parameter to be stored in the database and hardware domain IDs to serve as a link between actual data records and experimental hardware. The data tables (e.g., dAGR_Temperature in top right of Figure 6), which are the largest tables in the database, contain data values (or records) and multiple associated integer IDs. These ID numbers correspond to unique attributes and descriptions in the reference tables and plan tables to link the data records with their metadata information. Because AGR irradiation data consisted of several serial data streams, each data value is also associated with a unique event ID, AGRIrrEvent_ID, corresponding to a time stamp stored in the event table (e.g., dAGR_IrrEvent on bottom right). Besides domain data, each data value is assigned a certain data state (e.g., raw, in-process, or capture passed representing by the unique Data_State_ID), and 
qualification state (e.g., Qualified, Failed, or Trend) represented by the unique Qual_State_ID), as required by NQA-1 standards.

The new downstream flow data were also added to the NDMAS database (TFR-747), which stored the first flow record for AGR-3/4 experiment on October 29, 2013 (Cycle 155A). This data stream is associated with the FPMS detectors as described in the reference table rAGR_DetectorGasLine and the plan table bAGR_DetectorGasFlow_Plan. The AGR-3/4 FPMS detectors are connected with the AGR-3/4 capsule through the rAGR_CapsuleDetectorHist reference table (Figure 7). Generally, the detector numbers are the same as capsule numbers when all detectors are in good working condition. Any failed detector will be replaced with spare Detector 7 or 14 and that information will be recorded in the rAGR_CapsuleDetectorHist reference table.

To pull necessary information associated with a data value from various tables for data users (e.g., data analysts), numerous SQL views were created in the database. A view is a structured query language query that uses the stored data IDs to link a data value with associated attributes from all supporting tables. For example, each temperature response in the database will be connected with a TC description, capsule location, data state and qualification state. This data structure allows the data state and qualification state to be assigned individually for each TC temperature value as required (Hull 2012).

\begin{tabular}{|c|c|c|c|c|c|c|c|c|}
\hline \multicolumn{3}{|c|}{ rThermocouple } & \multicolumn{2}{|c|}{ bAGR_Temperature_Plan } & \multicolumn{4}{|c|}{ dAGR_Temperature } \\
\hline \multirow[t]{9}{*}{0} & \multicolumn{2}{|c|}{ Thermocouple_ID $\boldsymbol{\Delta}$} & & \multirow{2}{*}{$\begin{array}{l}\text { AGRTemperaturePlan_ID } \\
\text { TemperaturePlanName }\end{array}$} & \multirow[t]{2}{*}{0} & \multicolumn{2}{|c|}{ AGRTemperature_ID } & $\boldsymbol{\Delta}$ \\
\hline & \multicolumn{2}{|c|}{ ThermocoupleName } & & & & \multicolumn{2}{|l|}{ TemperatureValue } & \\
\hline & \multicolumn{2}{|l|}{ Serial_Number } & & Description & & \multicolumn{2}{|l|}{ Duration } & \\
\hline & \multicolumn{2}{|l|}{ Description } & & TemperaturePlanLabel & & \multicolumn{2}{|l|}{ DateTime_Stat_EID } & \\
\hline & \multicolumn{2}{|l|}{ Min_Temp } & & DateTime_Stat_EID & & \multicolumn{2}{|c|}{ AGRTemperaturePlan_ID } & \\
\hline & \multicolumn{2}{|l|}{ Max_Temp } & & IncomingVarName & & \multicolumn{2}{|l|}{ AGRIrrEvent_ID } & \\
\hline & TC_Type & & & Position_X & & \multicolumn{2}{|l|}{ DataPackage_ID } & \\
\hline & TC_Diameter & & & Position_Theta & & \multicolumn{2}{|l|}{ Data_State_EID } & \multirow[b]{3}{*}{$\boldsymbol{\nabla}$} \\
\hline & TC_Wire_Diameter & $\nabla$ & & Position_R & & \multicolumn{2}{|l|}{ Qual_State_EID } & \\
\hline & 1 & & & Position_Ref_Point & & \multicolumn{2}{|l|}{ Modified_Date } & \\
\hline 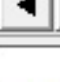 & & & & TemperatureValue_Min & 1 & & 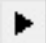 & \\
\hline \multirow{2}{*}{\multicolumn{3}{|c|}{ rAGR_Capsule }} & & TemperatureValue_Max & \multirow{2}{*}{\multicolumn{4}{|c|}{8}} \\
\hline \multirow{8}{*}{$\nabla$} & & & & Failed_Datetime & & & & \\
\hline & AGRCapsule_ID & & & Trend_Datetime & \multicolumn{2}{|c|}{ dAGR_IrrEvent } & & \\
\hline & CapsuleName & & & Thermocouple_ID & 8 & AGRIrrEvent_ID & & \\
\hline & Label & & & AGRCapsule_ID & & StdDateTime & & \\
\hline & Description & & & Comment & & SourceDateTime & & \\
\hline & FuelOwner & & & Modified_Date & & Comment & & \\
\hline & Fuel_type & & & Modified_By & & Modified_Date & & \\
\hline & Project_ID & $\boldsymbol{\nabla}$ & & & & Modified_By & & \\
\hline 1 & 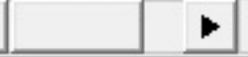 & & & & & Batch_ID & & \\
\hline
\end{tabular}

Figure 6. Diagram of TC temperature values used for AGR experiment. 


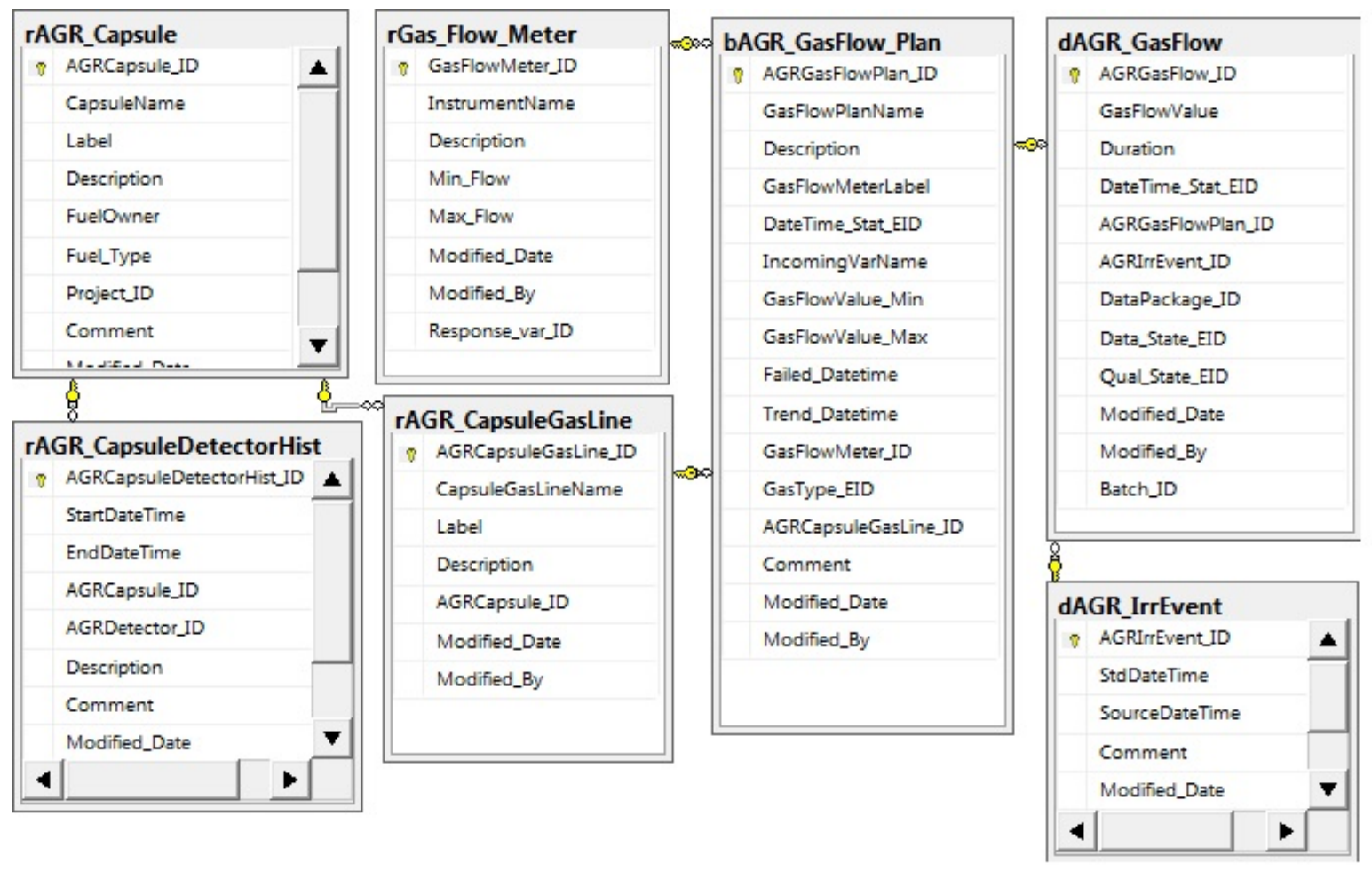

Figure 7. Diagram of gas flow rate values used for AGR experiment.

\subsubsection{Data Delivery}

For NDMAS to reach its maximum utility in support of the temperature control of the AGR-3/4 experiment, ATR operating data (from RDAS) and irradiation monitoring data (from CDCS) were delivered to NDMAS automatically and in near real-time every 2 hours in a readily accessible comma separated value format, starting with ATR Cycle 152A in May 2012. Each batch of data received was a text file either from RDAS (e.g., 2013-03-19-05-13.csc) containing ATR operating condition data or from CDCS (e.g., 2013-03-19-10_cap.csc) containing irradiation monitoring data for AGR current experiments. The automatic data transfer includes instantaneous values at 1-minute intervals for irradiation monitoring data listed in Table 1. 
Table 1. Irradiation monitoring data transferred from CDCS to NDMAS.

\begin{tabular}{lll}
\hline Monitoring Data & Tag Name & Measurement Location \\
\hline $\begin{array}{l}\text { TC temperature } \\
\text { Pressure }\end{array}$ & AGR2TIxy & Capsules 1-12 [x=1-12] and TCs 1-3 [y=1-3] \\
Moisture & AGR2PIINx & Capsules 1-12 inlet [x=1-12] \\
Outlet flow & AGR2MIOUTx & Capsules 1-12 outlet [x=1-12] \\
Impure gas flow & AGR2FIOUTx & Capsules 1-12 outlet [x=1-12] \\
AGR2FIGIINz & Capsules 7-12 inlet [z=7-12] \\
Neon flow & ITVNE2FINESHF2z & Capsules 1-6 inlet [2 $z=21-26]$ \\
ITVNE2FINESHF3z & Capsules 7-12 inlet [3z=31-36] \\
Downstream flow & ATVHE2FINESHF2 $z$ & Leadout flow [2z=27] \\
& ITVHE2FINESHF3z & Detectors 1-14 outlet [zz=01-14] (7 and 14 are spare)
\end{tabular}

FPMS technical staff provides the FPMS release rate and R/B data to NDMAS at the end of each reactor cycle. Twelve capsule-specific release rate and $12 \mathrm{R} / \mathrm{B}$ comma separated value (.csv) text files are placed in the NDMAS data archive location under configuration control. Data are generally provided as 8-hour averages. The first three columns of data contain SPEC_ID (sample name containing the detector number, date/time, and instrument reset index), date, and time. Columns 4 and 5 contain parameters used by the FPMS technical staff to calculate radionuclide concentrations. The remaining 24 columns contain the release rates (or R/B values) and percent error for the 12 gaseous fission products. The data variables stored for the AGR-3/4 irradiation monitoring data streams are listed in Table 2.

Table 2. NDMAS data values for the AGR-3/4 irradiation monitoring and FPMS data.

\begin{tabular}{|c|c|c|}
\hline \multirow{2}{*}{$\begin{array}{c}\text { Response Element } \\
\text { Response Plan Name }\end{array}$} & \multicolumn{2}{|r|}{ Attribute Element } \\
\hline & Component Name & Response Description \\
\hline \multicolumn{3}{|c|}{ Irradiation Monitoring: } \\
\hline $\mathrm{TC}-\mathrm{xx}-1$ & AGR3_Cxx_TC1 & TC1 Temperature in Capsule $\mathrm{xx}\left({ }^{\circ} \mathrm{C}\right)[\mathrm{xx}=01-12]$ \\
\hline $\mathrm{TC}-\mathrm{xx}-2$ & AGR3_Cxx_TC2 & TC2 Temperature in Capsule $\mathrm{xx}\left({ }^{\circ} \mathrm{C}\right)[\mathrm{xx}=01-12]$ \\
\hline $\mathrm{TC}-\mathrm{xx}-3$ & AGR3_Cxx_TC3 & TC3 Temperature in Capsule $\mathrm{xx}\left({ }^{\circ} \mathrm{C}\right)[\mathrm{xx}=01-12]$ \\
\hline Cxx_out_MI & AGR3_C $[01-12, \mathrm{LO}]$ & $\begin{array}{l}\text { Humidity in Capsules } 1-12 \text { and leadout gas flow } \\
\text { (ppmv) }[\mathrm{xx}=01-12, \mathrm{LO}]\end{array}$ \\
\hline Cxx_in_PI & AGR3_C[01-12, LO ] & Pressure in Capsules 1-12 and leadout gas flow (psia) \\
\hline Cxx_in_Q_He & AGR3_C $[01-12, \mathrm{LO}]$ & Helium flow to Capsules 1-12 and leadout (sccm) \\
\hline Cxx_in_Q_Ne & AGR3_C $[01-12, \mathrm{LO}]$ & Neon flow to Capsules 1-12 and leadout (sccm) \\
\hline Cxx_out_Q_Total & AGR3_C[01-12] & Outflow from Capsules $1-12(\mathrm{sccm})[\mathrm{xx}=01-12]$ \\
\hline Gxx_in_Q_Contam & AGR3_C[07-12] & Impure gas flow to Capsules $7-12(\mathrm{sccm})[\mathrm{xx}=07-12]$ \\
\hline GSpecxx_QTotal_out & AGR3_G[01-14] & $\begin{array}{l}\text { Gas outflow from Detectors } 1 \text { through } 14[\mathrm{xx}=01-14] \\
\text { (Detectors } 1-6 \text { are from Capsules } 1-6 \text {; Detectors } 8-13 \\
\text { are from Capsules } 7-12 \text {; Detectors } 7 \text { and } 14 \text { are spares) }\end{array}$ \\
\hline
\end{tabular}




\begin{tabular}{|c|c|c|}
\hline \multirow{2}{*}{$\begin{array}{c}\text { Response Element } \\
\text { Response Plan Name }\end{array}$} & \multicolumn{2}{|r|}{ Attribute Element } \\
\hline & Component Name & Response Description \\
\hline \multicolumn{3}{|r|}{ FPMS: } \\
\hline $\mathrm{Kr} \_[\mathrm{A}] \_\mathrm{Rel}$ & AGR3 Capsule [1-12] & $\begin{array}{l}\text { Release rate for five krypton isotopes (atoms } / \mathrm{s}) \\
(\mathrm{A}=85 \mathrm{~m}, 87,88,89,90) \text { for each capsule }\end{array}$ \\
\hline $\mathrm{Kr} \_[\mathrm{A}] \_$Rat & AGR3 Capsule [1-12] & $\mathrm{R} / \mathrm{B}$ for five krypton isotopes (unitless) \\
\hline $\mathrm{Xe}[\mathrm{A}] \_\mathrm{Rel}$ & AGR3 Capsule [1-12] & $\begin{array}{l}\text { Release rate for seven xenon isotopes (atoms/s) } \\
(\mathrm{A}=131 \mathrm{~m}, 133,135,135 \mathrm{~m}, 137,138,139)\end{array}$ \\
\hline $\mathrm{Xe}$ [A] $]_{-} \mathrm{Rat}$ & AGR3 Capsule [1-12] & $\mathrm{R} / \mathrm{B}$ for seven xenon isotopes (unitless) \\
\hline $\mathrm{Kr}[\mathrm{A}] \_\mathrm{Err}$ & AGR3 Capsule [1-12] & Release rate error for five krypton isotopes (\%) \\
\hline $\mathrm{Kr} \_[\mathrm{A}] \_\mathrm{REr}$ & AGR3 Capsule [1-12] & $\mathrm{R} / \mathrm{B}$ error for five krypton isotopes $(\%)$ \\
\hline $\mathrm{Xe}$ [A] $]$ Err & AGR3 Capsule [1-12] & Release rate error for seven xenon isotopes (\%) \\
\hline $\mathrm{Xe}[\mathrm{A}] \_\mathrm{REr}$ & AGR3 Capsule [1-12] & $\mathrm{R} / \mathrm{B}$ error for seven xenon isotopes $(\%)$ \\
\hline
\end{tabular}

\subsubsection{Irradiation Monitoring Data Capture and Testing}

\subsubsection{Data Capture}

Upon automatic data transfer from the ATR servers, these raw data files are automatically processed into the NDMAS database by the following steps:

1. Extract data according to the tags described in TFR-747.

2. Assign appropriate descriptive IDs for each response value and unique event ID for the associated time stamp.

3. Assign data state flag either to Capture Passed or Accuracy Failed based on the results of the initial range test and instrument failure time tests to identify any clear anomalies.

4. Assign the data qualification flag to In-process until qualification flags are updated according to the qualification decisions resulting from the DRC meeting.

5. Push unique time stamps into the appropriate event table (e.g., dAGR_IrrEvent) in the NDMAS production database; push response values and associated integer IDs into appropriate data tables (e.g., dAGR_Temperature for TC readings).

6. Copy raw data files to the NDMAS archive folder.

The automation of this data processing step uses stored procedures written in the C\# language on the .Net Application Version 1.0 framework of the Microsoft Studio 2012 development tool. All processing codes to push data to the Vault and views to pull desired data from the Vault are subject to rigorous review and testing procedures in compliance with software QA requirements described in MCP-3058 and PLN-2690.

\subsubsection{Range Tests}

Range tests evaluate whether instrument readings fall within an expected range of values, given what is known about experimental operating conditions or instrument range specifications. Range tests are used as a simple screening tool to identify data records that could potentially be bad, or they can be used to identify and reexamine extreme, but valid, data. For example, all the TCs terminated in the graphite holders will read the graphite temperatures, which are less than the fuel compact temperature. Therefore, the time averaged peak fuel temperature specifications given in Section 2.1.1 can be used as a coarse 
upper limit for a TC temperature range test. Range tests are currently only applied to the TC and sweep gas (flow rates, pressure, and moisture) data that NDMAS receives. The range test limits selected for these response variables are listed in Table 3.

Table 3. Range test limits applied to AGR-3/4 irradiation monitoring data (see Section 2.1).

\begin{tabular}{ll}
\hline Response Variable & Range Test Lim \\
Temperature & 0 to $1400^{\circ} \mathrm{C}$ \\
helium/neon inlet & 0 to $102 \mathrm{sccm}$ \\
gas flow & \\
$\begin{array}{l}\text { Capsule gas } \\
\text { mixture outlet flow }\end{array}$ & 0 to $102 \mathrm{sccm}$ \\
$\begin{array}{l}\text { Impure gas flow } \\
\text { FPM gas flow- }\end{array}$ & 0 to $102 \mathrm{sccm}$ \\
$\begin{array}{l}\text { FPMS detector } \\
\text { outlet }\end{array}$ & \\
$\begin{array}{l}\text { Gas pressure- } \\
\text { capsule inlet }\end{array}$ & 0 to $90 \mathrm{sccm}$ \\
$\begin{array}{l}\text { Moisture-capsule } \\
\text { outlet }\end{array}$ & 0 to $5 \mathrm{ppm}$
\end{tabular}
Comments

Capsules 1-12. Based on the time averaged, peak fuel temperature requirement for UCO fuel (SPC-1345). TC temperatures are expected to be lower than the fuel temperature requirement.

Capsules 1-12 and leadout. Nominal flow rates are 0-30 sccm, but short-term peaks in helium flow up to and exceeding 100 sccm are assumed to be valid (TFR-656).

Capsules 1-12 (TFR-656). Nominal flow rates are 15 or $30 \mathrm{sccm}$.

Capsules 7-12. Nominal flow rates are $0.5 \mathrm{sccm}$.

Flow meters installed downstream from FPMS Detectors 1-14 (7 and 14 are spare detectors). Nominal flow rates are 15 or 30 sccm.

Capsules 1-12 and leadout. Pressure relief valve setting (TFR-656).

Capsules 1-12 and leadout. No published limit for capsule outlet moisture level. Limit is set to the gas inlet specification in SPC-1345, the exceedance of which may indicate a leak.

a. A missing value is out-of-range and counted as a Failed record in the range test because it is not a valid representation of a measurement.

\subsubsection{FPMS Data Capture}

Upon receiving the FPMS data files after the end of each cycle, SAS Enterprise Guide projects were used to capture the data from the .csv files into SAS datasets. The database required description and appropriate IDs are assigned to each response value. Then, FPMS SAS data sets are pushed into four separate tables in NDMAS database as follow: date and time data are inserted into dAGR_FPMEvent, $\mathrm{R} / \mathrm{B}$ data are inserted into dAGR_FPMRatio, release data are inserted into dAGR_FPMRedata are inserted into dAGR_FPMFlow.

NDMAS does not perform any accuracy testing for FPMS data, although data analysis (e.g., regressions of R/B data with temperature) may be performed. Data states for FPMS records are assigned to Capture passed after matching verification between data captured to NDMAS database and raw data files. Data qualification for the FPMS data stream is typically documented for one or more reactor cycles in an ECAR submitted by FPMS staff. When a QA-approved ECAR is received by NDMAS, a certification test is recorded in the vault for that data package, and the qualification status of the data is set according to this document (e.g., Qualified, Trend, or Failed). If the FPMS data transmittal and its associated ECAR are designated as Preliminary data (as is currently the practice), it is assumed that this qualification status is subject to change if revisions to the data and revised ECARs are submitted later by the FPMS staff (as was done for AGR-1). Only the latest version of FPMS data will be used for Web page display and data download. Data from older versions are still stored in the database with an Obsolete qualification status and are available on special request. 


\section{DATA ANALYSIS AND TESTING RESULTS}

NDMAS provides a controlled and secure electronic data storage environment, supports data qualification, identifies the qualification status of data, provides data analysis and modeling products, and makes data available for use by the program (PLN-2709). The data delivery portal (https://ndmas.inl.gov) is Web-based so both internal and external INL ART TDO program participants can access the system and review data, obtain analysis results (including statistics and graphics), and download data. By performing these roles, NDMAS ensures the correct data are used by the project, and data of known quality are available to support future licensing. The evidence used in determination of qualification status for AGR-3/4 irradiation data are presented in this section.

\subsection{Data Overview}

\subsubsection{Irradiation Data by Cycle}

The AGR-3/4 experiment was in the reactor core for eight ATR cycles, 151A, 151B, 152A, 152B, 154A, 154B, 155A, and 155B (ATR Cycle 155B-1 data were combined with ATR Cycle 155B), resulting in 369.1 EFPDs of irradiation between December 14, 2011 and April 12, 2014. Table 4 provides a summary of the AGR-3/4 irradiation data by cycle examined in this data qualification report covering the period from December 12, 2011 (when records start) through April 22, 2014 (10 days after the last power-down, when records stop). The extension of 10 days after the power-down of ATR Cycle 155B-1 is needed to store gas flow rate data used in FPMS data calculation. The number of records increases substantially after ATR Cycle $152 \mathrm{~A}$ due to the automatic data transfer, which includes instantaneous values at 1-minute intervals for monitoring data instead of 5-minute averaged values during earlier cycles. The addition of FPM flow rate records for the last two cycles (155A and 155B/155B-1) caused another increase in the number of records. There are also some fill-in irradiation data for ATR Cycles 151A and151B (outages) as requested by the FPMS staff. These fill-in data are also instantaneous measurements at 1-minute intervals, which are needed for fission product release calculations. As a result, $53,608,130 \mathrm{TC}$ temperature and gas flow rate records are covered by this report. The numbers in all following summary tables for Cycles between 151A and 154B were changed from previously reported in EXT-14-31186 document because of these "fill-in" data added after completion of irradiation and Cycle 152B extension.

Table 4. Overview of ATR cycles during AGR-3/4 irradiation.

\begin{tabular}{lccccc}
\hline ATR Cycle & Power Up & Power Down & EFPDs & $\begin{array}{c}\text { Total No. } \\
\text { Records }\end{array}$ & Cycle Comment \\
\hline 151A & $12 / 14 / 111: 00$ & $02 / 11 / 1211: 00$ & 56.1 & $1,257,055$ & Normal \\
151B & $03 / 01 / 126: 00$ & $05 / 05 / 1211: 00$ & 51.3 & $2,490,977$ & Normal \\
152A & \multicolumn{2}{c}{ No fuel burn-up accumulated } & 0 & $6,614,715$ & Low power \\
152B & $11 / 27 / 124: 00$ & $01 / 18 / 1319: 00$ & 51.0 & $5,751,591$ & Normal \\
154A & $05 / 19 / 133: 00$ & $07 / 13 / 1311: 00$ & 52.3 & $6,798,333$ & Normal \\
154B & $08 / 23 / 1315: 00$ & $10 / 16 / 1311: 00$ & 53.4 & $8,146,253$ & Normal \\
155A & $11 / 08 / 131: 00$ & $01 / 17 / 1416: 00$ & 55.1 & $11,023,886$ & Normal \\
155B & $02 / 13 / 145: 00$ & $04 / 12 / 145: 00$ & 49.9 & $11,525,320$ & Normal \\
& & Total: & $\mathbf{3 6 9 . 1}$ & $\mathbf{5 3 , 6 0 8 , 1 3 0}$ &
\end{tabular}


Summary plots of the ATR operating parameters during the AGR-3/4 irradiation are presented in Figure 8 to provide an overview of the ATR operating history. Even through, NDMAS does not formally qualify these data, they are needed to interpret AGR experimental data. Because the AGR-3/4 experiment is located in the NEFT location, the power levels of the northeast lobe and the Quadrant 1 are plotted as ATR power (Panel 4). The angular positions of the outer shim control cylinders regulating the ATR power distribution in each corner of the reactor are presented in Panel 3. Two other ATR operating parameters are the insertion depth of the regulator rods (Panel 2) and the number of neck shims that are inserted (Panel 1). Column for ATR Cycle 152A is empty because there was no burn-up accumulated for AGR-3/4 test fuel during this very low power cycle. Columns for ATR Cycles 153A and 153B are empty because the test train was removed from the reactor for those cycles.

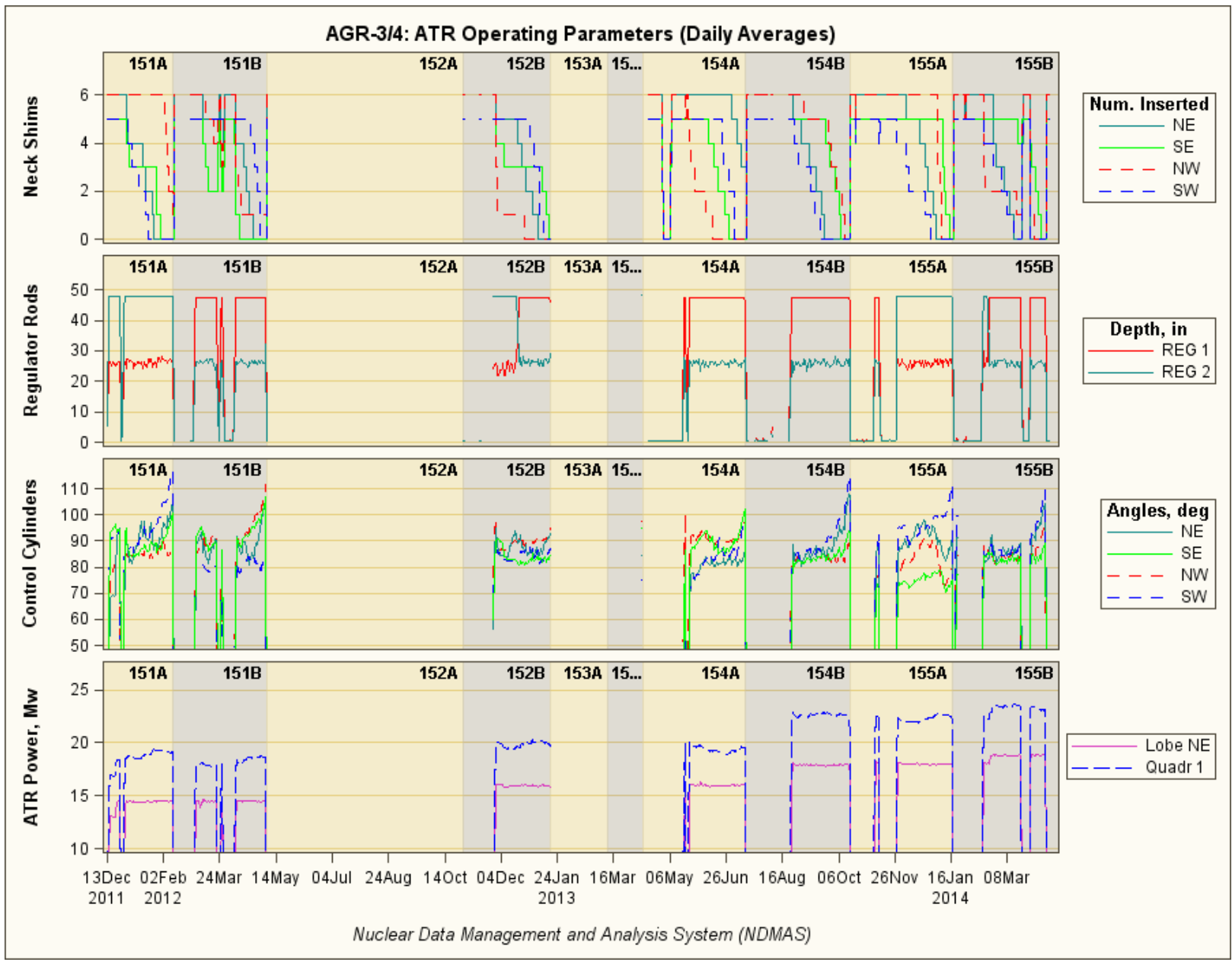

Figure 8. ATR operating parameters during AGR-3/4 irradiation.

During cycle 152A, ATR power was raised to a low level for a short time, resulting in an average effective power of $0.209 \mathrm{MW}$ (nominal values are in 14-19 MW range) for 89.6 hours. During this time, pure helium was circulated to all the AGR-3/4 capsules and leadout. For the test fuel depletion calculation, this cycle is considered as an extended power outage and no fuel burn-up is accumulated. Consequently, there are no thermal calculations for the AGR-3/4 capsules during this time. Because the test train remained in the reactor core, the irradiation data captured and stored in the NDMAS database are valid measurements, thus their qualification states are documented in this report. 
On the other hand, ATR Cycles 153A and 153B were not included in this data report because during the outage cycle (153A) the AGR-3/4 test train was removed from the ATR core and stored in the canal to prevent overheating of fuel compacts because of high ATR lobe powers during the subsequent ATR PALM Cycle 153B. On April 26, 2013, the AGR-3/4 experiment was reinserted into the ATR NEFT location during the outage of ATR Cycle 154A. As a result, most of the irradiation data during these two cycles are irrelevant because the experiment instruments were disconnected. However, the gas flow rates before the experiment removal at the start of ATR Cycle 153A are still needed for fission product release calculation, so they are included in ATR Cycle 152B. Therefore, ATR Cycle 152B is extended until January 24, 2013 at 12:41, which is 6 days after the usual end of a cycle at power-down.

ATR Cycle 154A began on April 12, 2013. However, Figure 9 shows that the TCs in Capsule 10 did not respond to capsule temperature variations until 8:50 on April 29, 2013 (All TCs in other capsules show similar behavior). In addition, Figure 10 also shows that the gas flow rates started to respond to actual flow measurements at the same time as TC readings after being stuck at zero sccm. Apparently, both gas flow rates and $\mathrm{TC}$ readings before this time are not actual measurements. As a result, the irradiation records for this cycle start on April 29, 2013 at 8:50, 17 days after official start of the cycle.

DRC Decision: Delete all AGR-3/4 irradiation data (gas flow rates, TC readings, inlet gas moisture, and pressures) recorded during the period of January 24, 2013, at 12:42 (6 days after 152B power-down and the AGR-3/4 experiment was removed from the ATR core) to April 29, 2013, 08:50 (when the actual measurements began after AGR-3/4 was reinserted into the ATR core).

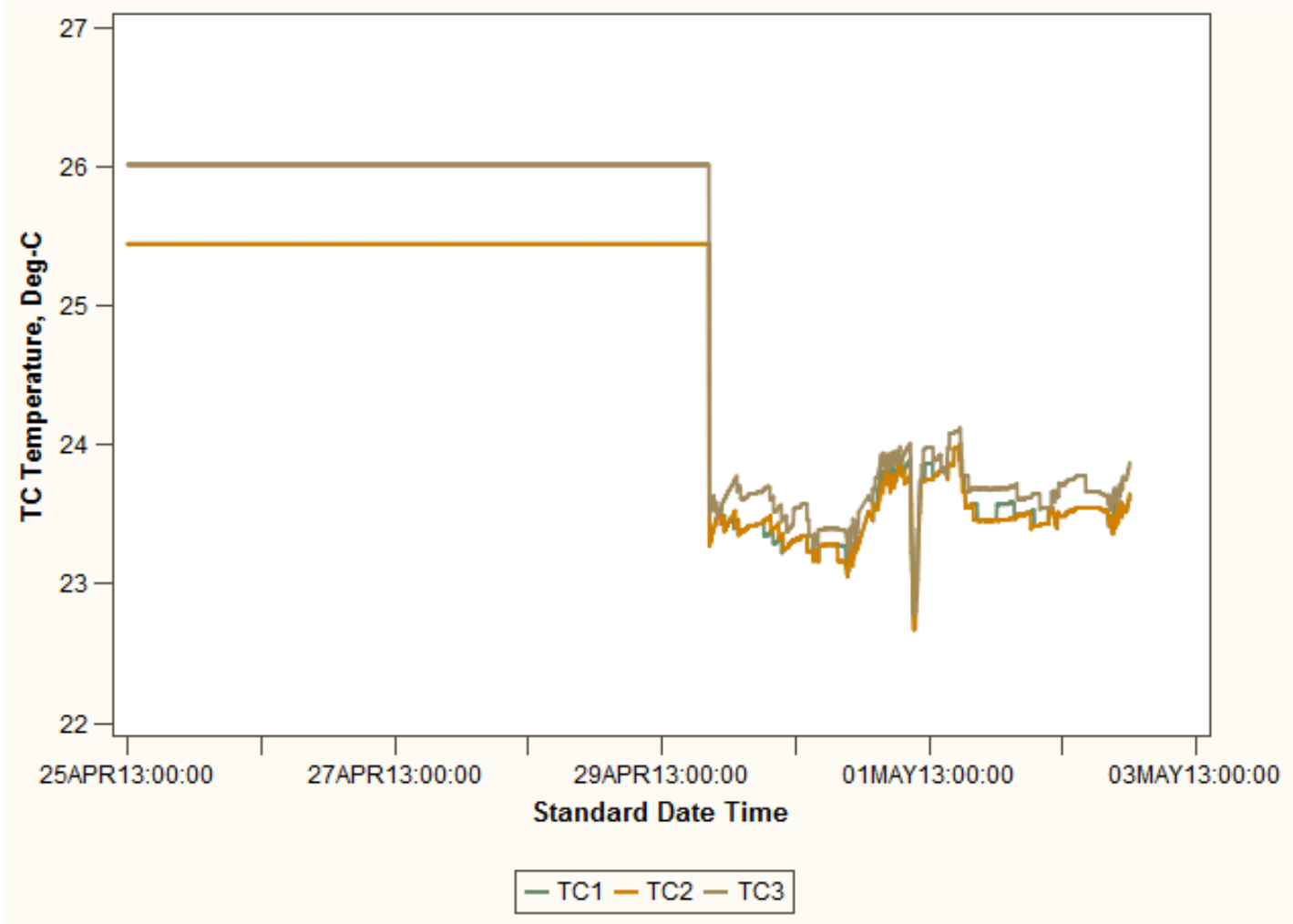

Figure 9. Capsule $10 \mathrm{TC}$ readings around the time when AGR-3/4 was reinserted into the ATR core. 
AGR-3/4: Sweep Gas Flow Rates in Capsules 7-12

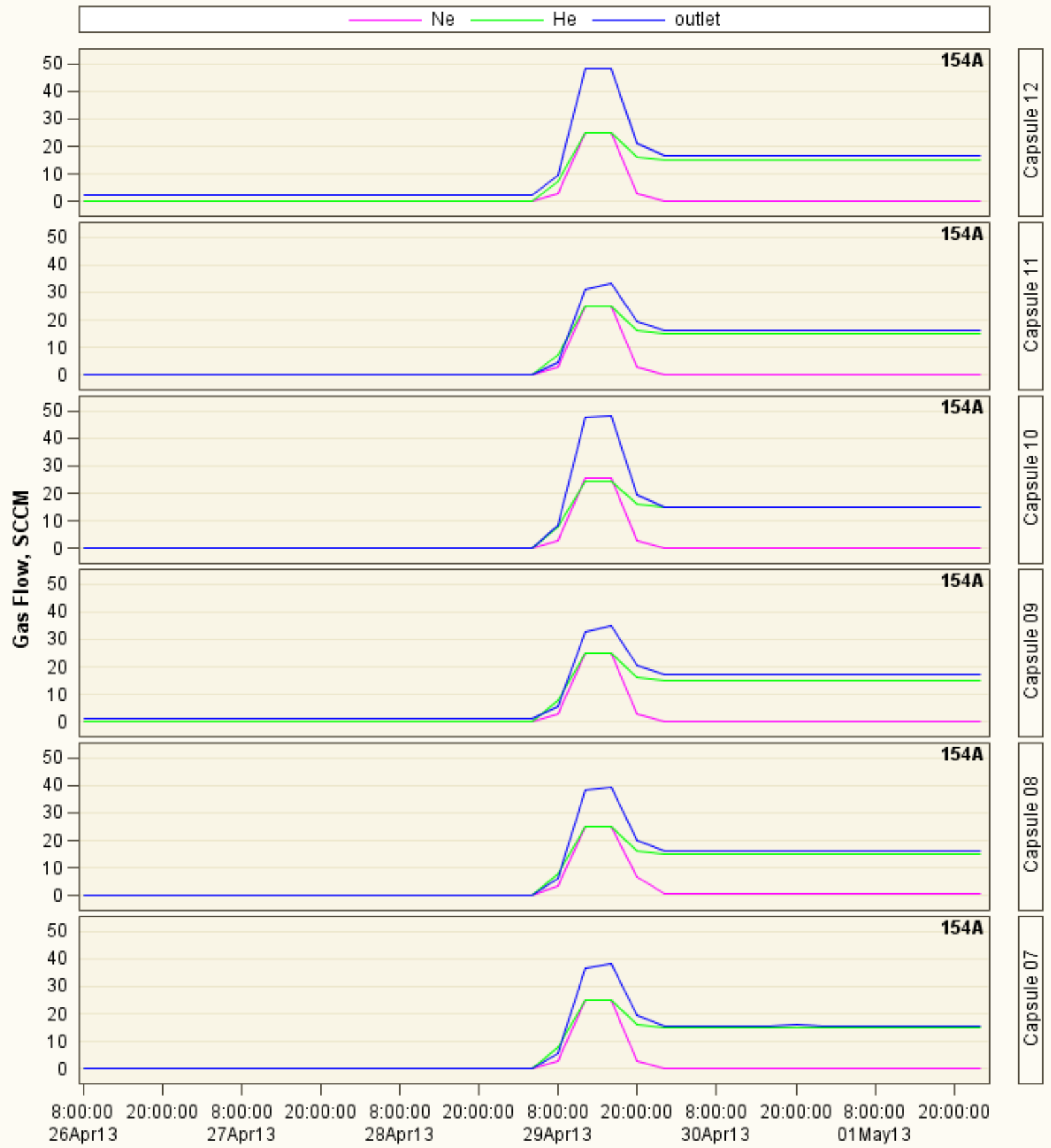

Figure 10. Gas flow rates for Capsules 7-12 around the time when AGR-3/4 was reinserted into the ATR core. 


\subsubsection{Temperature Data}

A total of 19,398,074 TC temperatures recorded from 27 TCs installed in 12 capsules were captured in the NDMAS database during the entire AGR-3/4 irradiation. Table 5 gives an overview of all TC temperature records broken down by ATR fuel cycle.

Figure 11 and Figure 12 show the average hourly TC temperatures for each of the 12 AGR-3/4 capsules. Gaps in TC plots represent periods with missing irradiation data, which happened only during ATR power outages due to equipment maintenance. For low power cycle 152A, TC readings in all 12 capsules were largely low ranging from $\sim 30$ to $50^{\circ} \mathrm{C}$ except for a short time (i.e., 89.6 hours around the beginning of October 2012), when TC readings were raised to more than $450^{\circ} \mathrm{C}$ (Figure 11 and Figure 12). Plots are empty during Cycles $153 \mathrm{~A}$ and $153 \mathrm{~B}$ because AGR-3/4 was not in the ATR core.

It is apparent from Figure 12 that there are five TC failures starting from ATR Cycle 154A. The TC failures occurred in the following order: TC2 in Capsule 2 and TC1 in Capsule 3 failed at the powering up of ATR Cycle 154A, TC2 in Capsule 3 failed near the end of ATR Cycle 154B, TC1 in Capsule 5 failed near the end of ATR Cycle 155A, and TC1 in Capsule 6 failed near the powering up of ATR Cycle 155B. Only Capsule 3 lost all of its TCs, as shown in Panel 4 in Figure 12. A discussion on TC temperature failures as they relate to data qualification is presented in Section 3.2.

Table 5. Overview of TC temperature data captured during AGR-3/4 irradiation.

\begin{tabular}{cccccc}
\hline & & & & Maximum & Minimum \\
ATR Cycle & No. of Records & Start Record Time & End Record Time & $\begin{array}{c}\text { value }\left({ }^{\circ} \mathrm{C}\right) \\
\text { value }\left({ }^{\circ} \mathrm{C}\right)\end{array}$ \\
\hline 151A & 478,035 & $12 / 12 / 01109: 00$ & $02 / 11 / 201210: 00$ & 1,071 & 5.9 \\
151B & 946,269 & $02 / 11 / 201210: 05$ & $05 / 05 / 201209: 10$ & 1,075 & -19.9 \\
152A & $2,515,455$ & $05 / 05 / 201209: 15$ & $10 / 18 / 201219: 59$ & 701 & -0.3 \\
152B & $2,288,601$ & $10 / 31 / 201209: 51$ & $01 / 24 / 01312: 41$ & 1,072 & 2.7 \\
154A & $2,780,327$ & $04 / 29 / / 201308: 50$ & $07 / 13 / 201309: 04$ & 1,032 & 0.1 \\
154B & $3,157,981$ & $07 / 13 / 201309: 05$ & $10 / 16 / 201309: 34$ & 1,060 & 11.3 \\
155A & $3,570,422$ & $10 / 16 / 201309: 35$ & $01 / 17 / 201415: 09$ & 1,020 & 9.0 \\
155B & $3,660,984$ & $01 / 17 / 201415: 10$ & $04 / 22 / 201413: 46$ & 1,039 & -25.3 \\
Total= & $\mathbf{1 9 , 3 9 8 , 0 7 4}$ & & & &
\end{tabular}


AGR-3/4: Thermocouple Temperatures

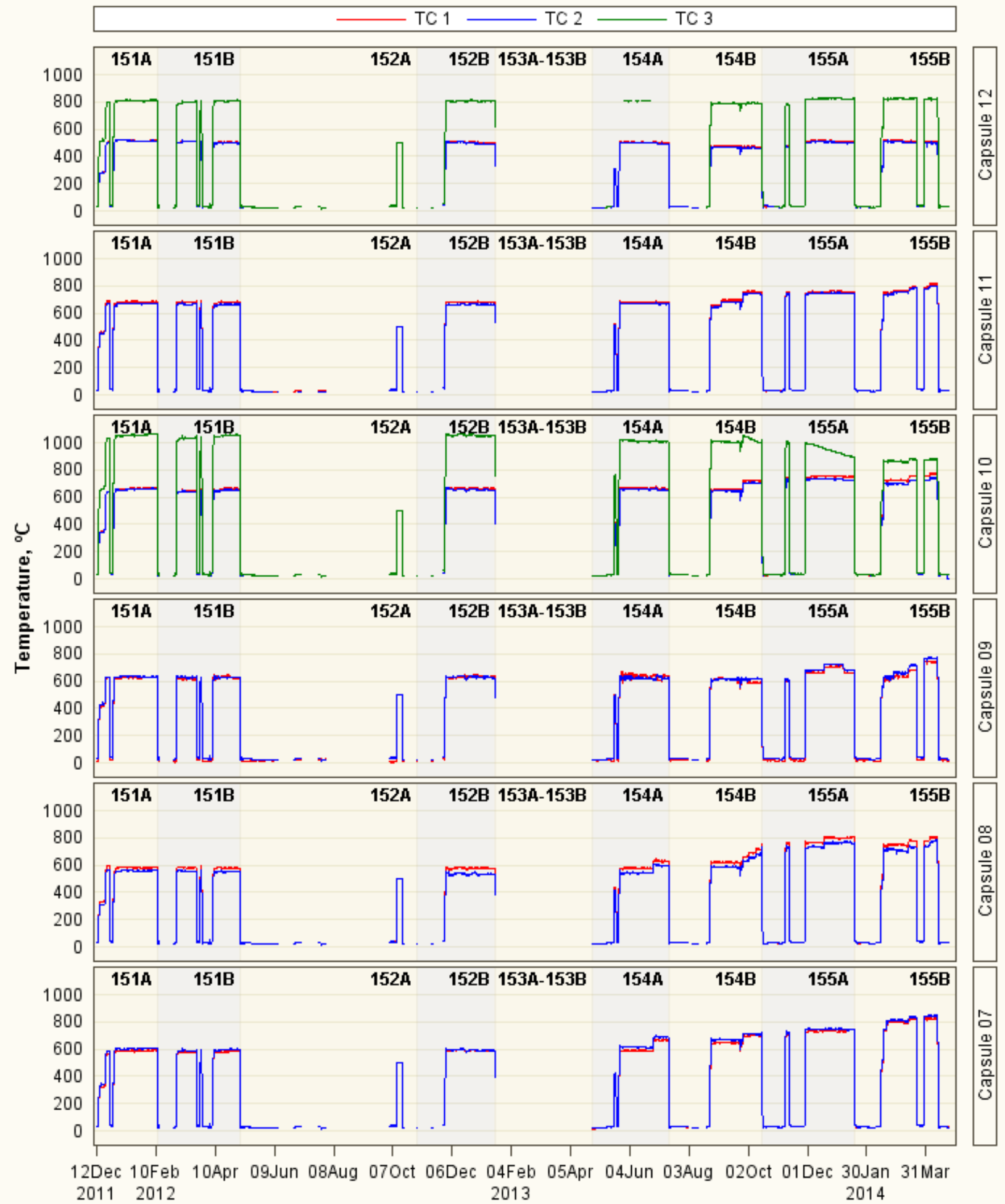

Figure 11. Capsules 7-12 TC temperature data for Cycles 151A-155B. 


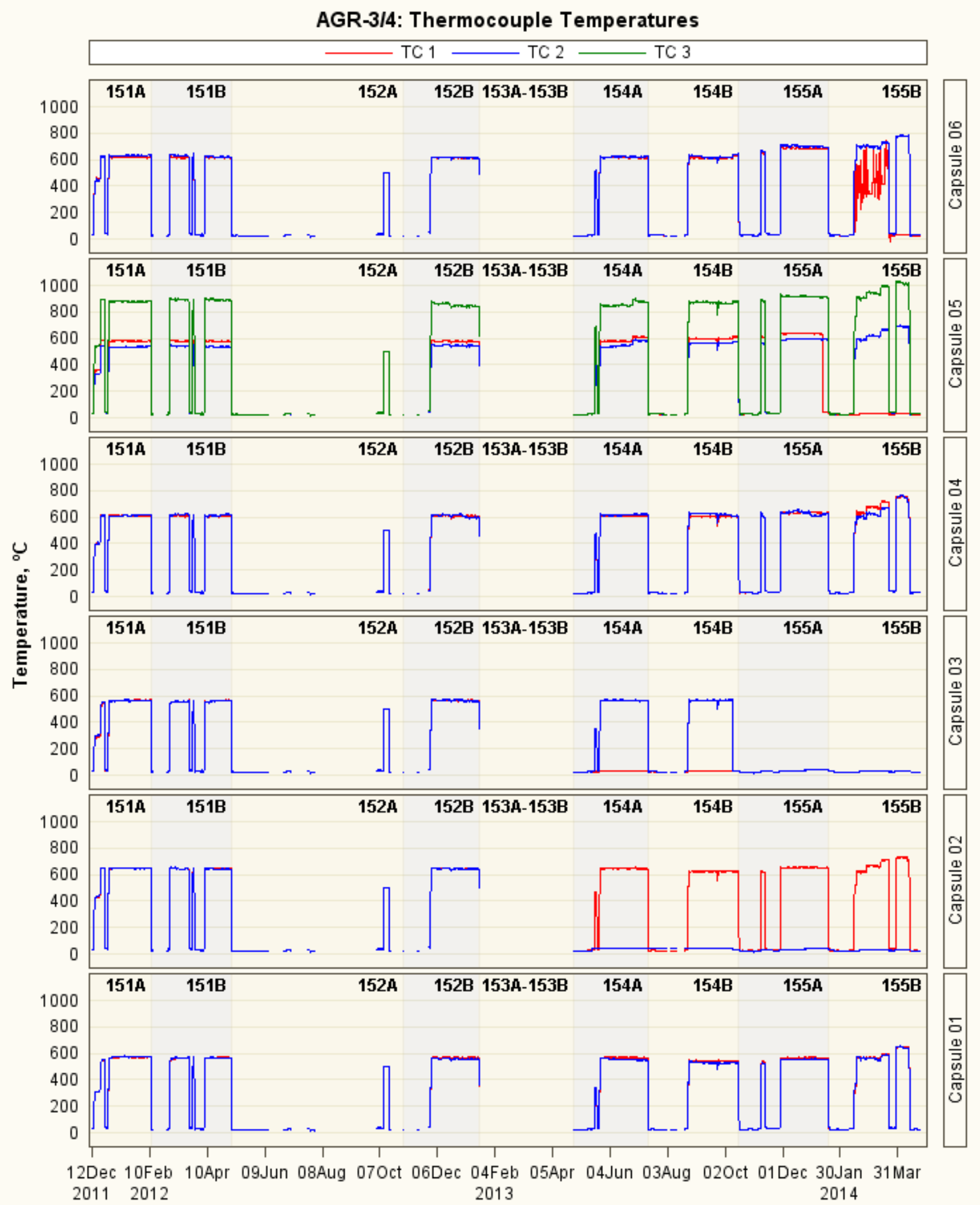

Figure 12. Capsules 1-6 TC temperature data for Cycles 151A-155B. 


\subsubsection{Sweep Gas Data}

NDMAS received 34,210,056 gas flow rate records for the AGR-3/4 irradiation campaign, covering the 12 capsules, the leadout, and 14 additional flow meters installed downstream from the FPMS detectors. Figure 13 and Figure 14 show the average hourly sweep gas flow rates for each capsule including helium inlet, neon inlet, total outlet, and the downstream (FPM) flow. Leadout gas flows (both helium and neon) are shown in the bottom panel of Figure 14 (same for all capsules). Table 6 gives an overview of all gas flow rates captured in the NDMAS database broken down by ATR fuel cycle.

As in the TC plots in Figure 11 and Figure 12, gaps in gas flow plots represent periods with missing irradiation data during the outage phase of some cycles. During outages, AGR-3/4 usually runs on pure helium at a lower flow rate (approximately $15 \mathrm{sccm}$ instead of $30 \mathrm{sccm}$ ) in all capsules and the leadout, except for a few short flow meter testing periods. During these tests, the gas flow rate can be abnormally high (see vertical lines out of normal boundary in Figure 13 and Figure 14). Therefore, these higher than normal flow rates are still valid unless they are greater than the flow controller limit of $102 \mathrm{sccm}$, as stated in Table 3. For the AGR-3/4 experiment, no apparent flow failures occurred in the capsule gas flow system, especially during ATR full power periods, as indicated by the regular behavior of the neon and helium inlet and the outlet flow rates across cycles in all 12 capsules and the leadout.

Figure 15 shows the impure gas flow rates in Capsules 7 through 12. The impure gas consisted of at least than $98 \%$ helium contaminated with gas impurities such as $\mathrm{CO}, \mathrm{H}_{2} \mathrm{O}$, and $\mathrm{H}_{2}$. On August 23, 2013, shortly after ATR Cycle 154B powered up, $0.5 \mathrm{sccm}$ of impure gas was mixed into the Capsule 11 gas flow using an additional flow controller. Hence, the impure gas was only injected into the Capsule 11 gas line during the full power phase of the last three cycles of irradiation (i.e., ATR Cycles 154B, 155A, and 155B). A discussion on gas flow rate anomalies as they relate to data qualification is presented in Section 3.3.

Table 6. Overview of gas flow rate data captured during AGR-3/4 irradiation.

\begin{tabular}{cccccc}
\hline \multirow{2}{*}{ ATR Cycle } & $\begin{array}{c}\text { Total No. } \\
\text { Records }\end{array}$ & Start Record Time & End Record Time & $\begin{array}{c}\text { Maximum } \\
(\mathrm{sccm})\end{array}$ & $\begin{array}{c}\text { Minimum } \\
(\mathrm{sccm})\end{array}$ \\
\hline 151A & 779,020 & $12 / 12 / 01109: 00$ & $02 / 11 / 201210: 00$ & 58.29 & 0 \\
151B & $1,544,708$ & $02 / 11 / 201210: 05$ & $05 / 05 / 201209: 10$ & 103.40 & 0 \\
152A & $4,099,260$ & $05 / 05 / 201209: 15$ & $10 / 18 / 201219: 59$ & 120.25 & 0 \\
152B & $3,462,990$ & $10 / 31 / 201209: 51$ & $01 / 24 / 01312: 41$ & 38.06 & 0 \\
154A & $4,018,006$ & $04 / 29 / / 201308: 50$ & $07 / 13 / 201309: 04$ & 55.80 & 0 \\
154B & $4,988,272$ & $07 / 13 / 201309: 05$ & $10 / 16 / 201309: 34$ & 45.87 & 0 \\
155A & $7,453,464$ & $10 / 16 / 201309: 35$ & $01 / 17 / 201415: 09$ & 120.90 & -0.24 \\
155B & $7,864,336$ & $01 / 17 / 201415: 10$ & $04 / 22 / 201413: 46$ & 103.24 & -61.32 \\
Total= & $\mathbf{3 4 , 2 1 0 , 0 5 6}$ & & & &
\end{tabular}


AGR-3/4: Sweep Gas Flow Rates in Capsules 7-12

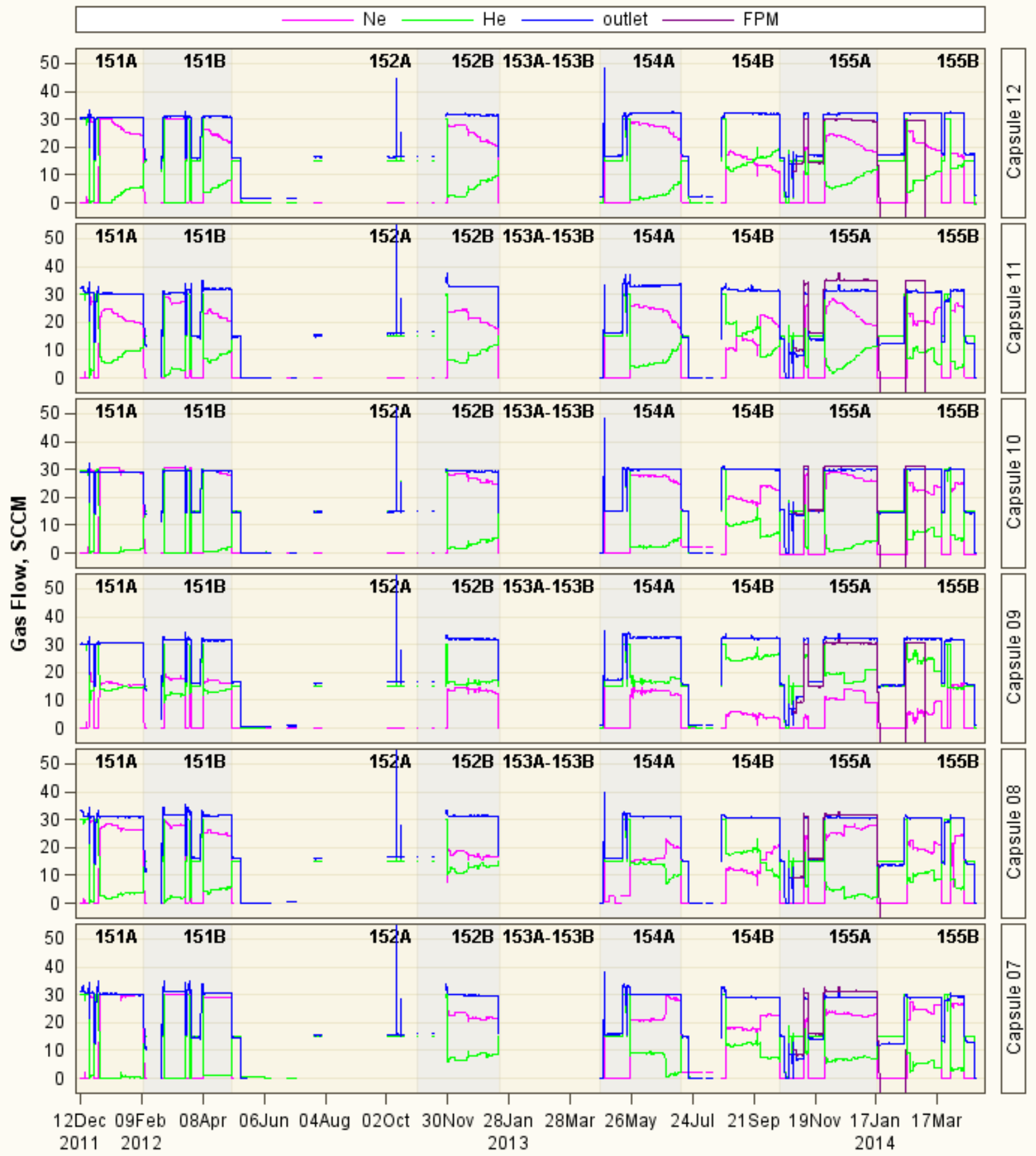

Figure 13. Capsules 7-12 sweep gas flow rates (sccm). 
AGR-3/4: Sweep Gas Flow Rates in Capsules $1-6$ and Leadout

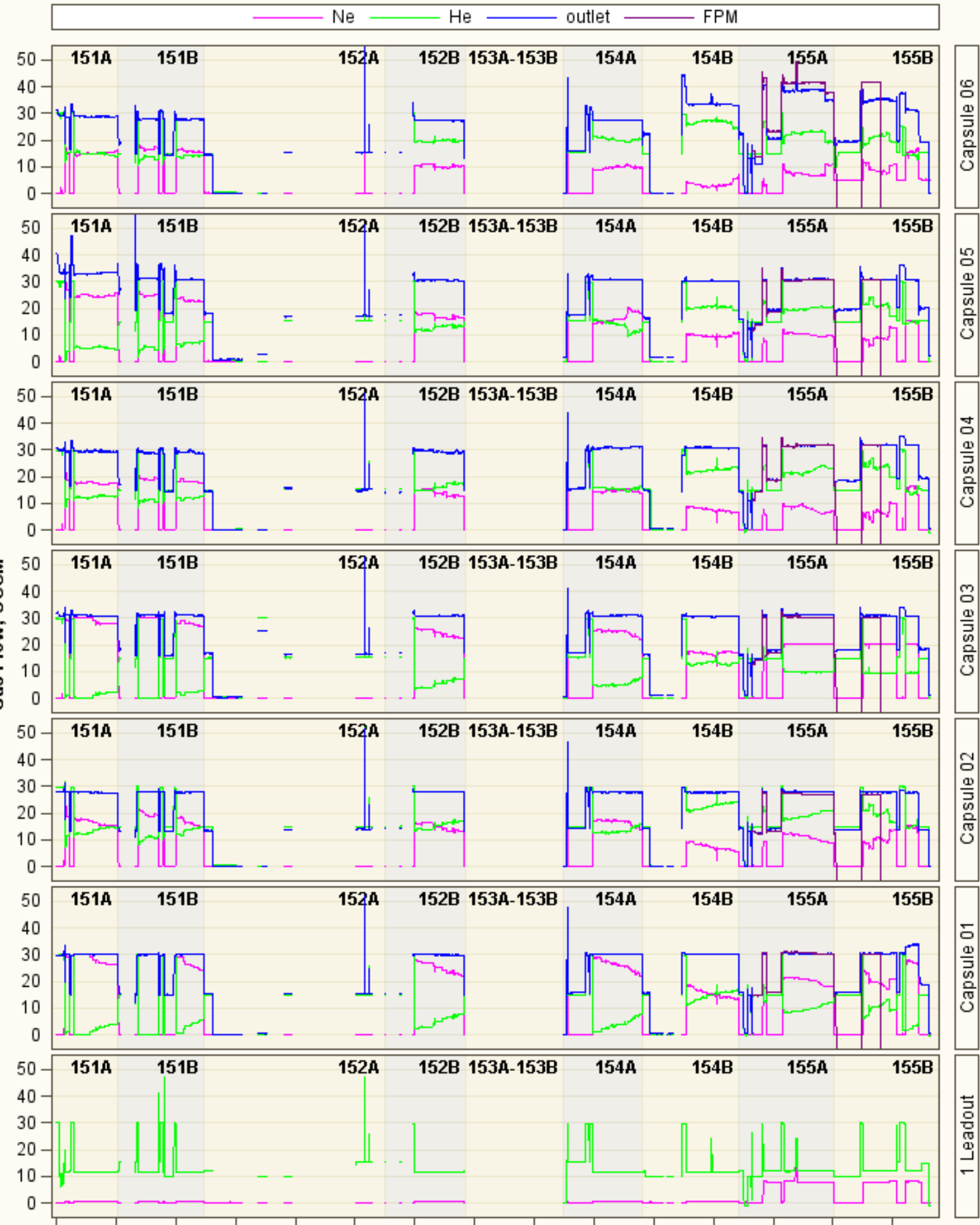

12Dec 09Feb 08Apr 06Jun 04Aug 020ct 30Nov 28Jan 28Mar 26May 24Jul 21Sep 19Nov 17Jan 17Mar 20112012 2013

2014

Figure 14. Capsules 1-6 and the Leadout sweep gas flow rates (sccm). 


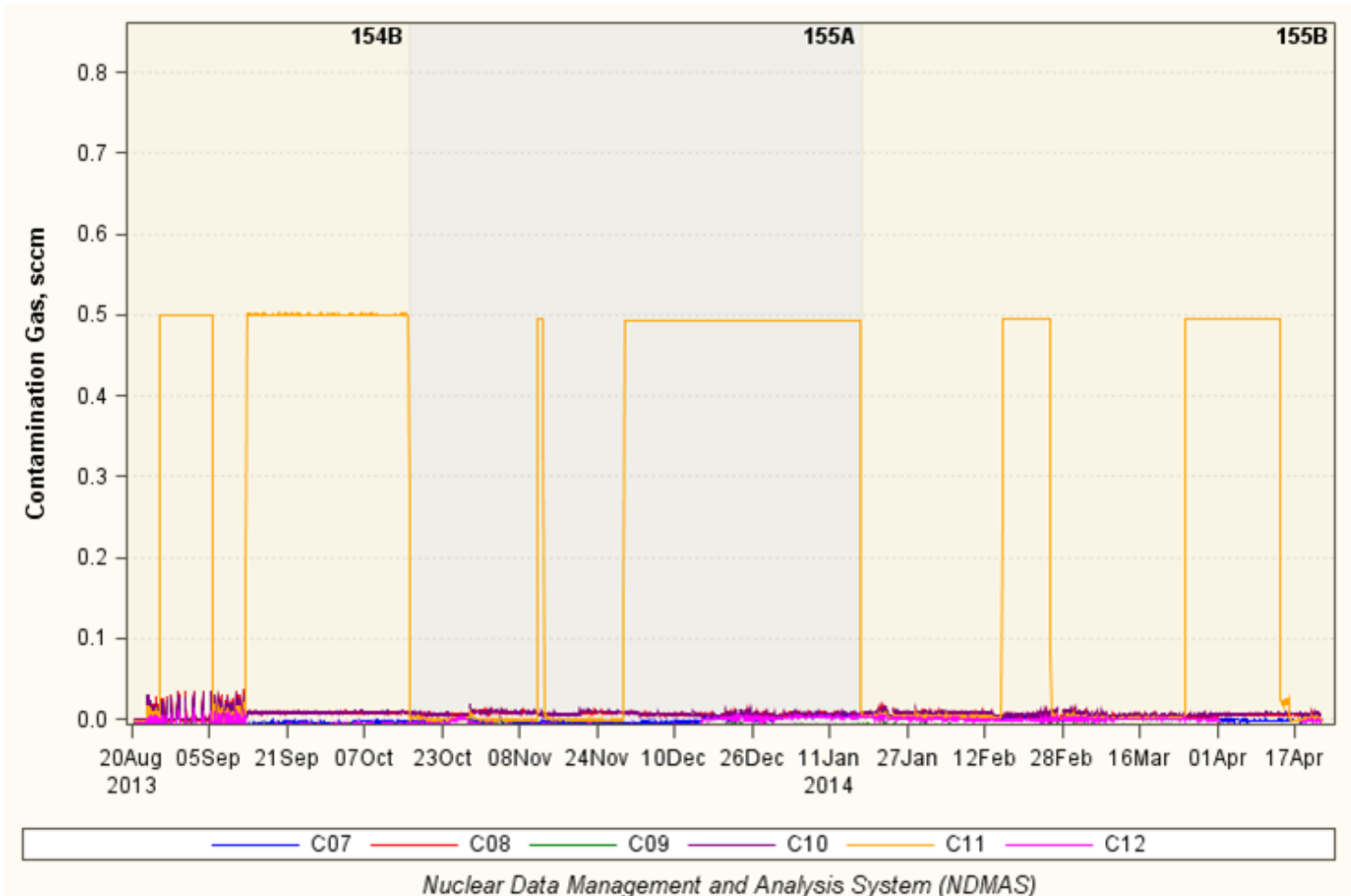

Figure 15. Capsules 7-12 impure gas flow rates (sccm).

\subsubsection{FPMS Data}

\subsubsection{Fission Product Release Rate and Release-to-Birth Ratio}

NDMAS received and processed 259,896 release rate records and 259,896 R/B records for the 12 radionuclides (Kr-85m, Kr-87, Kr-88, Kr-89, Kr-90, Xe-131m, Xe-133, Xe-135, Xe-135m, Xe-137, Xe-138, and Xe-139) reported for the 12 AGR-3/4 capsules during the AGR-3/4 irradiation (only for the seven full-power ATR cycles ). Each record is associated with an estimated uncertainty. To date, the FPMS data stored in NDMAS database are preliminary data and their qualification statuses are set to $\mathrm{In}$ process. Detailed documentation of the release rate and R/B data for the AGR-3/4 experiment is being issued by the FPMS team in an ECAR that will provide the basis for qualification of the AGR-3/4 FPMS data. Following release of the ECAR, qualification statuses in NDMAS will be updated accordingly. Additionally, the FPMS team provides the requirements for storage and display of FPMS data within the NDMAS database. These requirements prevent the use of data with high measurement uncertainty in fission product release data analysis. As a result, there are two sets of release rate and R/B data created for download: the full data set and a clean data set as follows:

- Full data set - Contains all release rate and R/B data passed to the NDMAS server. These AGR-3/4 FPMS data are qualified because of the acceptance testing performed within the measurement system and operability test plans.

- Clean data set - Contains all meaningful data that are ready to use in fission product release analysis. In the clean data set, the negative values and values where associated uncertainties are greater than $50 \%$ are omitted. A large uncertainty usually occurs when the peak was not clearly seen in a particular spectrum. These data filters remove data from the short leadout flow runs or measurements that were incomplete, while leaving other runs that have enough counting statistics unaffected.

As an example, Figure 16 through Figure 19 plot the full sets of release rate and R/B data for $\mathrm{Kr}-85 \mathrm{~m}$, $\mathrm{Kr}-88$, and Xe-138 isotopes. The R/B data in Figure 18 and Figure 19 are the latest version of calculated 
$\mathrm{R} / \mathrm{B}$ using the isotope daily birthrate; therefore, these $\mathrm{R} / \mathrm{B}$ values are named daily $\mathrm{R} / \mathrm{B}$ to differentiate them from the earlier version of $\mathrm{R} / \mathrm{B}$. The daily $\mathrm{R} / \mathrm{B}$ data replace the earlier version of $\mathrm{R} / \mathrm{B}$ data calculated using a four-point isotope birthrate. Currently, the four-point FPMS data are flagged as Obsolete data in the NDMAS database, and they are available upon special request. The daily FPMS data are used for display on the NDMAS web pages and are available for data download.

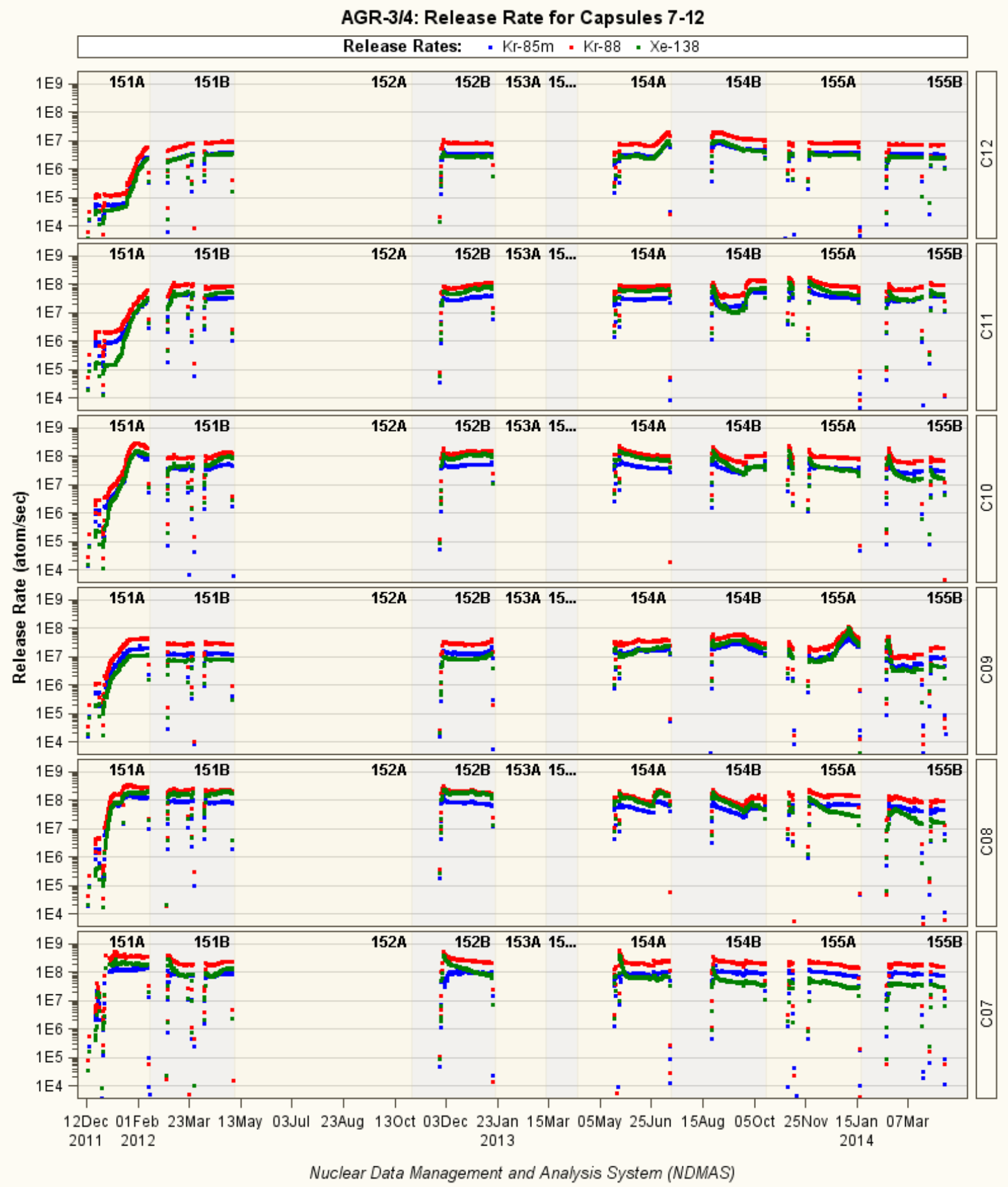

Figure 16. Fission product release rates for $\mathrm{Kr}-85 \mathrm{~m}, \mathrm{Kr}-88$, and $\mathrm{Xe-138}$ for Capsules 7-12. 
AGR-3/4: Release Rate for Capsules $1-6$

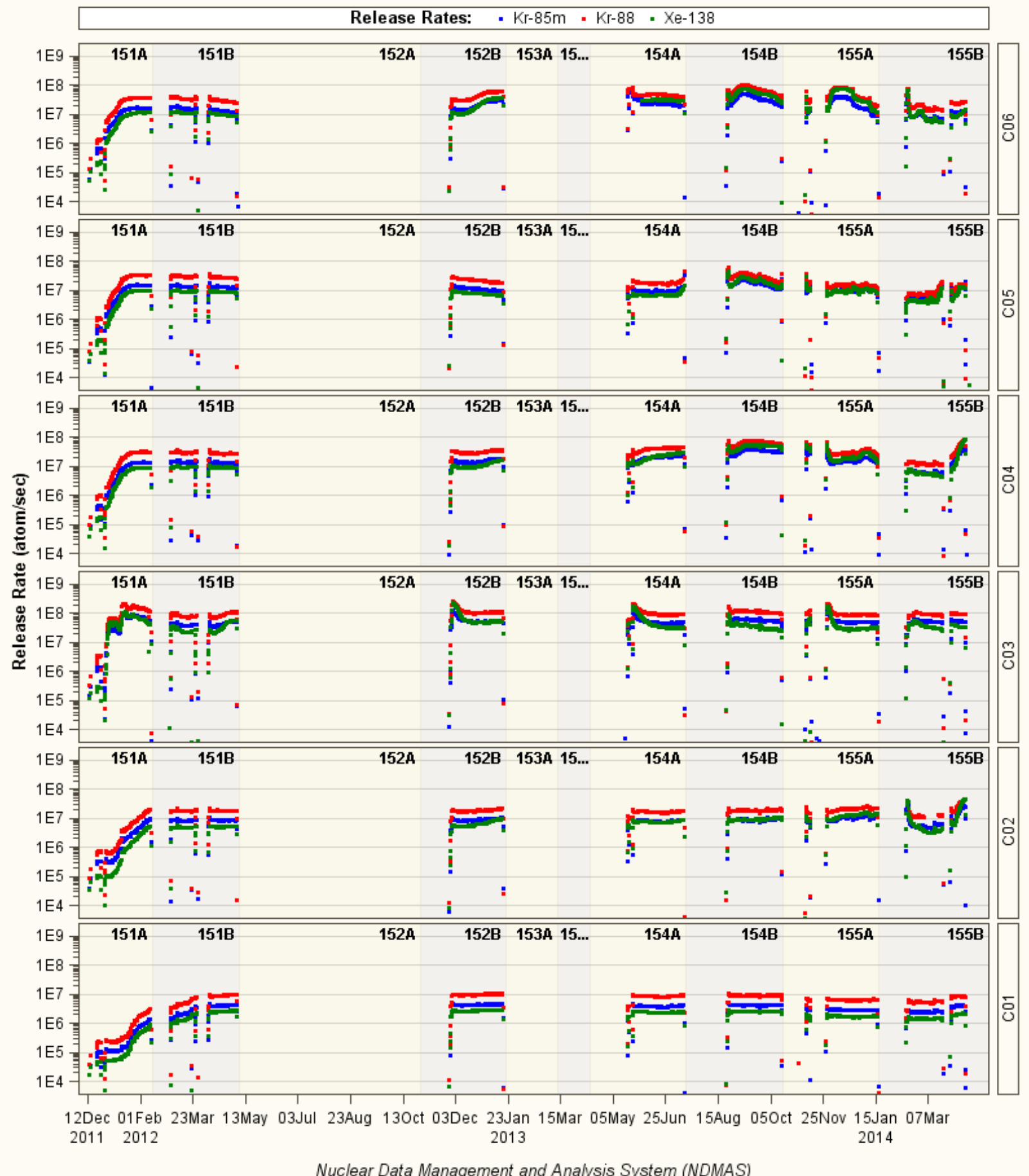

Figure 17. Fission product release rates for $\mathrm{Kr}-85 \mathrm{~m}, \mathrm{Kr}-88$, and $\mathrm{Xe}-138$ for Capsules 1-6. 


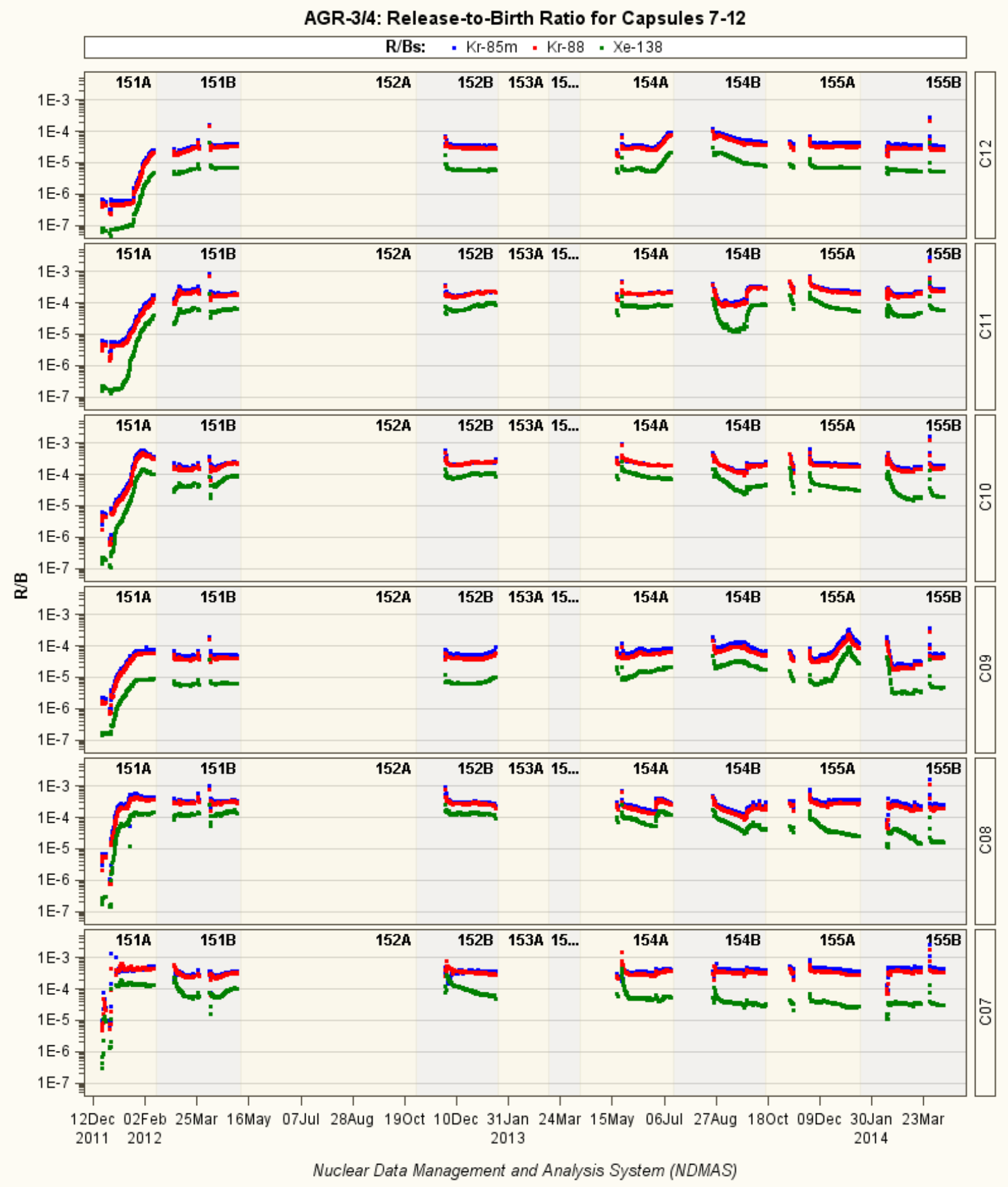

Figure 18. Fission product R/B ratios for $\mathrm{Kr}-85 \mathrm{~m}, \mathrm{Kr}-88$, and Xe-138 for Capsules 7-12. 


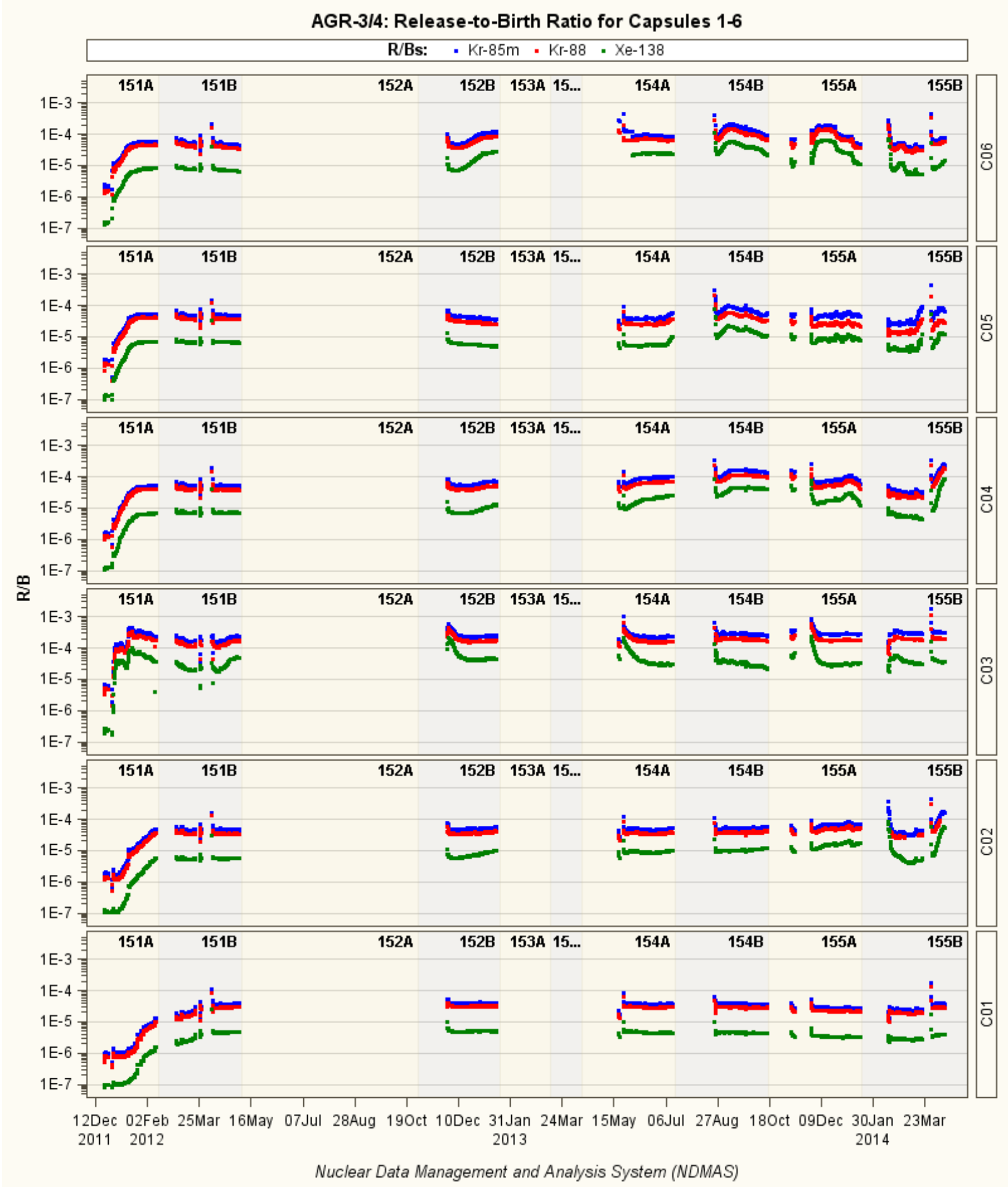

Figure 19. Fission product R/B ratios for Kr-85m, Kr-88, and Xe-138 for Capsules 1-6. 


\subsubsection{Fuel Particle Failure Counts}

The in-pile failures of embedded DTF particles in each capsule are detected using the independent capsule-specific $\mathrm{NaI}(\mathrm{Tl})$ total radiation detector. Even though the detector is sensitive to each fuel particle failure (up to 250 failures), visually counting the exact number of failed particles during the whole AGR-3/4 irradiation was a challenging task. This is due to the impact of multiple failures of DTF fuel particles occurring at the same time, partial failures, and high background activity caused by releases from already failed particles. The challenges in the failure detection process could lead to high uncertainty of particle failure counts in some capsules. Therefore, each inspection period provides three estimates of failure counts: (1) best-estimate, (2) maximum, and (3) minimum. For Capsule 1 (plots on the left of Figure 20) the three failure estimates are quite different from each other, indicating high counting uncertainty. By contrast, for Capsule 9 (plots on the right of Figure 20), the three failure estimates are very similar, indicating low counting uncertainty or high confidence about the number of particle failures.

NDMAS received 732 records of weekly particle failure counts for 12 capsules throughout the AGR-3/4 irradiation. Each record contains the best-estimate, maximum, and minimum counts. Figure 21 plots the weekly cumulative best-estimated failure counts as a function of EFPDs for each of the 12 AGR-3/4 capsules. For most capsules, the fuel failures occurred in the first irradiation cycle (within the first 55 EFPDs). For a few of the capsules (e.g., Capsules 2 and 3), fuel failures occurred throughout irradiation. In Capsules 2, 3, and 9, the final best-estimated failure counts are higher than 80 DTFs in each capsule. Based on the AGR-1 irradiation fuel performance, it is reasonable to assume that there were no in-pile particle failures among the qualified driver fuel particles. Thus, the total number of fuel particle failures in each AGR-3/4 capsule should be capped at a maximum of 80 failures, as had been done in fission product data analysis.
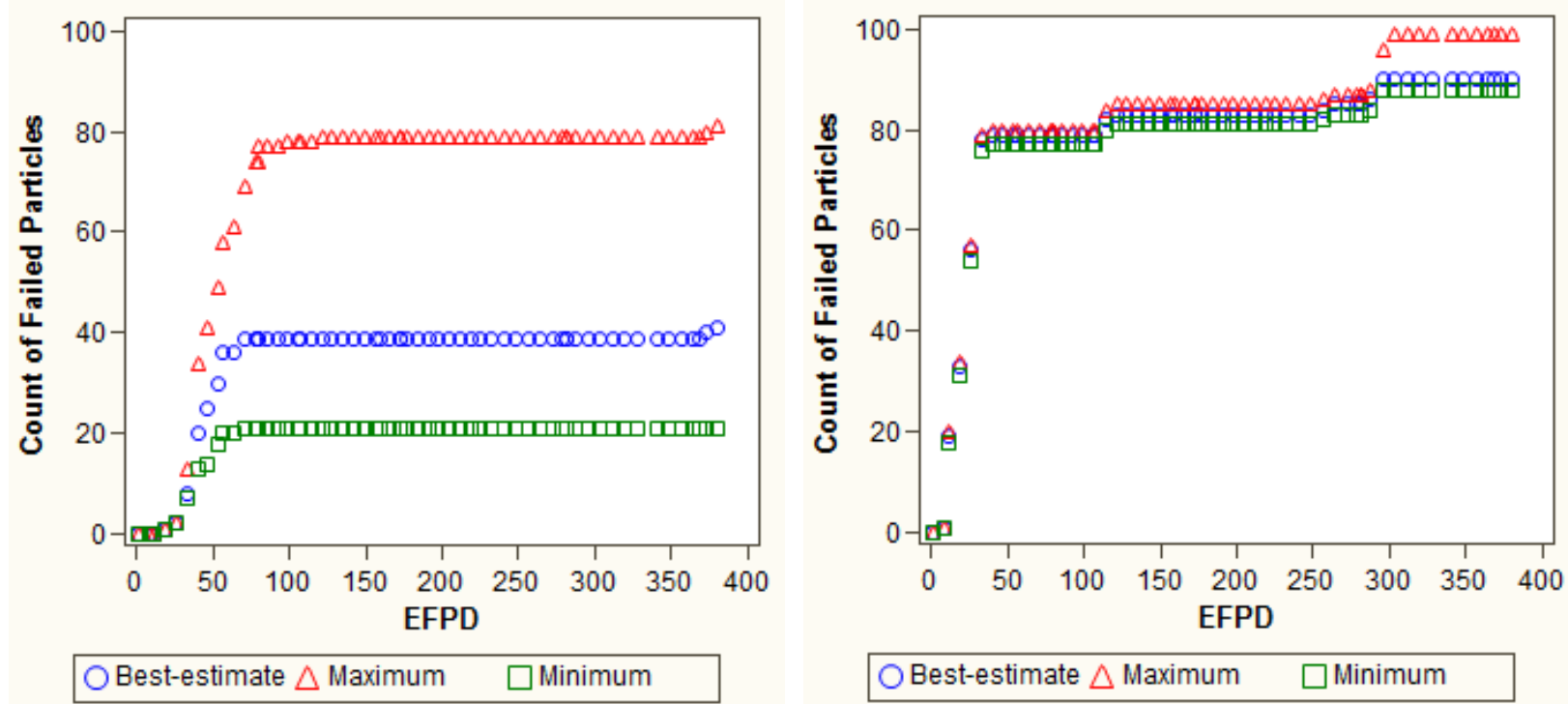

Figure 20. Particle failure counts for Capsule 1 (left plots) and Capsule 9 (right plots). 


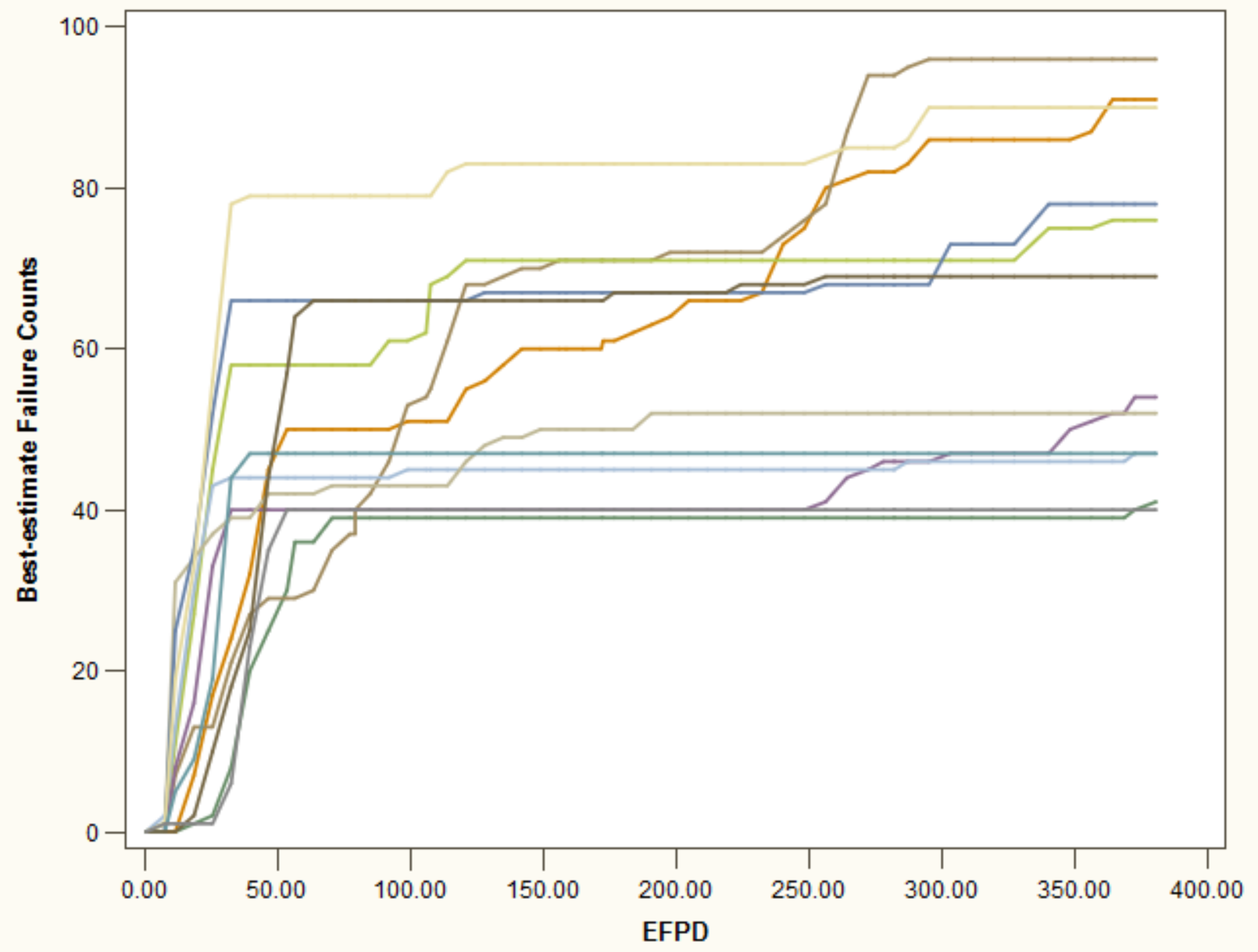

Capsule - Capsule 01 - Capsule 02 - Capsule 03 - Capsule 04 - Capsule 05 - Capsule 06 - Capsule 07 - Capsule 08 - Capsule 09 - Capsule 10 - Capsule 11 - Capsule 12

Figure 21. AGR-3/4 best-estimate failure counts.

\subsection{Testing for Data Anomalies of TC Temperatures}

NDMAS runs a number of tests for TC temperature data to identify potential anomalies (Table 7). Anomalies are data with values outside the expected range. Some of these may reflect bad data (e.g., as a result of instrument failure), but some may reflect transient events that produced correctly measured data outside of normal operating ranges. The anomalies are reviewed as part of the data qualification process to determine their quality (valid or failed) for future use. The accuracy range test is discussed in Subsection 2.3.4.2 as part of the NDMAS database activity. This section discusses the range and analytical tests in use, the basis for the tests, and presents test results. Qualification decisions based in part on the results of these tests are presented in Section 4. 
Table 7. NDMAS tests performed for AGR-3/4 irradiation monitoring data.

\begin{tabular}{lll}
\hline Test Type & Test Name & Test Description \\
\hline Capture & Range & $\begin{array}{l}\text { Used range test limits applied to AGR-3/4 TC data } \\
\text { Analysis }\end{array}$ \\
Instrument Failure & $\begin{array}{l}\text { Used to fail data collected from an instrument that has been deemed to } \\
\text { no longer be providing reliable data. }\end{array}$ \\
Analysis & $\begin{array}{l}\text { TC Difference } \\
\text { Control Charts }\end{array}$ & $\begin{array}{l}\text { Anomaly testing for TC drift: The temperature difference between TCs } \\
\text { in the same capsule should be similar over time. Trends and } \\
\text { discontinuities in the data suggest that one of the TCs is drifting. }\end{array}$ \\
Analysis & $\begin{array}{l}\text { TC Spatial } \\
\text { Correlations }\end{array}$ & $\begin{array}{l}\text { Anomaly testing for TC junction failure: A TC should be most highly } \\
\text { correlated with one in the same (or a nearby) capsule. Higher } \\
\text { correlation with a distant TC suggests a TC junction failure. }\end{array}$
\end{tabular}

\subsubsection{NDMAS Range Testing}

This section discusses data anomalies of TC readings resulting from data capture and range testing. A total of 19,083,794 TC records captured in the NDMAS database during AGR-3/4 irradiation are discussed here. Missing and out-of-range TC measurements are identified by range testing performed automatically during the NDMAS data capture process. Table 8 shows that there are only 20,723 TC readings (or only $0.11 \%$ of all TC readings) that failed the capture and range test (mostly due to missing values) out of 19,398,074 TC records.

Table 8. Results of range tests for TC readings during AGR-3/4 irradiation.

\begin{tabular}{cccccc}
\hline ATR Cycle & Total No. Records & Negative & Missing & Total No. Failed & \%Failed \\
\hline 151A & 478,035 & 0 & 0 & 0 & $0.0 \%$ \\
151B & 946,269 & 95 & 19 & 114 & $0.0 \%$ \\
152A & $2,515,455$ & 5 & 15,252 & 15,257 & $0.6 \%$ \\
152B & $2,288,601$ & 0 & 61 & 61 & $0.0 \%$ \\
154A & $2,780,327$ & 0 & 1,116 & 1,116 & $0.0 \%$ \\
154B & $3,157,981$ & 0 & 0 & 0 & $0.0 \%$ \\
155A & $3,570,422$ & 0 & 0 & 0 & $0.0 \%$ \\
155B & $3,660,984$ & 4,175 & 0 & 4,175 & $0.02 \%$ \\
Total $=$ & $\mathbf{1 9 , 3 9 8 , 0 7 4}$ & $\mathbf{4 , 2 7 5}$ & $\mathbf{1 6 , 4 4 8}$ & $\mathbf{2 0 , 7 2 3}$ & $\mathbf{0 . 1 1 \%}$
\end{tabular}




\subsubsection{Out-of-Range Data}

Based on fuel temperature test requirements and the location of the TCs, TC readings are not expected to exceed $1400^{\circ} \mathrm{C}$. The range test for TC values flags temperatures below freezing and temperatures above $1400^{\circ} \mathrm{C}$, resulting in a Failed data status as a result of the NDMAS capture range testing. As shown in Table 8, there were no excessively high TC readings and an insignificant number of negative TC readings identified during AGR-3/4 irradiation. Most of the 4,275 negative TC readings were recorded during ATR Cycle 155B from two TCs, TC1 in Capsule 6 and TC2 in Capsule 10. For the operational TC2 in Capsule 10, the 1,724 negative readings on April 21 and 22, 2014 occurred more than 1 week after the power-down of the last cycle. Among 2,451 negative readings from TC1 in Capsule 6, only 23 negative readings occurred before the established $\mathrm{TC}$ failure. The negative readings for $\mathrm{TC} 1 \mathrm{in}$ Capsule 6 that occurred after the TC failure will be categorized as instrument failure, rather than range testing failure.

DRC recommendation: Fail 4,275 negative TC readings.

\subsubsection{Missing Data}

Data are classified as Failed missing only if there is no record present for an existing time stamp in the raw data files provided by the data generators. There are 16,448 missing TC readings out of $19,398,074$ TC records (only $0.08 \%$ of the total). Most of the missing TC data were received during the low power cycle (152A). They were not critical to the test objectives because this cycle was considered a long outage period. There are 1,116 missing values from TC3 in Capsule 12 during ATR Cycle 154A because of a mistake in the automated data output script, which was fixed for subsequent cycles.

DRC recommendation: Fail 16,448 missing TC records.

\subsubsection{Instrument Failure Testing}

AGR TCs deteriorate and sometimes fail because of the high-irradiation and temperature conditions that occur during test reactor cycles. Failures are likely caused by deterioration or damage to the TC sheath and/or dielectric insulating material that separates the TC thermal elements. This produces an electrical path ("virtual junction") at some location along the TC wire other than at the terminal tip. Failure is clearly exhibited when the temperature reading drops to or near zero during ATR full-power conditions, does not respond during reactor power-up, or responds in a way that is inconsistent with reactor power conditions, capsule gas mixture, or other TC responses. The five TC failures and associated failure date/time and corresponding ATR cycle for the AGR-3/4 experiment are identified in Table 9. These TC failures contribute to 1,480,546 Failed TC readings ( $7.6 \%$ of the total TC records).

Table 9. TC failures during AGR-3/4 irradiation.

\begin{tabular}{ccccc}
\hline Capsule & TC & Failure Time & ATR Cycle & Number of Failed Records \\
\hline 2 & 2 & $04 / 29 / 201308: 45$ & $154 \mathrm{~A}$ & 492,470 \\
3 & 1 & $05 / 17 / 201303: 15$ & $154 \mathrm{~A}$ & 468,288 \\
3 & 2 & $10 / 09 / 201312: 15$ & $154 \mathrm{~B}$ & 278,374 \\
5 & 1 & $01 / 11 / 201408: 30$ & $155 \mathrm{~A}$ & 144,632 \\
6 & 1 & $02 / 13 / 201414: 00$ & $155 \mathrm{~B}$ & 96,782 \\
& & & & Total $=\mathbf{1 , 4 8 0 , 5 4 6}$
\end{tabular}

Interestingly, all five failed TCs are in capsules located in the bottom half of the AGR-3/4 test train. Evidence of these TC failures is shown using plots and discussions in the following subsections. Both INL ART TDO program leads and NDMAS analysts identified these failures in a timely manner over the 
course of the experiment. The date/time of the failures were confirmed by the DRC during the data qualification process. After DRC verification, the Data State and Qualification State flags are set to Failed in the NDMAS database for all temperature records from the failed TC after the failure date. These failure flags ensure the data are managed and used appropriately (e.g., are not used in any plots or downloads and are identified as Failed in the data tables).

\subsubsection{TC2 in Capsule 2}

DRC Recommendation: Failure on April 29, 2013, at 08:45 (Cycle 154A)

AGR-3/4 was moved from the ATR canal and reinserted into the NEFT location on April 26, 2013, during the outage portion of ATR Cycle 154A. The AGR-3/4 irradiation data for ATR Cycle 154A recorded before April 26 are therefore invalid data. Readings of TC1 and TC2 in Capsule 2 during the beginning of ATR Cycle 154A presented in Figure 22 show that TC2 (orange line) was initially unresponsive, exhibiting none of the fluctuations seen in the TC1 readings (green line). Further, TC2 readings remained at a very low level even as the ATR reached full power, as shown in Panel 5 from the top of Figure 12. Based on this response, TC2 is assumed to have failed on April 26, 2013, at 08:45, and all data from this TC are labelled Failed after this date/time.

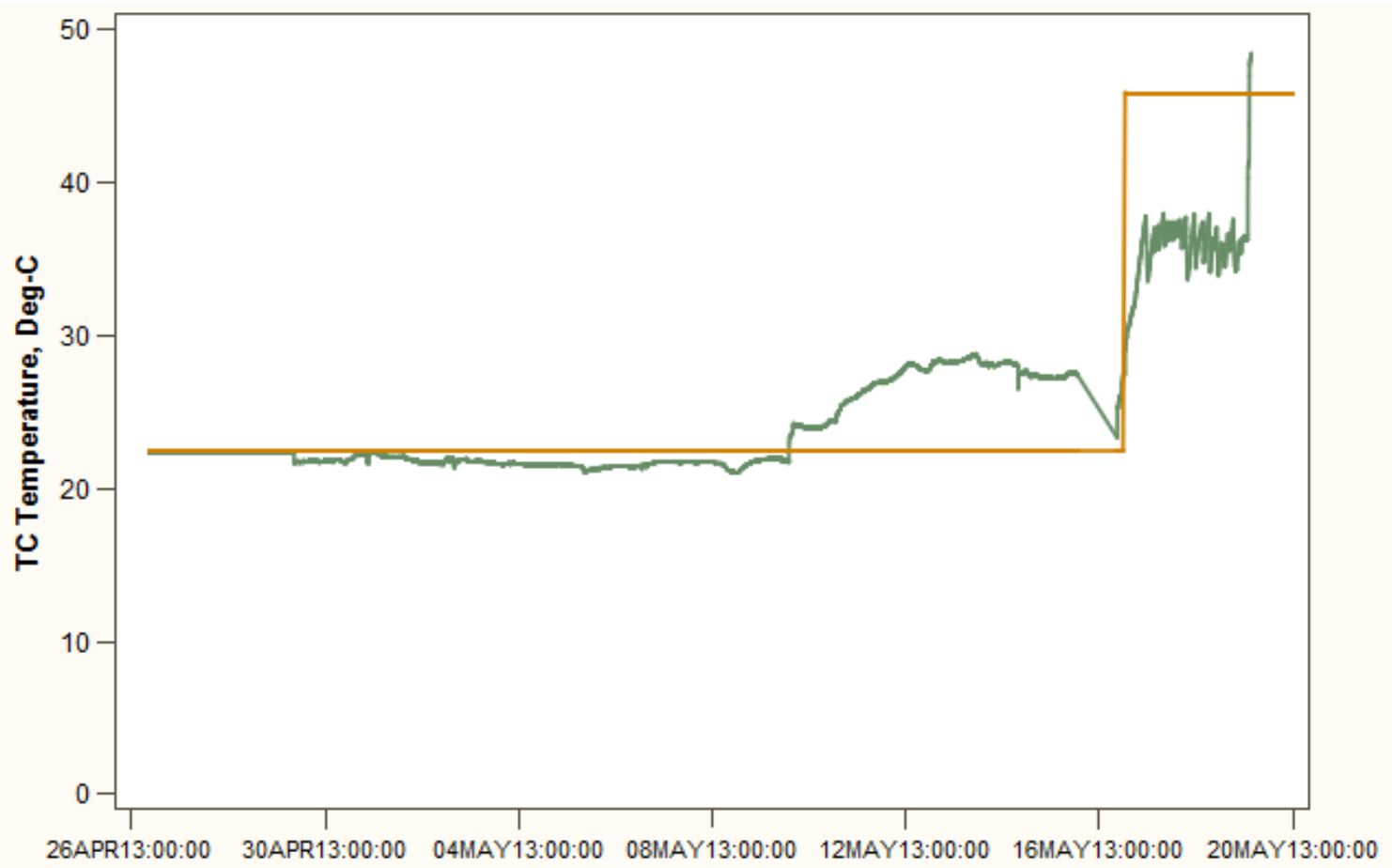

Standard Date Time

$-\mathrm{TC} 1-\mathrm{TC} 2$

Figure 22. TC2 in Capsule 2 failed right at the beginning of Cycle 154A on 29 April, 2013 at 08:45. 


\subsubsection{TC1 in Capsule 3}

DRC Recommendation: Failure on May 17, 2013, at 03:15 (Cycle 154A)

Figure 23 shows that TC1 in Capsule 3 also failed during the outage portion of the ATR Cycle 154A. Initially, TC1 and TC2 readings in Capsule 3 followed each other perfectly, but from May 17, 2013, at 03:15 TC1 readings (green line) dropped significantly, remaining low even when ATR powered up, as shown in Panel 4 from the top of Figure 12. Based on this response, TC1 is assumed to have failed on May 17, 2013, at 03:15, and all data from this TC are labelled Failed after this date/time.

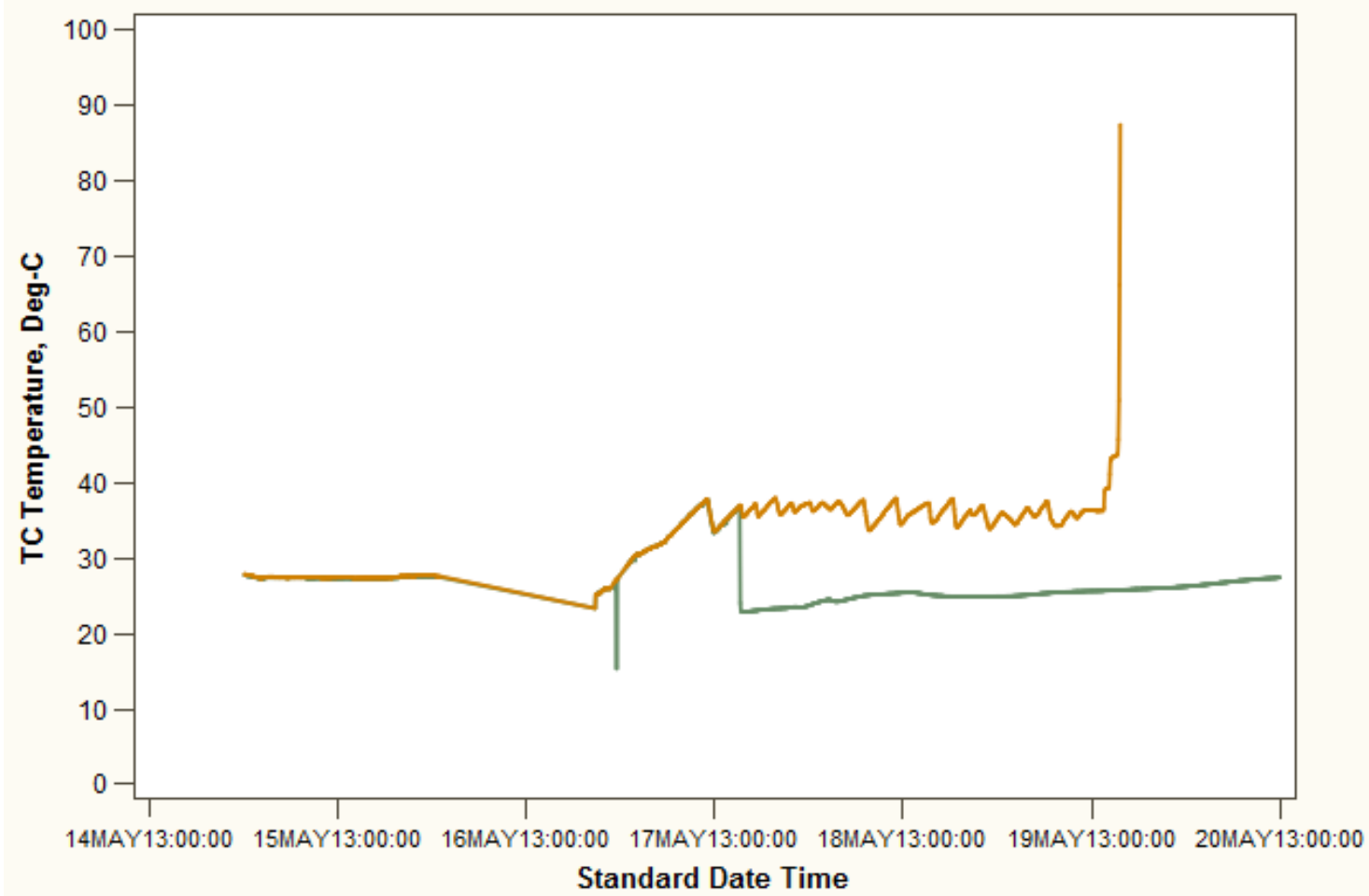

$$
-\mathrm{TC} 1-\mathrm{TC} 2
$$

Figure 23. TC1 in Capsule 3 failed on May 17, 2013, at 03:15 (based on actual data). 


\subsubsection{TC2 in Capsule 3}

DRC Recommendation: Failure on October 9, 2013, at 12:15 (Cycle 154B)

Figure 24 shows that TC2 in Capsule 3 clearly failed on October 9, 2013 at 12:15 when its readings dropped to approximately $30^{\circ} \mathrm{C}$ while ATR was at full power. All data from this TC are failed after this date/time.

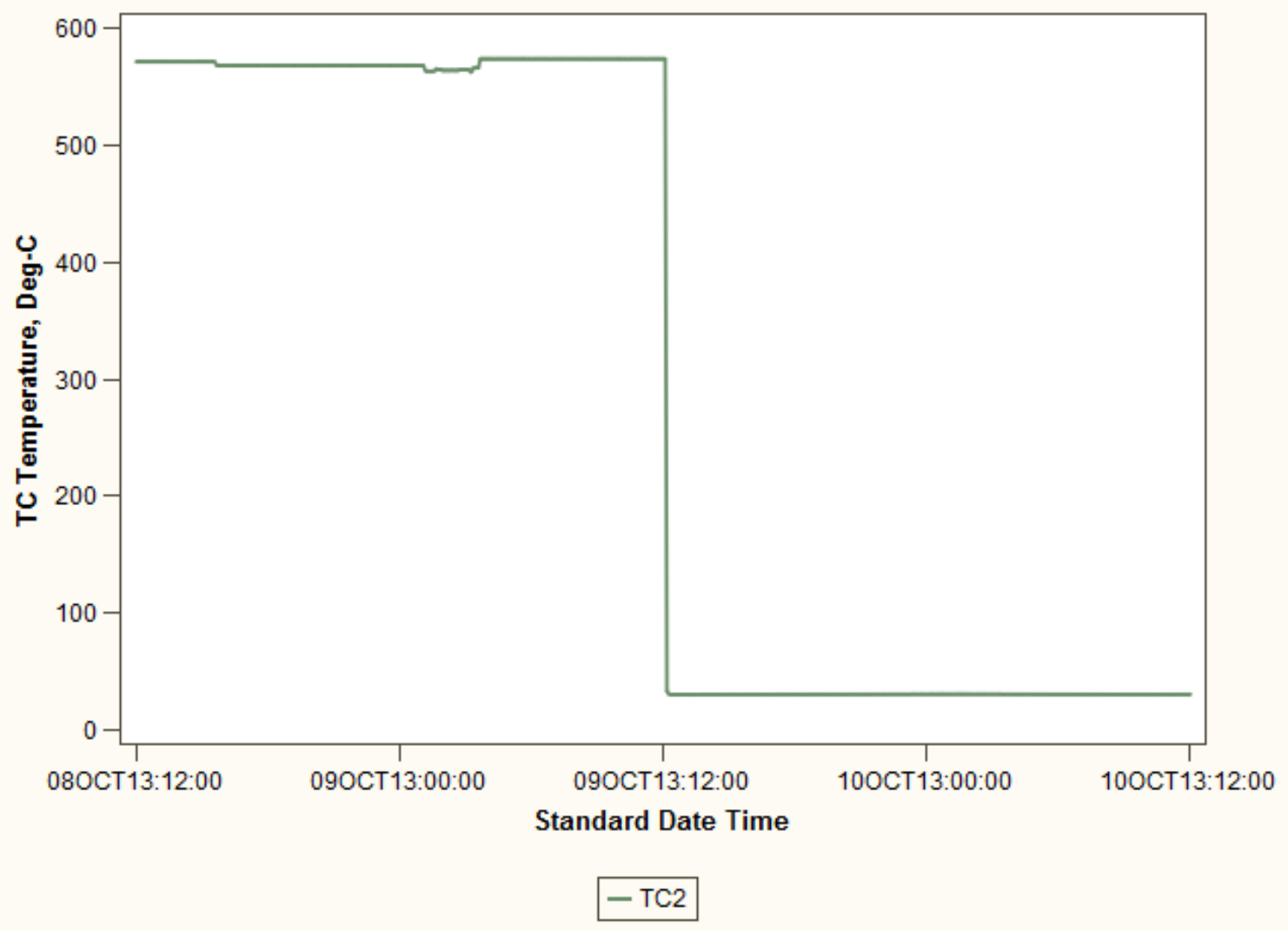

Figure 24. TC2 in Capsule 3 failed on October 9, 2013 at 12:15 (based on actual data). 


\subsubsection{TC1 in Capsule 5}

DRC Recommendation: Failure on January 11, 2014 at 08:30 (Cycle 155A)

Figure 25 shows clear failure of TC1 in Capsule 5 on January 11, 2014 at 08:30 when its readings dropped to approximately $30^{\circ} \mathrm{C}$ while ATR was at full power. All data from TC1 are failed after this date/time.

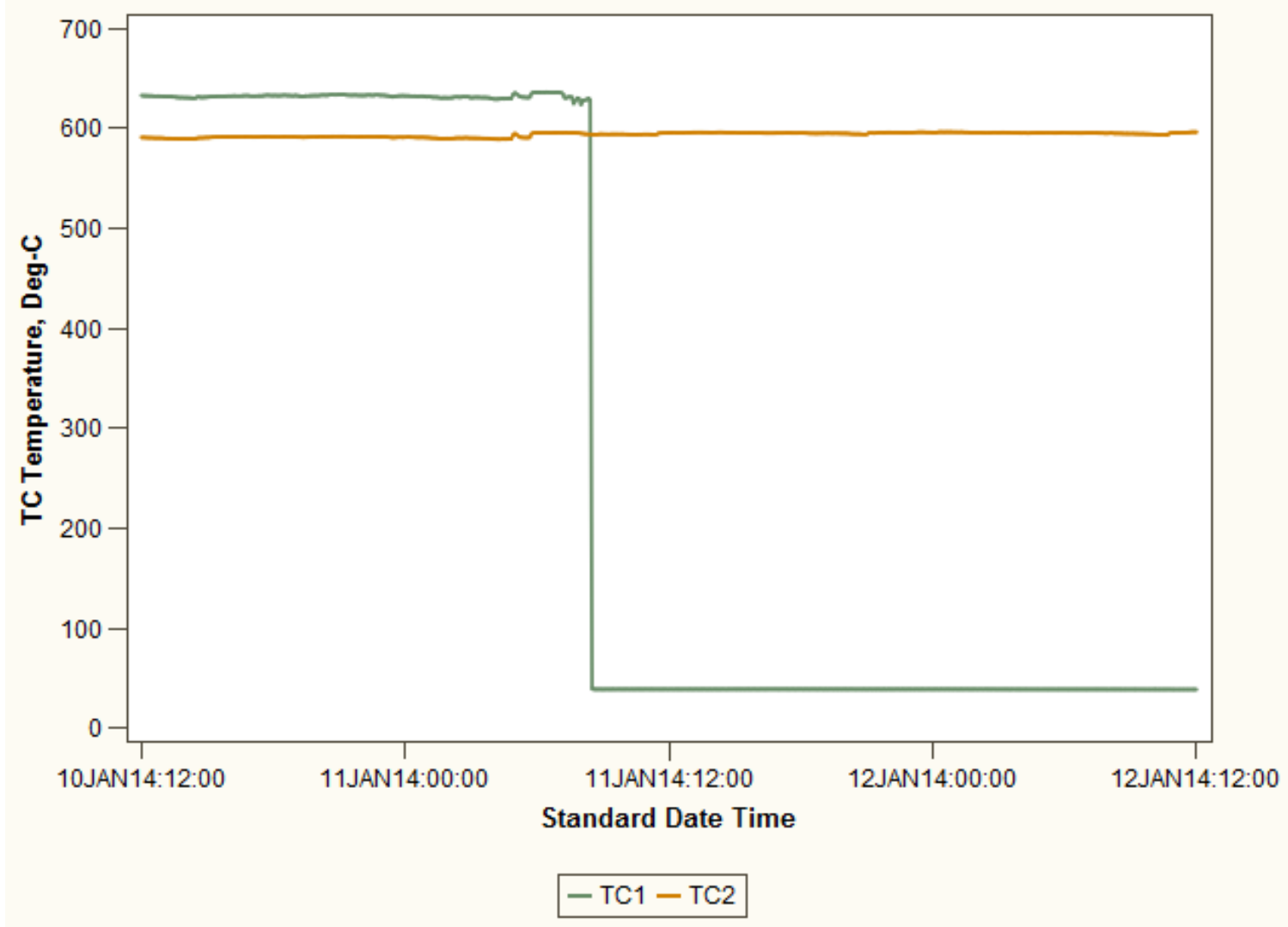

Figure 25. TC1 in Capsule 5 failed on January 11, 2014 at 08:30 (based on actual data). 


\subsubsection{TC1 in Capsule 6}

DRC Recommendation: Failure on February 13, 2014 at 14:00 (Cycle 155B)

Figure 26 shows that TC1 in Capsule 6 failed on February 13, 2014 at 14:00 when its readings (green line) began fluctuating significantly as compared to the operational TC2 temperatures (orange line) during the powering up phase for the last ATR Cycle 155B. All data from this TC are failed after this date/time.

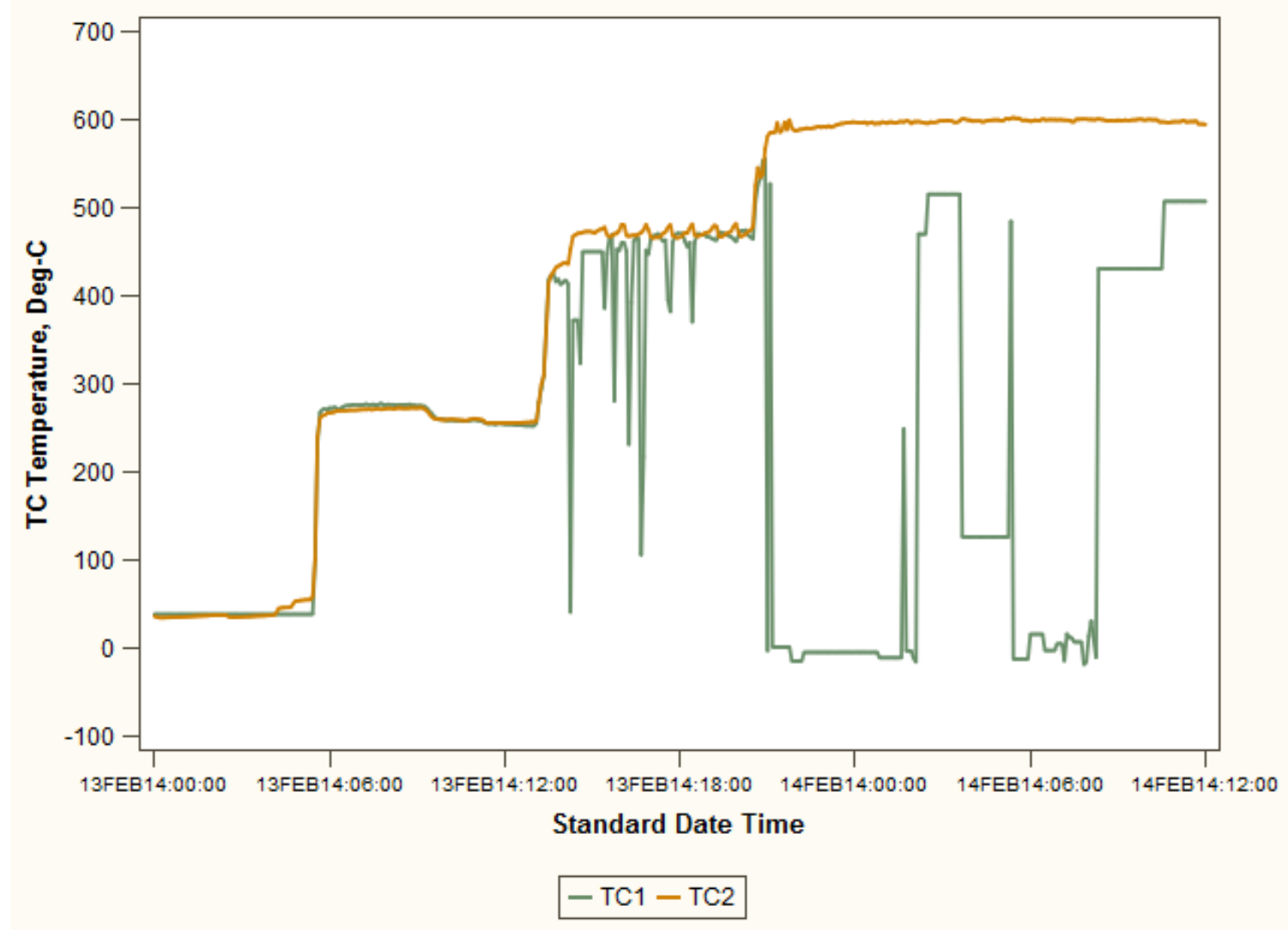

Figure 26. TC1 in Capsule 6 failed on February 13, 2014 at 14:00 (based on actual data).

\subsubsection{Simulation aided TC Drift Detection}

The term TC drift refers to the differences in TC readings over time that are the result of a malfunctioning TC rather than changes in experimental conditions. NDMAS uses control charts to help visualize and identify unacceptable TC drift over the course of the experiment. A control chart uses an initial baseline period of data to calculate typical operating conditions and then evaluates a subsequent monitoring period of data relative to the baseline conditions. A control chart centerline is calculated for a given capsule using the mean of the differences between TC pairs in that capsule during the baseline period. Upper and lower control limits for the TC differences are then calculated as three standard deviations above and below the control chart mean difference.

The ABAQUS-based thermal models were created for each of the twelve AGR-3/4 capsules. The calculated TC temperatures provided for use here were recorded in (Hawkes 2015). Even though TC readings are used to calibrate these models, the calculated temperatures at TC locations can also be useful in TC performance assessment. TC drift monitoring is based on measurement and simulation data of a TC pair in the same capsule. The drift detection figure consists of four panels containing plots as functions of time as shown in Figure 27 through Figure 41. Panel 1 depicts the control charts of TC pair temperature differences for both measurement and simulation. Panel 2 shows TC residuals (measured minus simulated 
temperature). Panel 3 plots daily correlation coefficients along with measured and simulated TC values. Panel 4 presents TC pair readings. Data in these plots are daily averaged values. These monitoring panels provide complementary indications of potential TC drift and help define the failure mode. The TC drift criteria are determined as follows:

1. Control charts of TC pair temperature differences: For a stable TC pair located in thermally similar locations, the temperature differences in the monitoring period should stay within the established control limits of three standard deviations around the mean value. When consistently out-of-control instances in a monitoring period are apparent, two scenarios should be considered:

The measured TC differences follow the simulated TC differences (the red and blue plots are parallel); then the out-of-control instances are justified and the TC pair is deemed stable.

Otherwise, at least one of the TCs in the pair might be drifting.

2. TC residuals: The $\mathrm{TC}$ is deemed stable in relation to simulation when the residuals, as a function of time, are centered on a horizontal line. A consistent slope of TC residuals indicates a TC drift (either downward or upward depending on slope direction).

3. Daily correlation coefficients: The correlation coefficients between within-capsule TC pairs should be close to 1. Decreasing daily correlation coefficients indicate that at least one TC of the subject TC pair is deteriorating.

4. Actual measured TC data plots: These plots are used to confirm the drift indication identified in items 1 through 3 by the departure of the actual readings of a drifting TC from being parallel to readings of the other TC.

A key control chart assumption is that there is a constant mean and standard deviation between TC pairs within a capsule over both the baseline and monitoring periods. This assumption may not always be valid because of differential heating across TC pairs that may occur as the experiment progresses. Thus, interpretation of data responses relative to control chart limits cannot be strictly defined with regard to data qualification status. Although NDMAS provides control chart results and statistical interpretations, the final determination of whether there is unacceptable TC drift is made by AGR project leads during the DRC process using multiple performance indicators, including control charts, simulated fuel temperatures, and engineering judgment. All these plots for valid TC temperature data are available on the NDMAS Web portal (https://ndmas.inl.gov) under AGR-34/Analysis/Temperatures.

For the AGR-3/4 experiment, three capsules $(5,10$, and 12) have three TCs each, with TC1 and TC2 located in the graphite heat sink and TC3 in the graphite matrix. The remaining capsules have two TCs each located in the graphite heat sink. Consequently, TC1/2 pairs are expected to be more consistent with each other than TC1/3 pairs. Therefore, the calculated TCs are relied on more heavily for assessing TC1/3 pairs as shown in Figure 28, Figure 31, and Figure 37. The results show only TC3 in Capsule 10 drifted during this reporting period, which contributed to a total of 305,742 Trend TC readings as shown in Table 10 .

Table 10. Number of trend TC readings from drifted TC3 in Capsule 10

\begin{tabular}{lcccc}
\hline ATR Cycle & $154 \mathrm{~B}$ & $155 \mathrm{~A}$ & $155 \mathrm{~B}$ & Total \\
\hline Number of Trend records & 37,295 & 132,855 & 135,592 & $\mathbf{3 0 5 , 7 4 2}$
\end{tabular}

DRC recommendation: Based on the evidence presented in Figure 31, the DRC confirms that TC3 in Capsule 10 drifted starting from the middle of ATR Cycle 154B and 305,742 readings from this TC after September 20,2013 at 12:00 are Trend data. 


\subsubsection{Capsule 12: TC1, TC2, and TC3 are stable}

Figure 27 and Figure 28 show the drift monitoring results for the TC1/2 and TC1/3 pairs in Capsule 12. All three TCs in this capsule are stable relative to each other because readings of three TCs are consistent according to the four above listed criteria: TC differences are within the control bounds and similar to calculation, both TC residuals are flat across cycles, fairly high correlation coefficients (especially for $\mathrm{TC} 1 / 2$ pair), and their readings are consistent with each other.

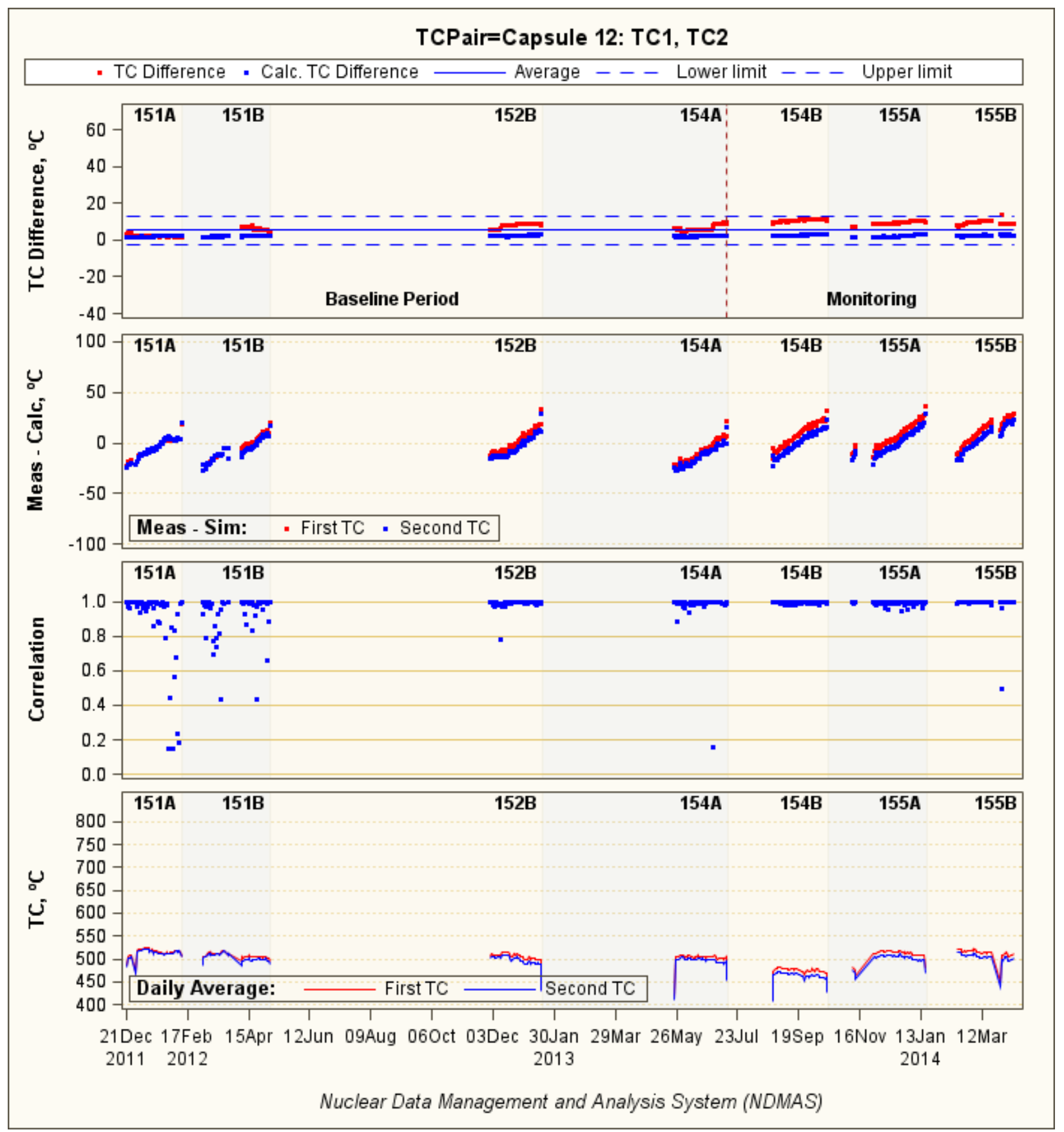

Figure 27. Drift monitoring for the TC1/2 pair in Capsule 12. 


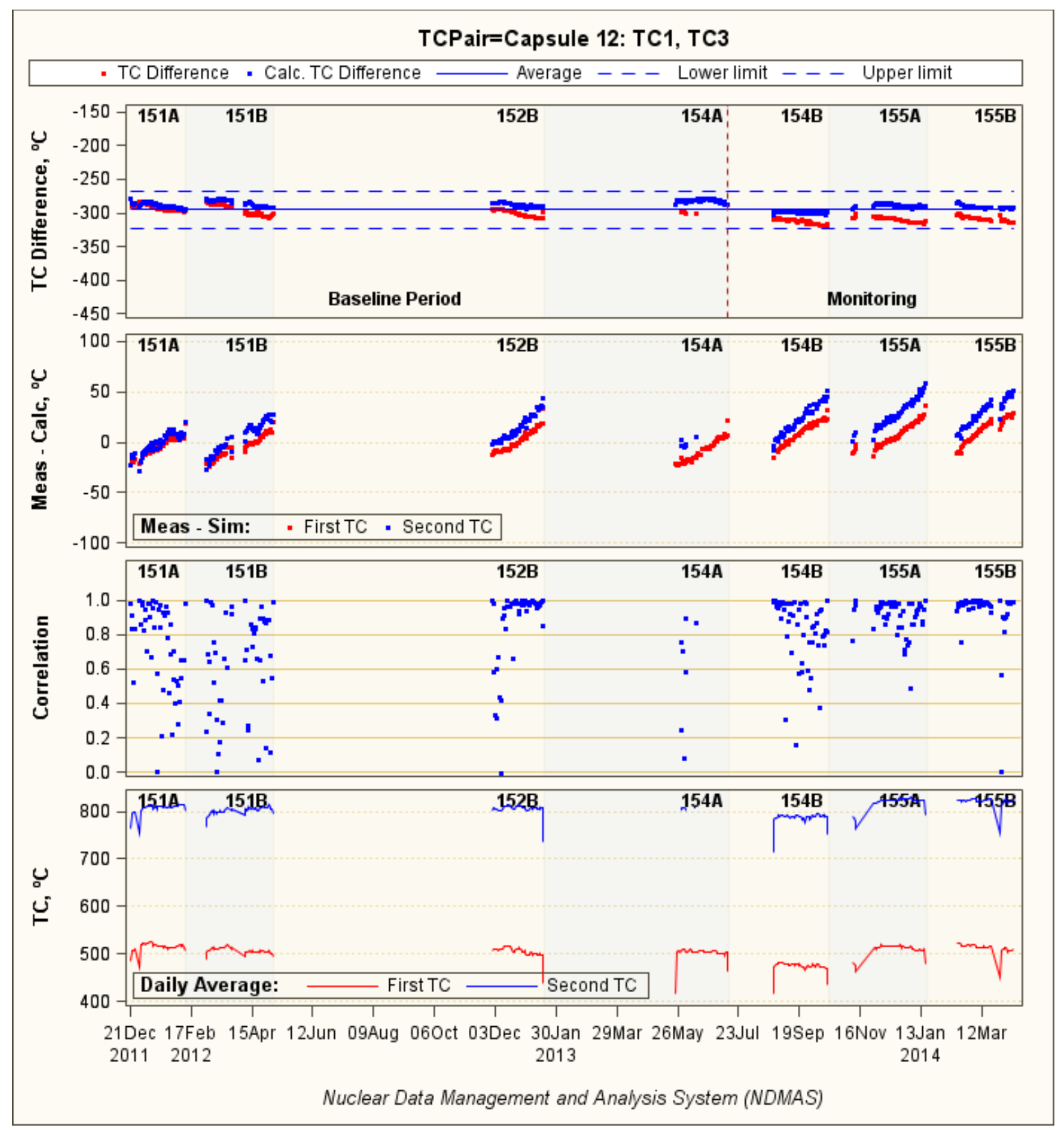

Figure 28. Drift monitoring for the TC1/3 pair in Capsule 12. 


\subsubsection{Capsule 11: TC1 and TC2 are stable}

Control charts of temperature differences between TC1 and TC2 in Capsule 11 in Figure 29 indicate that these two TCs were stable relative to each other, despite the fact that correlation coefficients between their readings are not consistently high.

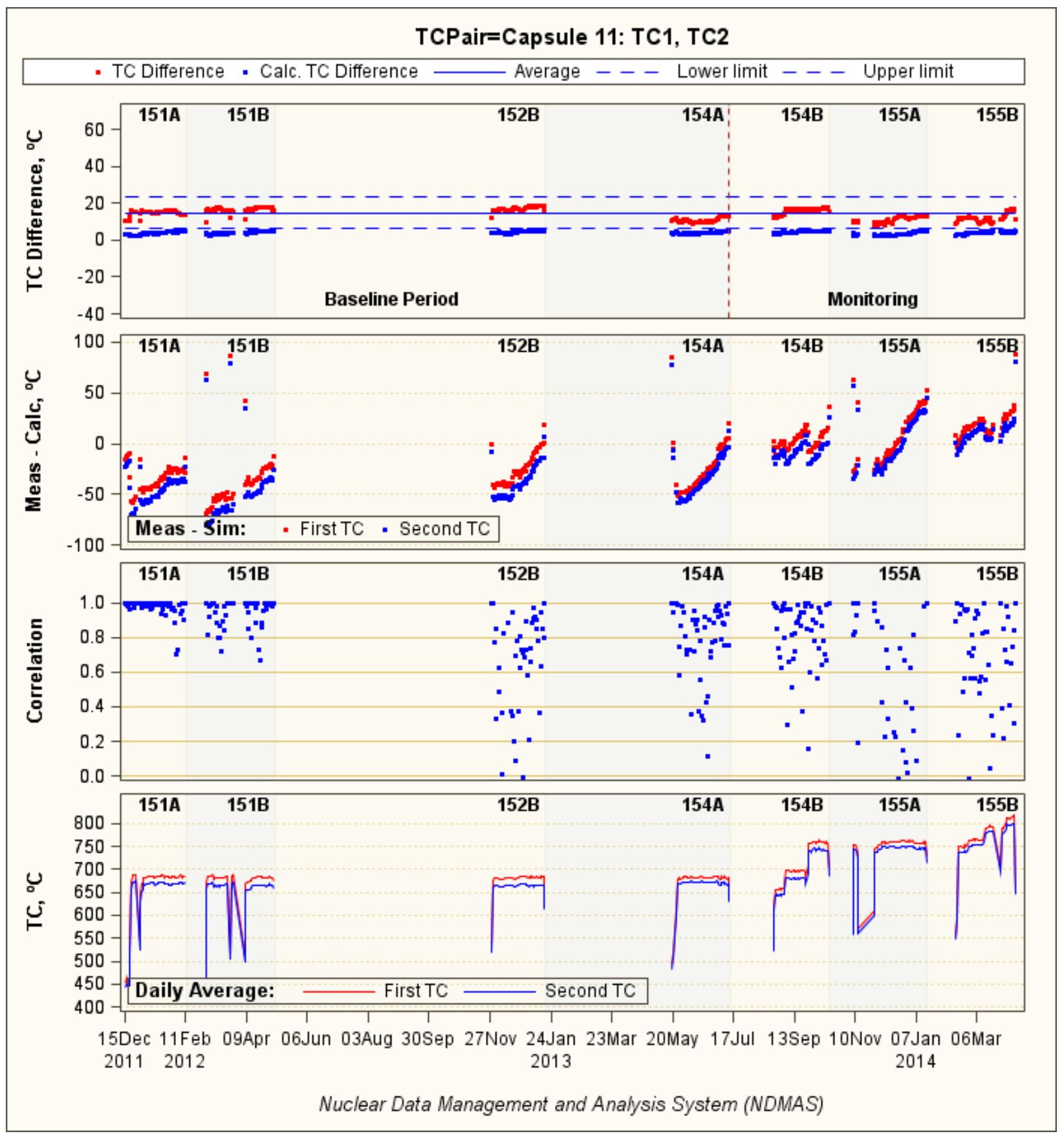

Figure 29. Drift monitoring for TC1 and TC2 in Capsule 11. 


\subsubsection{Capsule 10 - TC1, TC2 are fairly stable and TC3 is drifted}

Control charts of temperature differences between TC1 and TC2 in Capsule 10 in Figure 30 indicate that these two TCs were not perfectly stable relative to each other because the TC differences started to cross the upper limit of the control chart by the end of ATR Cycle 154B. However, the TC difference is too small (less than $30^{\circ} \mathrm{C}$ ) to clearly establish a drifting failure

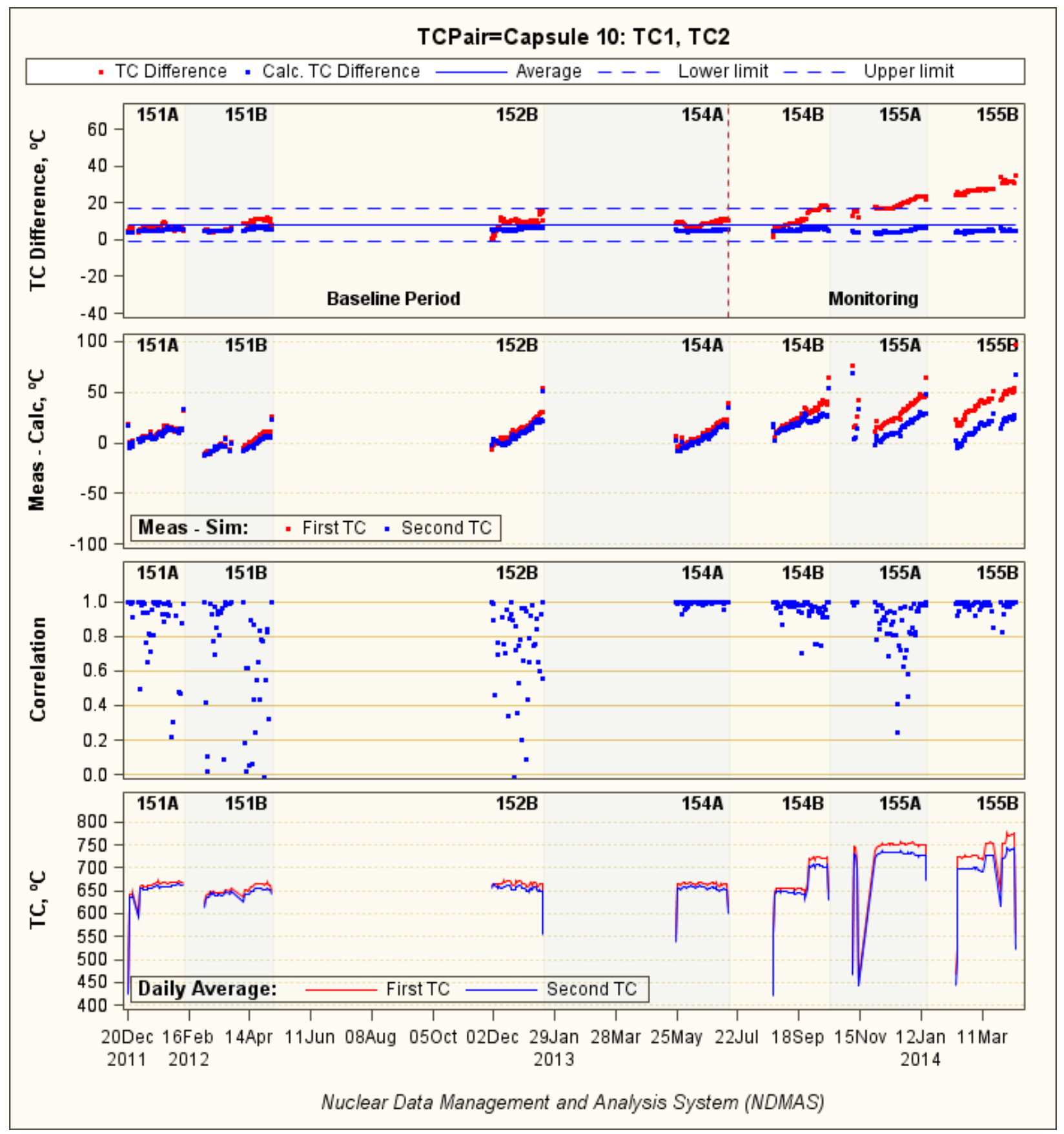

Figure 30. Drift monitoring for TC1 and TC2 in Capsule 10. 
On the other hand, control charts of temperature differences between TC1 and TC3 in Capsule 10 in Figure 31 indicate that TC3 was clearly drifting starting in the middle of ATR Cycle 154B. The TC differences (red dot in Panel 1) rapidly increased and TC3 residuals (measured - calculated in Panel 2) rapidly decreased more than $100^{\circ} \mathrm{C}$ (blue dots are outside of the plotting limits in the later cycles). In addition, the pair correlation coefficients (Panel 3) are predominantly low. Finally, the actual TC readings (red and blue lines in Panel 4) were clearly not parallel from the middle of ATR Cycle 154B.

DRC recommendation: Confirmed TC3 in Capsule 10 drifted starting from the middle of ATR Cycle 154B and its readings are labelled Trend data after September 20, 2013.

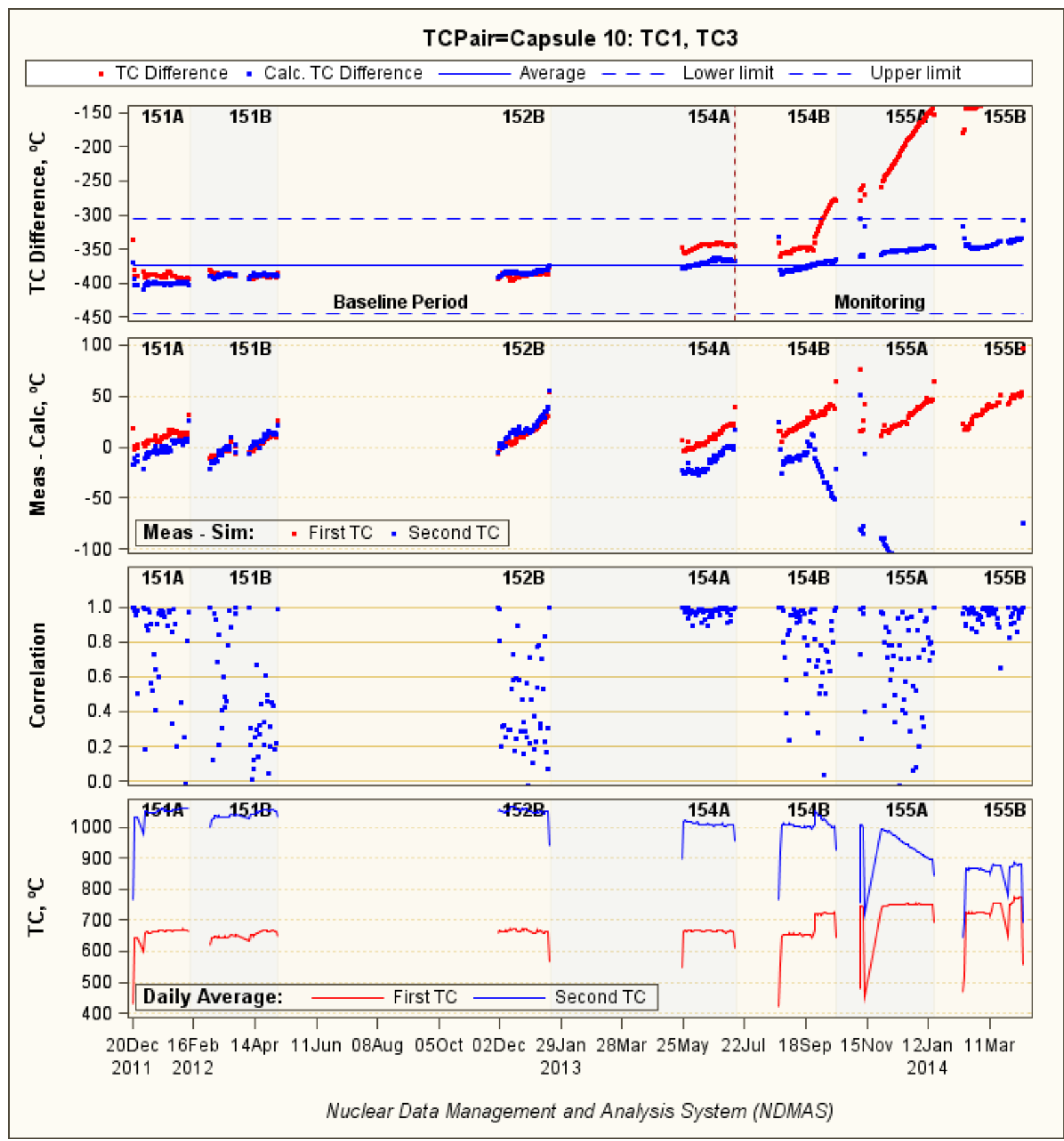

Figure 31. Drift monitoring for TC1 and TC3 in Capsule 10. 


\subsubsection{Capsule 9: TC1 and TC2 did not drift}

Control charts of temperature differences between TC1 and TC2 in Capsule 9 in Figure 32 indicate that these two TCs were not drifting, but their readings were not stable relative to each other. Readings of TC1 and TC2 seemed to be mirroring each other, but they are generally still maintaining similar time-averaged values. One possible explanation for this behavior is the fact that TC1 in Capsule 9 was found to have reversed polarity in the potting cup during the heat up test. At that time, the leads to TC1 were switched back at the connector at the top of the test. This resulted in a temperature offset for TC1 based on the temperature difference between the potting location, which is well above the core region and therefore runs at the reactor water inlet temperature $\left(50^{\circ} \mathrm{C}\right)$, and the connector location, which is right above the reactor vessel head and runs at about $30^{\circ} \mathrm{C},(\mathrm{Q} 15807901-$ "Engineering Work Instructions for Assembling the AGR-3/4 Experiment"). Therefore, TC1 temperature values are offset from the actual $\mathrm{TC} 1$ temperatures by approximately $20^{\circ} \mathrm{C}$. This temperature offset has a $5^{\circ} \mathrm{C}$ or $10^{\circ} \mathrm{C}$ variability due to variability in the temperature above the reactor top head.

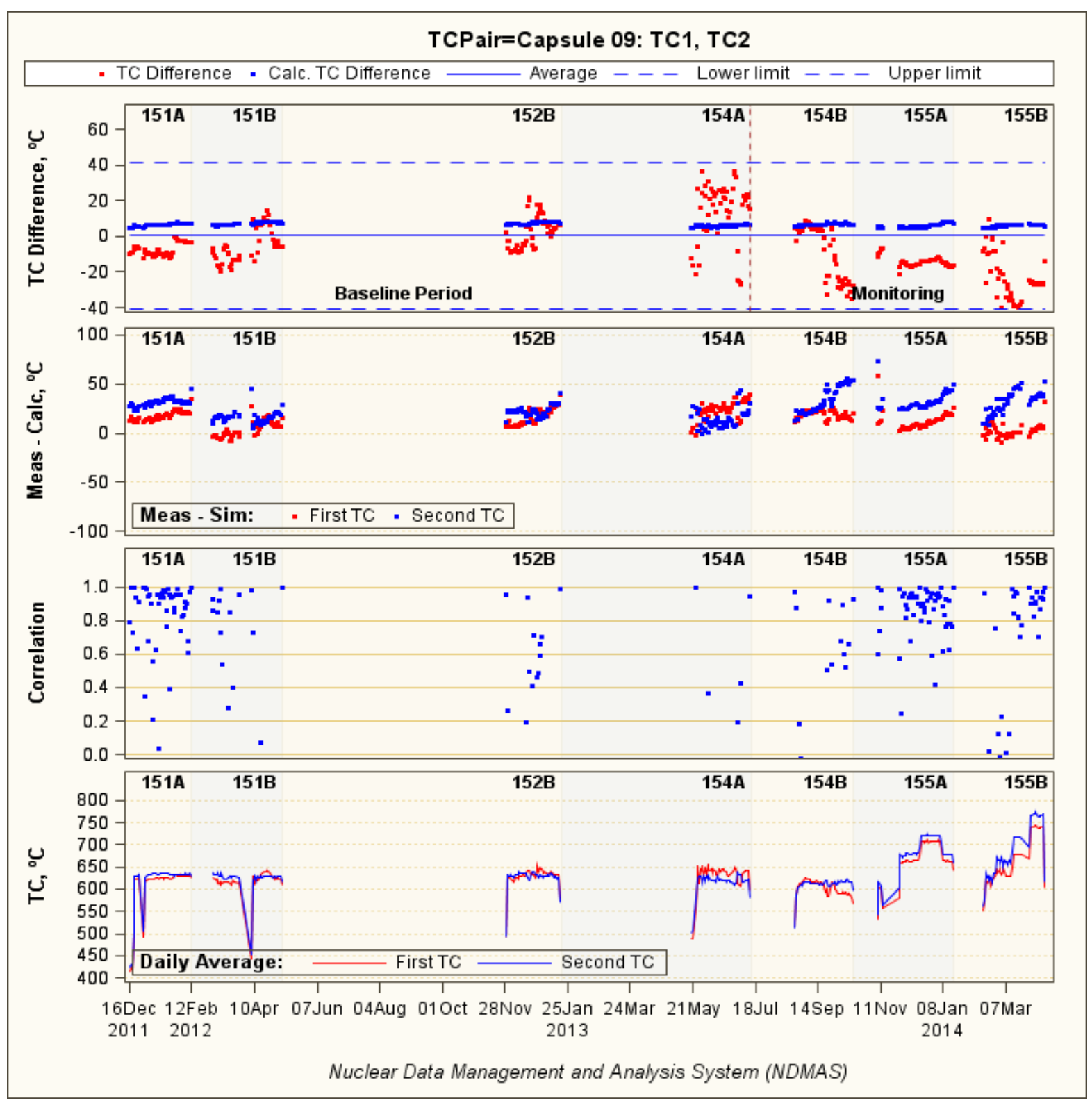

Figure 32. Drift monitoring for TC1 and TC2 in Capsule 9. 


\subsubsection{Capsule 8: TC1 and TC2 are stable}

Control charts of temperature differences between TC1 and TC2 in Capsule 8 (Figure 33) indicate that these two TCs were stable relative to each other. According to calculated TCs, one TC in this pair is biased relative to the other by the same amount during all cycles. This known bias does not affect fuel temperature control in Capsule 8, because it can be accounted for by adjusting the TC set point.

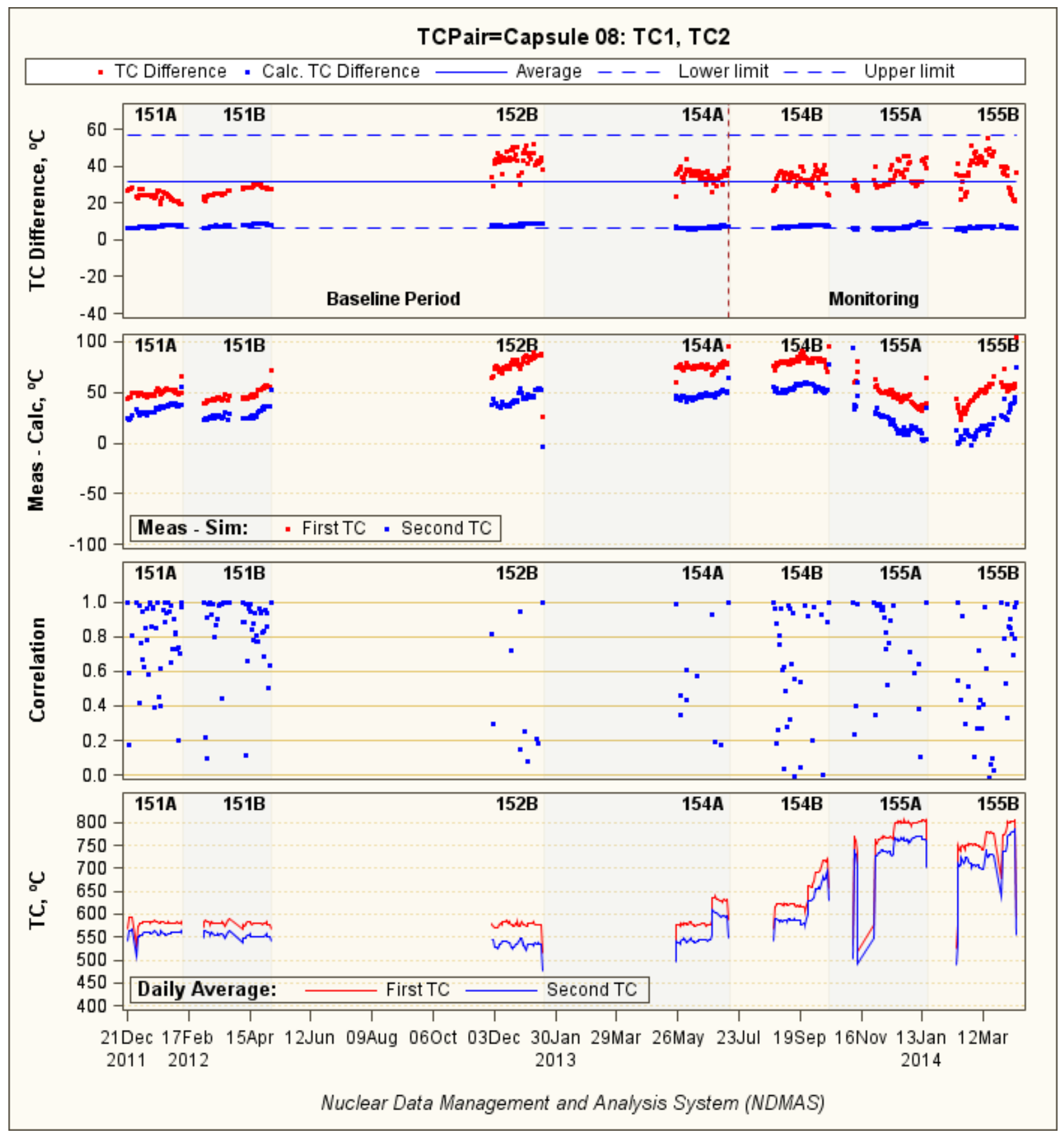

Figure 33. Drift monitoring for TC1 and TC2 in Capsule 8. 


\subsubsection{Capsule 7: TC1 and TC2 are fairly stable}

Control charts of temperature differences between TC1 and TC2 in Capsule 7 (Figure 34) indicate that although these two TCs were not drifting overall, they were not exactly stable relative to each other. A drift of $20^{\circ} \mathrm{C}$ occurred during ATR Cycle 154A, but reversed during Cycle 154B. Their correlation coefficients were low during ATR Cycles 154A and 154B.

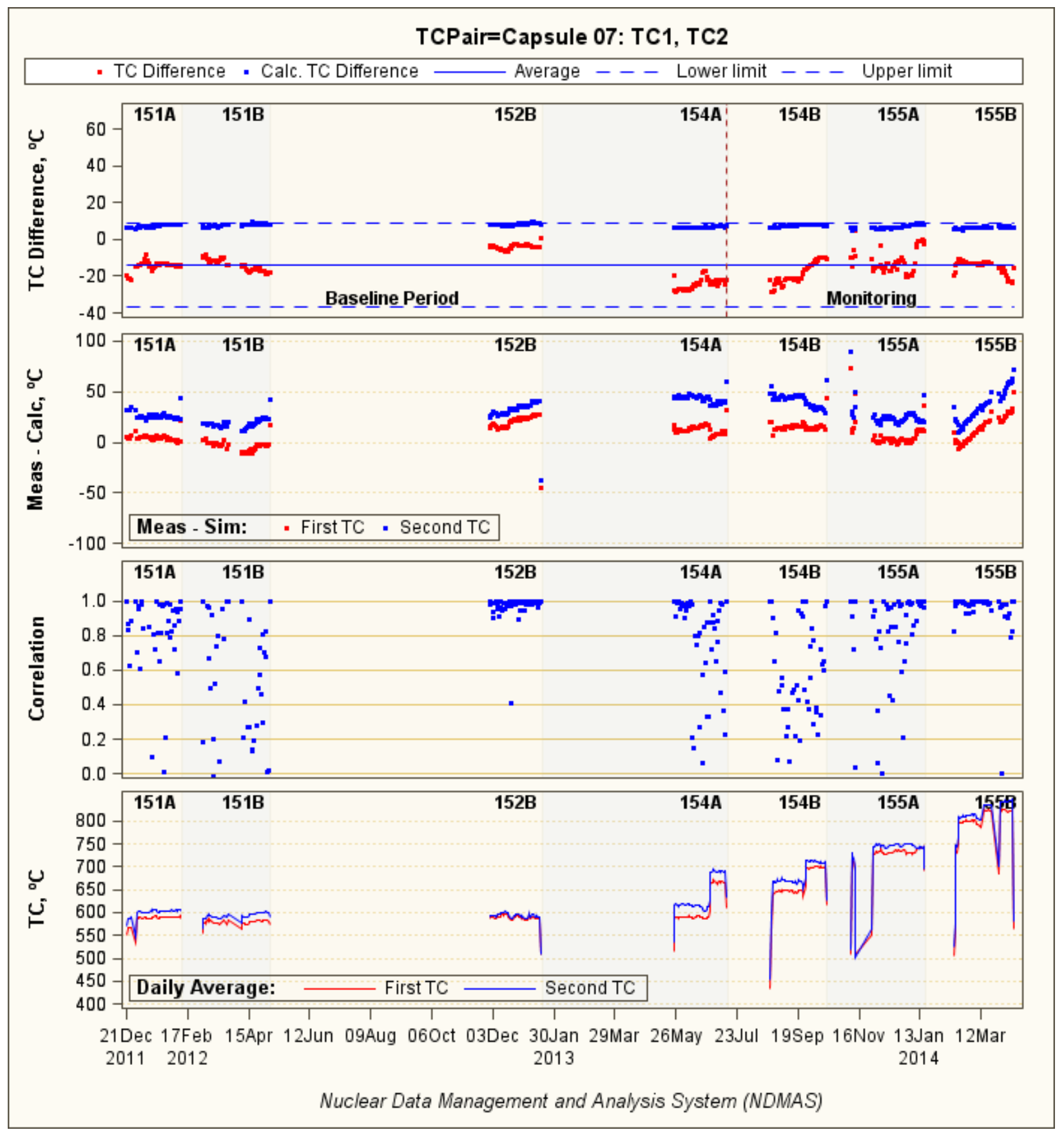

Figure 34. Drift monitoring for TC1 and TC2 in Capsule 7. 


\subsubsection{Capsule 6: TC1 and TC2 are fairly stable}

Control charts of temperature differences between TC1 and TC2 in Capsule 6 (Figure 35) indicate that these two TCs were not drifting prior to the failure of TC1 at the end of ATR Cycle 155A, but they were also not perfectly stable relative to each other. Their readings were also fairly consistent with thermal model predictions, with TC residuals (Frame 2) less than $50^{\circ} \mathrm{C}$.

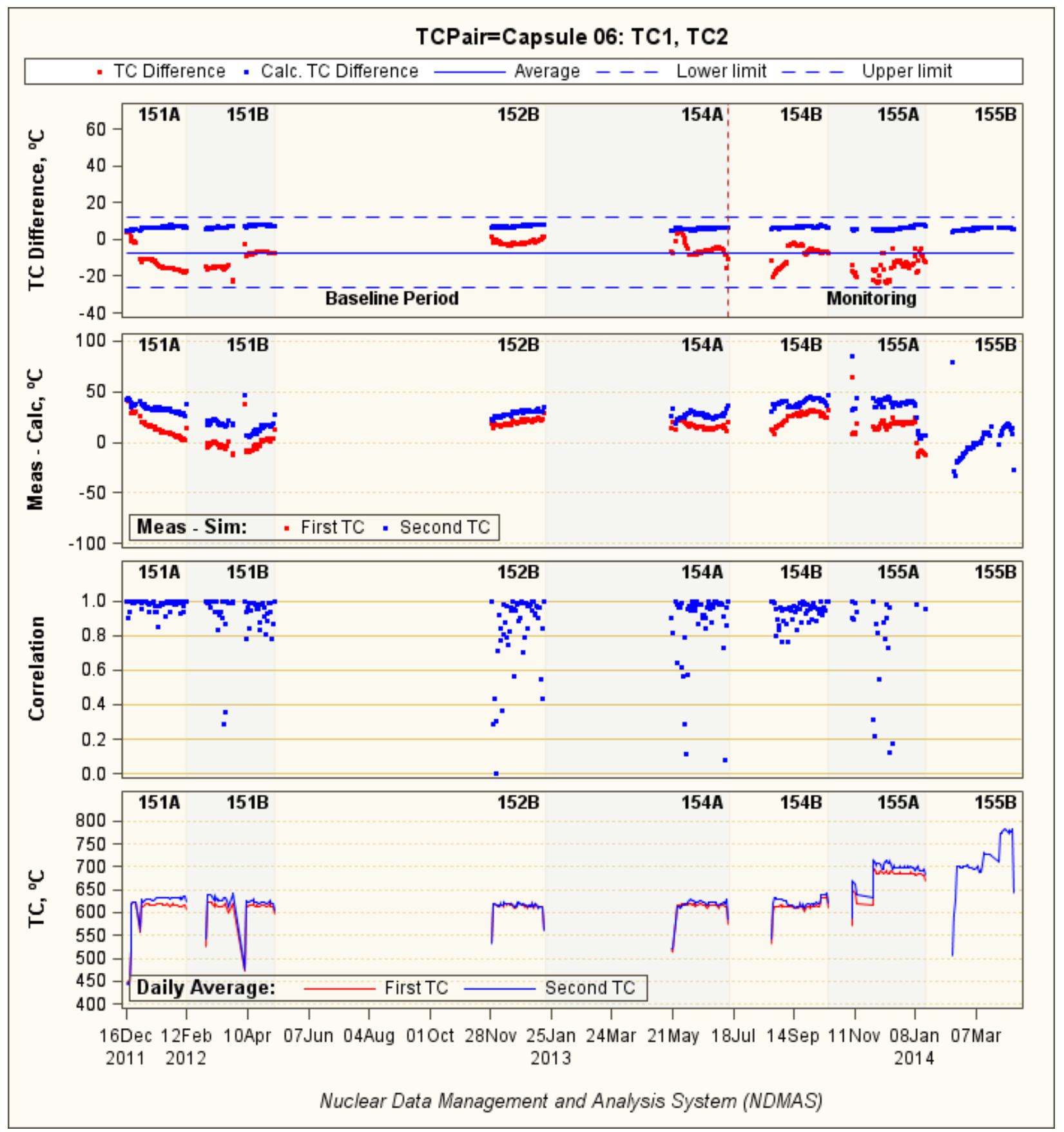

Figure 35. Drift monitoring for TC1 and TC2 in Capsule 6. 


\subsubsection{Capsule 5: TC1, TC2, and TC3 are stable}

Figure 36 shows the control chart results for the TC1/2 pairs in Capsule 5 indicating that TC1 and TC2 are stable relative to each other until TC1 failed near the end of ATR Cycle 155A. The TC differences are within the control bounds and similar to calculated results (both TC residuals are flat over time) and correlation coefficients for both TC pairs are high.

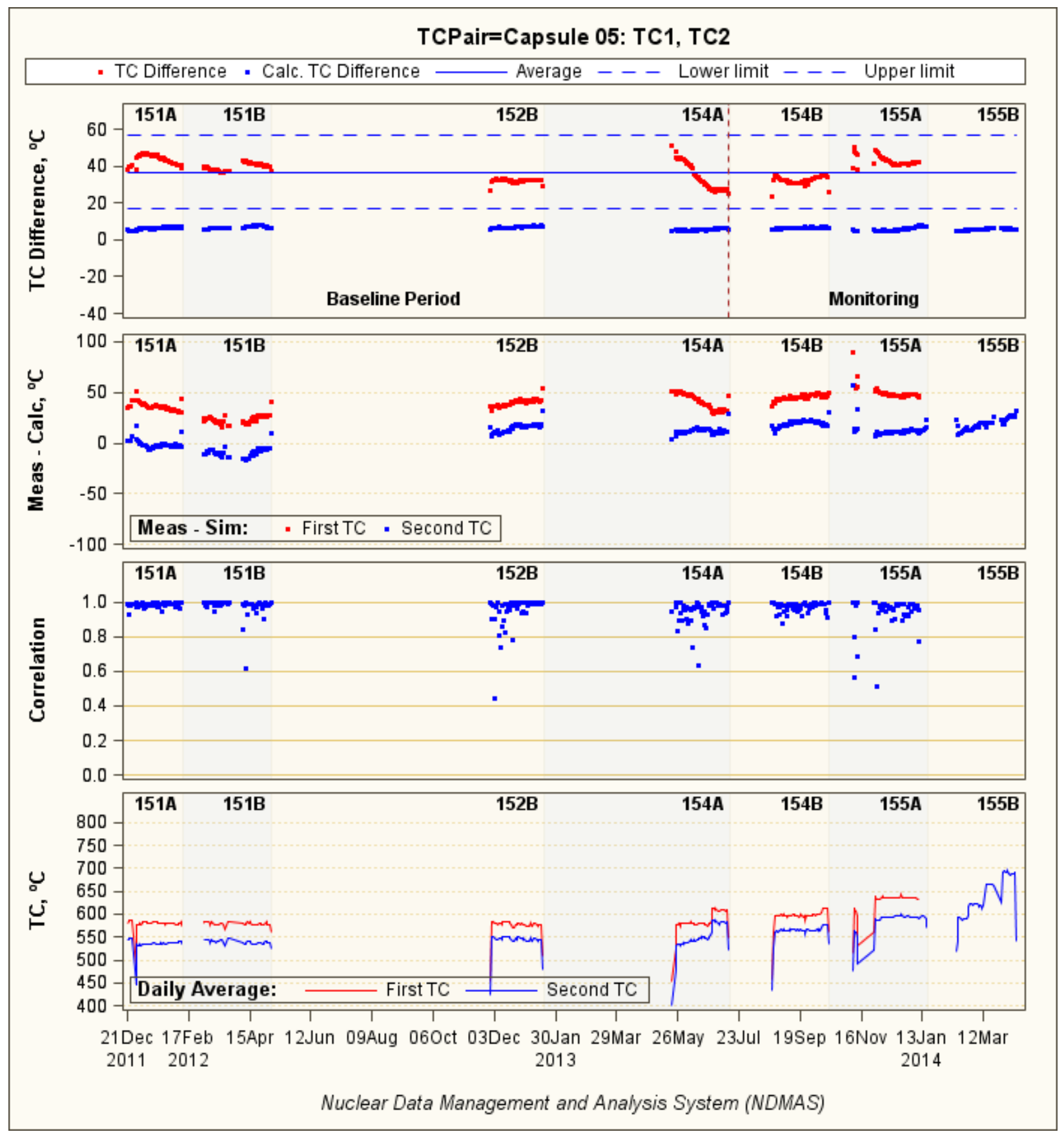

Figure 36. Drift monitoring for TC1 and TC2 in Capsule 5. 
Figure 37 shows the control chart results for the TC1/3 pair in Capsule 5 indicating that TC1 and TC3 are consistent with each other (red dots in Frame 1). The TC3 residuals (blue dots in Frame 2) begin increasing during ATR Cycle 154B, resulting in a residual value higher than $100^{\circ} \mathrm{C}$ (outside the plotting upper limit) by the end of Cycle 155B. Note that because TC3 is in the matrix ring nearer to the center, while TC1 and TC2 are in the graphite ring, the calculated differences between TC1 and TC3 (blue dots in Frame 1) are increasing, primarily due to changes in the gap between the two rings. However, the measured TC differences do not exhibit the same behavior. Correlation coefficients between TC1 and TC3 are high, indicating they are consistent with each other. These results suggest that the calculated TC3 increased faster over time than the measured TC3, indicating the modelled gap between matrix and sink cylinders was decreasing faster than in reality.

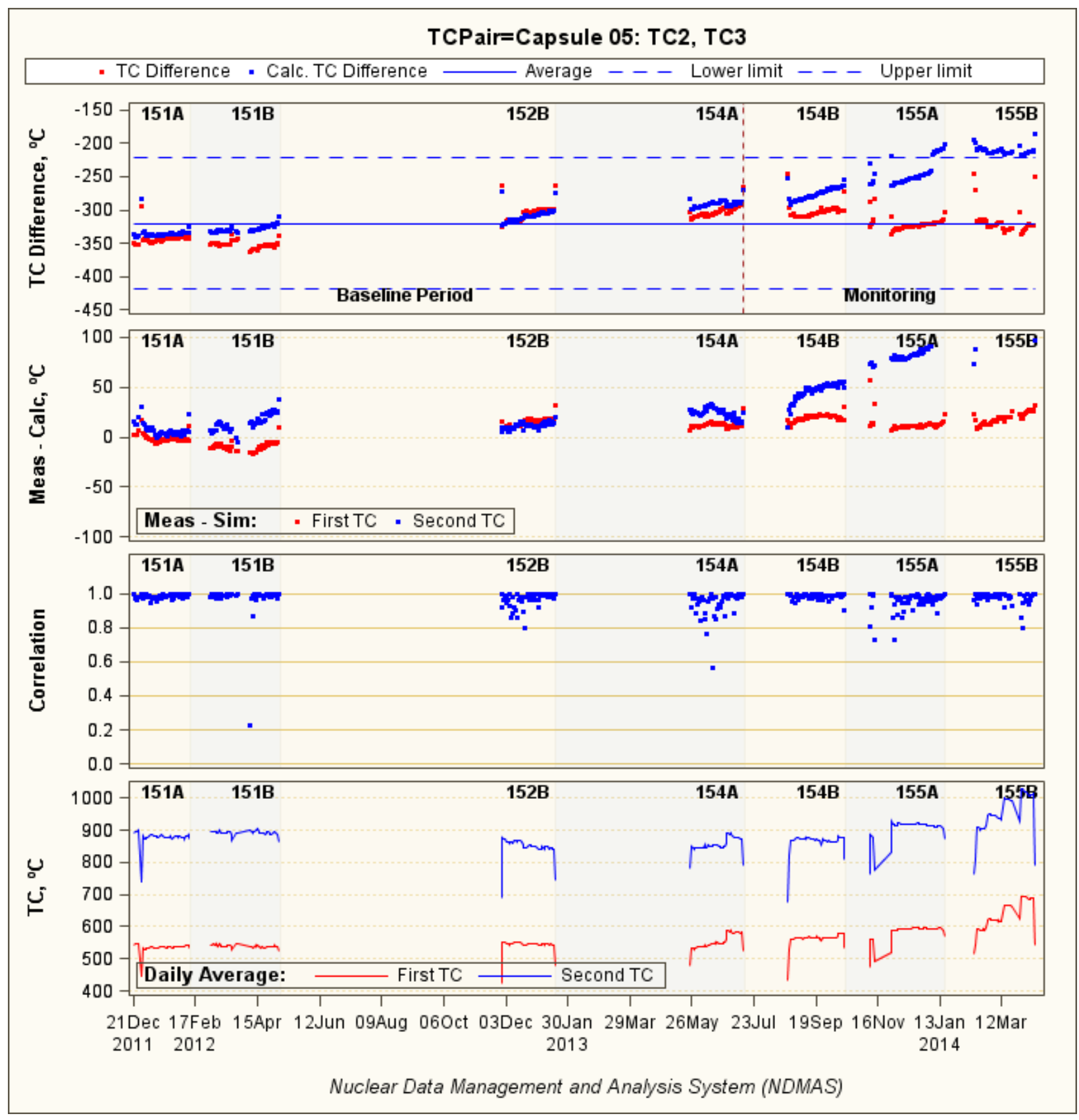

Figure 37. Drift monitoring for TC1 and TC3 in Capsule 5. 


\subsubsection{Capsule 4: TC1 and TC2 did not drift}

Control charts of temperature differences between TC1 and TC2 in Capsule 4 (Figure 38) indicate that these two TCs were not drifting, but their readings were not exactly stable relative to each other. Their readings behaved similarly to the TC pair in Capsule 9 (Figure 32), especially during the second half of irradiation.

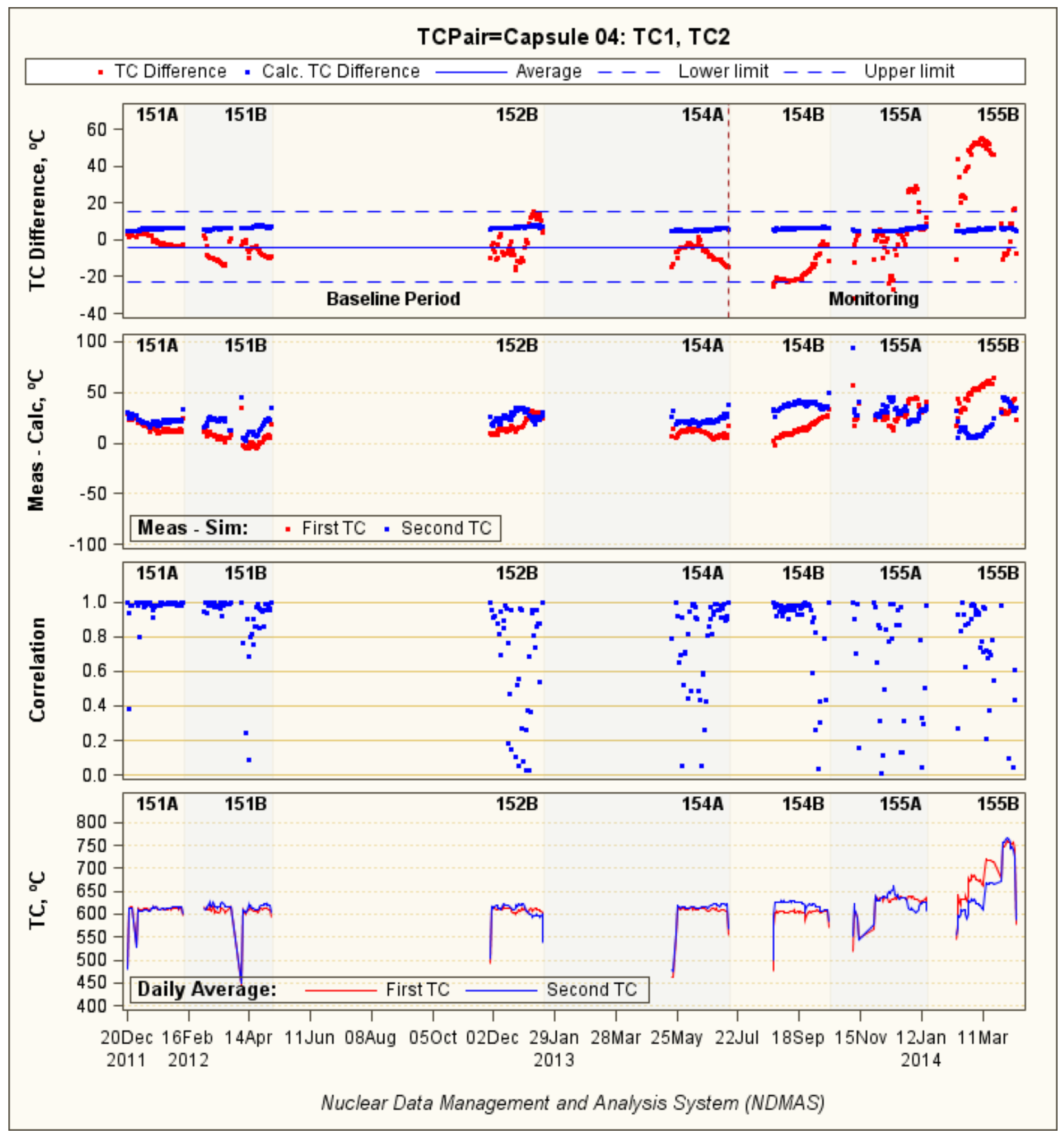

Figure 38. Drift monitoring for TC1 and TC2 in Capsule 4. 


\subsubsection{Capsule 3: TC1 and TC2 are stable}

Control charts of temperature differences between TC1 and TC2 in Capsule 3 (Figure 39) indicate that these two TCs were stable relative to each other until TC2 failure after ATR Cycle 152B. TC1 readings are also consistent with thermal model predictions prior to its failure.

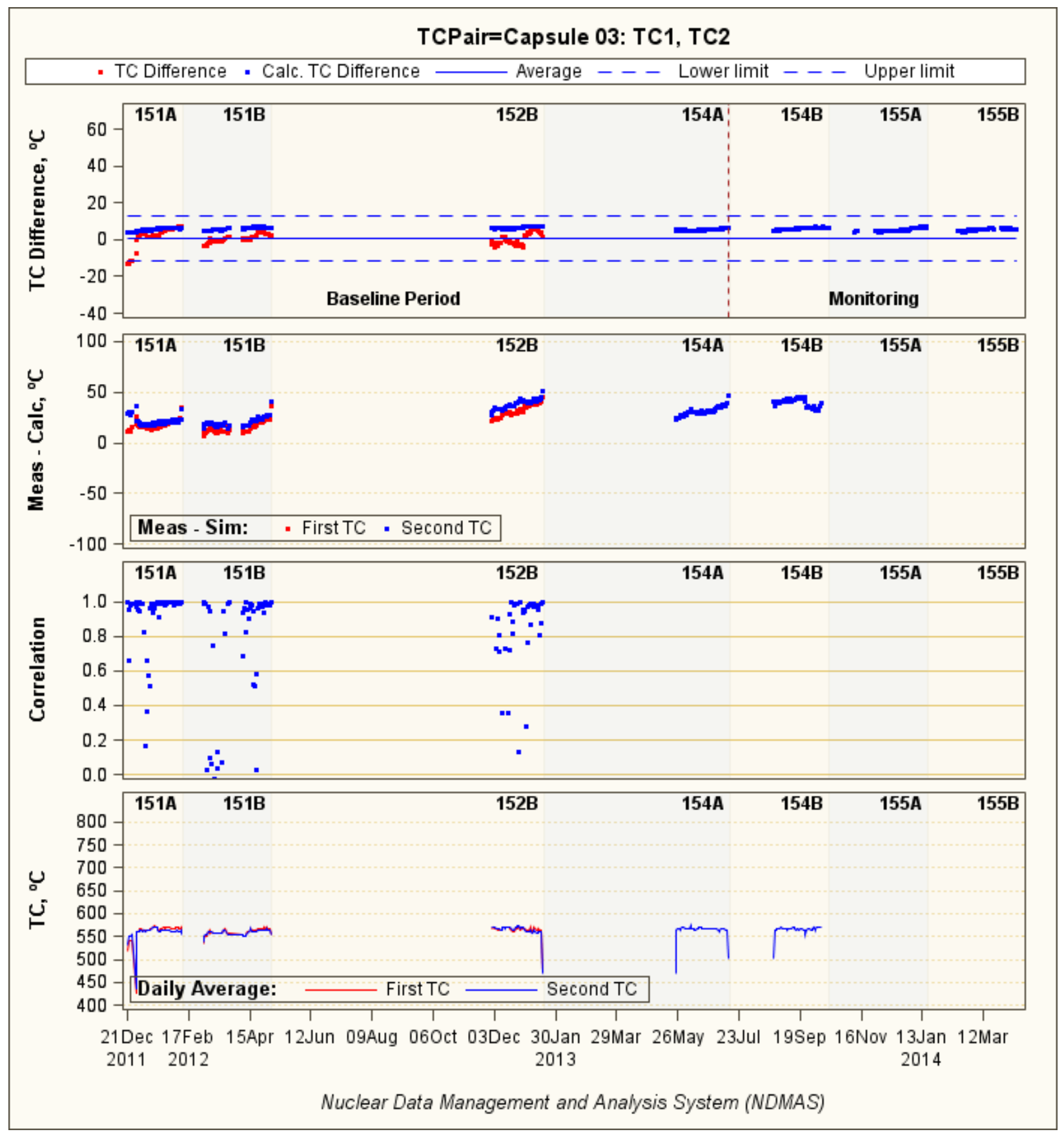

Figure 39. Drift monitoring for TC1 and TC2 in Capsule 3. 


\subsubsection{Capsule 2: TC1 and TC2 are stable}

Control charts of temperature differences between TC1 and TC2 in Capsule 2 (Figure 40) indicate that these two TCs were stable relative to each other until TC2 failed after ATR Cycle 152B. However, TC1 residuals are increasing over the whole irradiation indicating either TC1 drifted or the Capsule 2 thermal model did not correctly account for the gas gap changes over time.

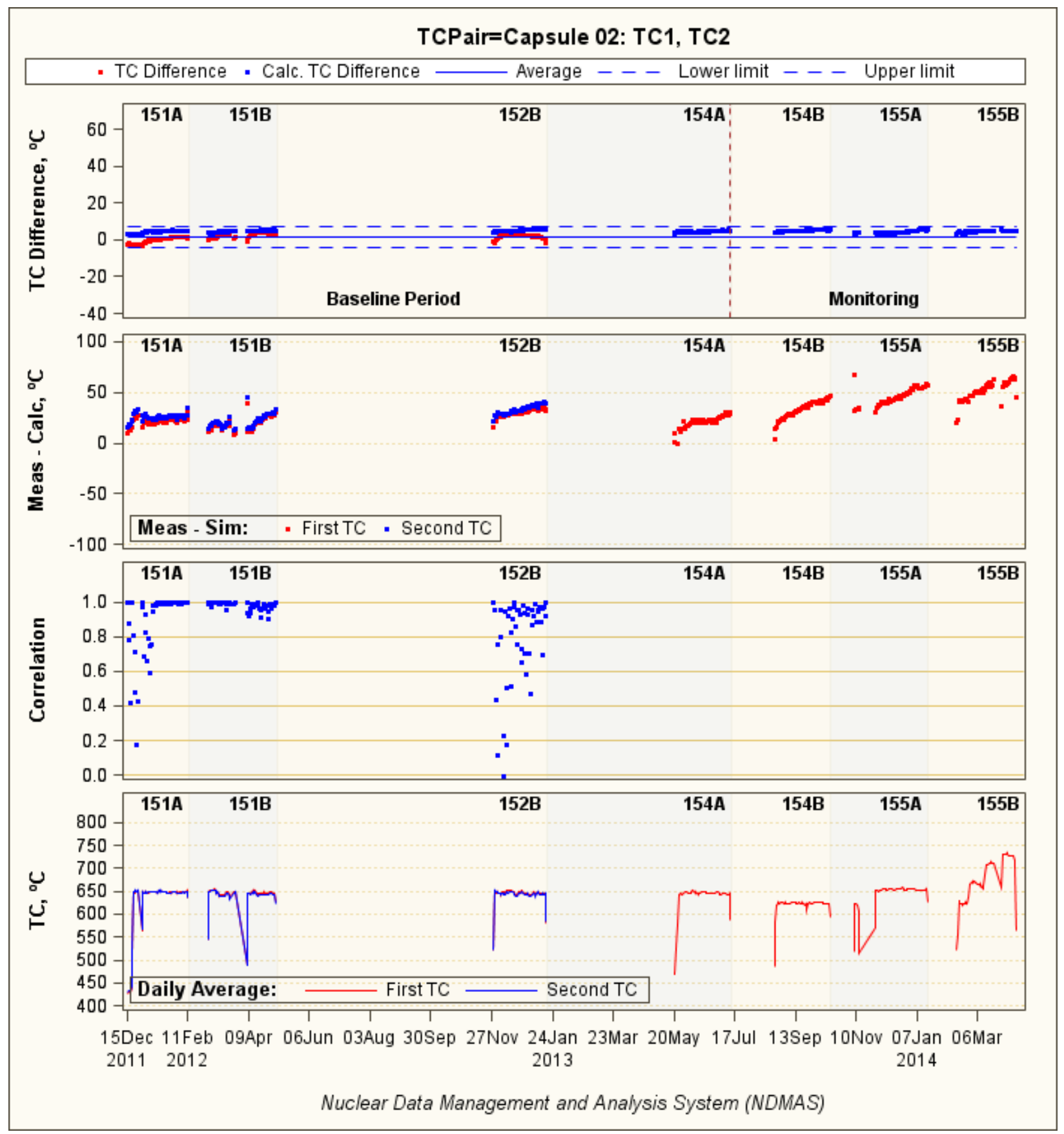

Figure 40. Drift monitoring for TC1 and TC2 in Capsule 2. 


\subsubsection{Capsule 1: TC1 and TC2 did not drift}

Control charts of temperature differences between TC1 and TC2 in Capsule 1 (Figure 41) indicate that these two TCs had not drifted, but they were also not perfectly stable relative to each other. The TC differences were within the control limits, but they began trending upward by approximately $20^{\circ} \mathrm{C}$ during ATR Cycles 154A and 154B. Their TC residuals in Panel 2 and the actual TC measurements in Panel 4 also indicate a possible small drift of at least one TC during these two cycles, but they came close to each other again during the last two cycles. Finally, their correlation coefficients are low the entire time.

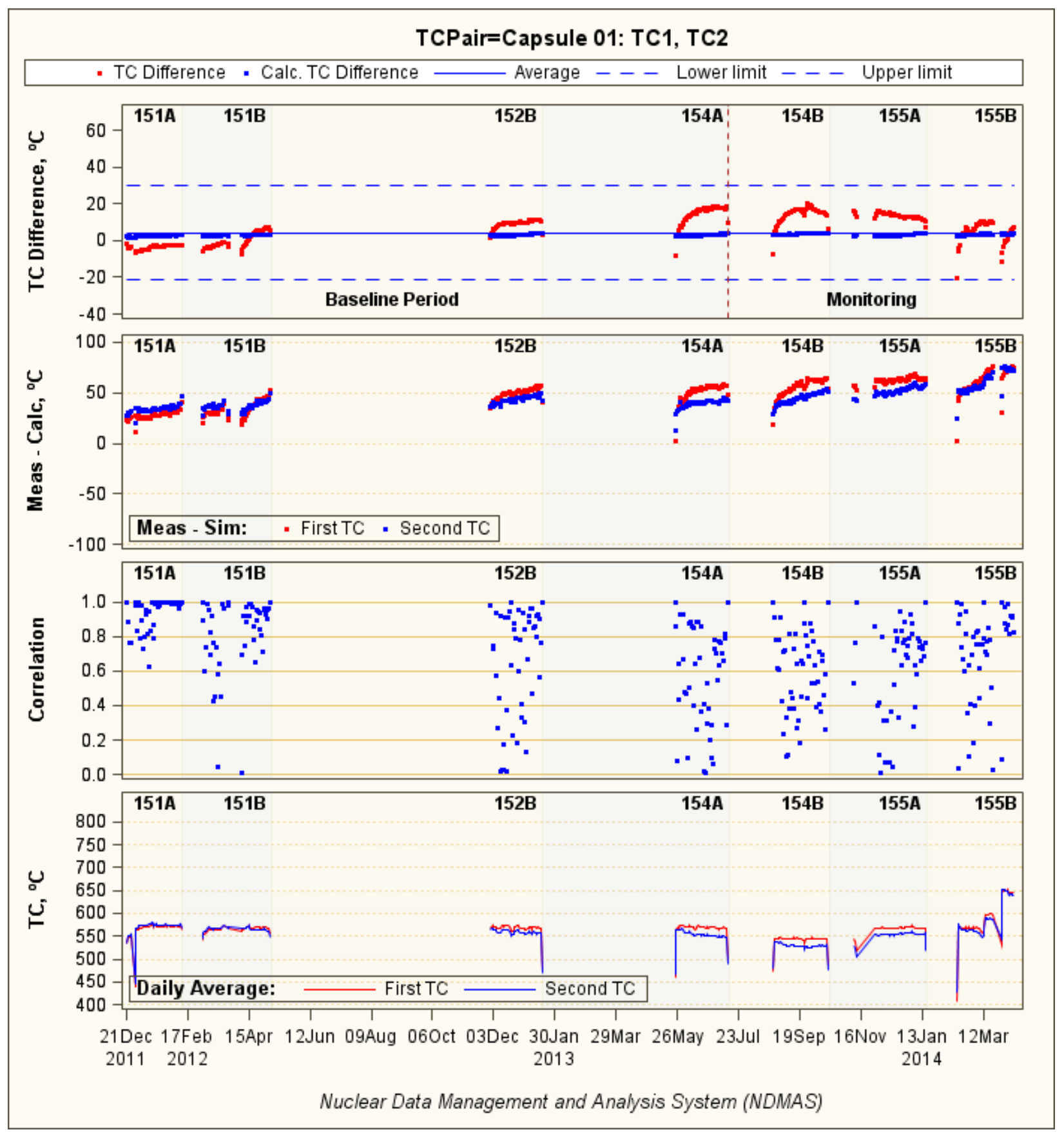

Figure 41. Drift monitoring for TC1 and TC2 in Capsule 1. 


\subsubsection{TC Virtual Junctions}

NDMAS developed a simple correlation test to help identify virtual junction failures in TCs. A virtual junction occurs when a TC starts to measure temperatures at a different location than at its installed terminal location (e.g., in a higher elevation capsule traversed by the TC wire).

When functioning properly, TC readings for a given capsule should be most highly correlated with other TCs in the same capsule. If a virtual junction occurs, the highest correlation will switch to a TC reading in a different capsule (where the junction occurs). To do this test for a given capsule, there must be at least two functioning TCs located in that capsule, and comparisons can only be made with other capsules that have functioning TCs. Figure 42 shows an example of the correlation coefficients for the TCs in Capsule 12. This plot shows that, for the majority of the time, all these TCs are most highly correlated with another TC in Capsule 12, indicating no virtual junctions.

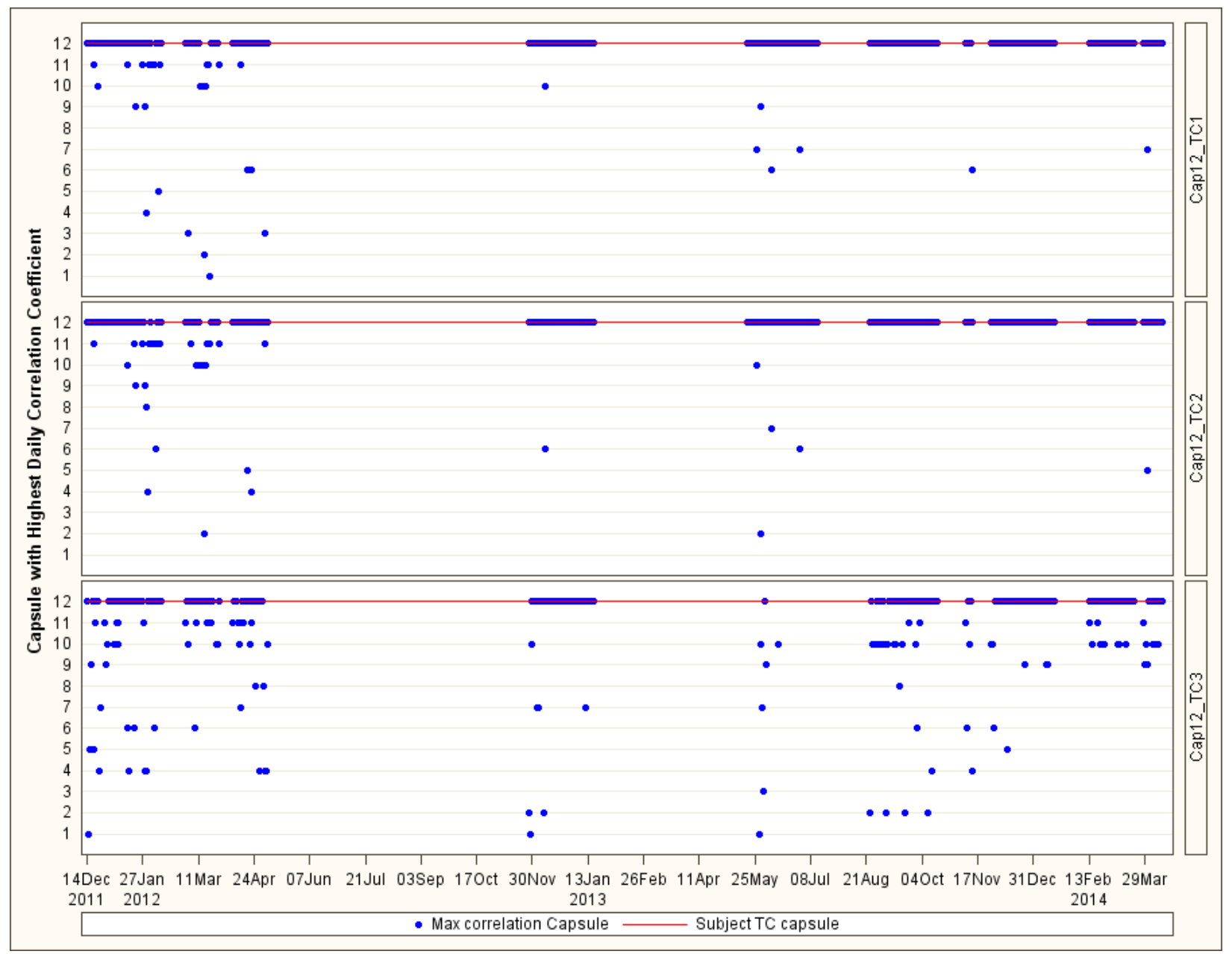

Figure 42. Example of a correlation plot for the TC1, TC2, and TC3 installed in Capsule 12. 
Figure 43 shows the correlation coefficients for the TCs in Capsule 9. In this case, the most highly correlated capsules were randomly scattered over time. Again there is no indication of virtual junctions, because, while TC readings in Capsule 9 were not highly correlated with each other, they are also not consistently correlated with any particular capsule. TCs in all remaining capsules have these same patterns, indicating no TC virtual junction failures for AGR-3/4.

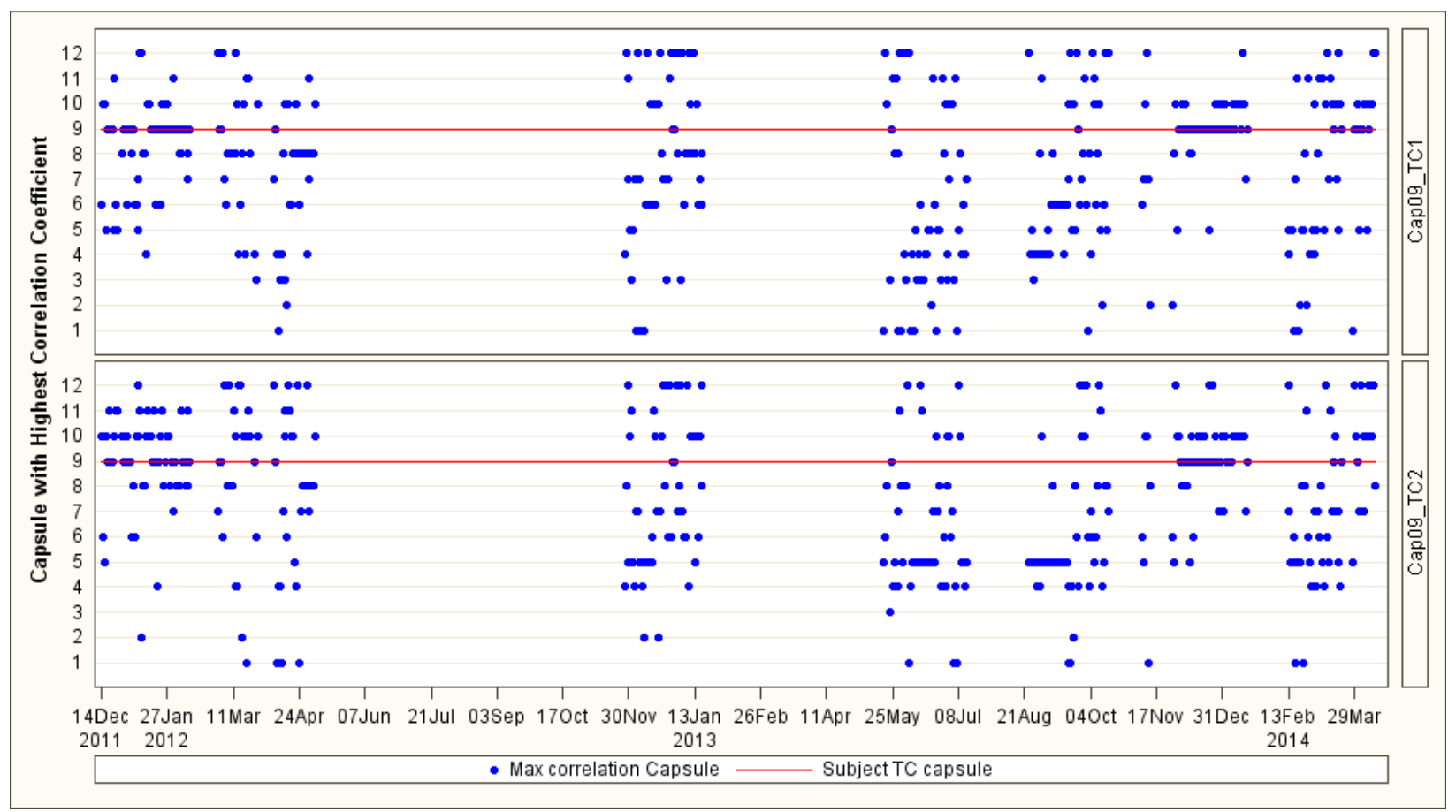

Figure 43. Example of a correlation plot for the TC1 and TC2 installed in Capsule 9.

\subsection{Testing for Data Anomalies of Gas Flow Rate Data}

This section discusses data anomalies among gas flow rates resulting from the range tests and DRC data qualification decisions, along with their impacts to program objectives. A total of 30,703,924 flow data records captured in the NDMAS database during AGR-3/4 irradiation are discussed here. The two failure modes of gas flow rate measurements are out-of-range and missing, which are identified by range testing within the NDMAS data capture process. The identified Failed flow rate records are carefully analyzed to make sure that they do not affect the calculation of the capsule gas composition (e.g., neon fraction) needed in the thermal calculations for AGR-3/4 capsules. Efforts were also made to correct the Failed flow rates such as missing flow rates occurred when ATR is at full power (Figure 44), especially when they do affect the neon fraction calculation. Details of the data analysis, testing results, and data corrections are presented in the following subsections.

\subsubsection{NDMAS Range Testing for Capsule Gas Flow Rates}

In this subsection, capsule neon, helium, impurity, and outlet sweep gas flow data testing results are discussed. The gas flow rates recorded by the additional flow meters installed downstream from the FPMS detectors are discussed separately in Subsection 3.3.2. Table 11 shows that during this reporting period there were 1,293,583 gas flow records (or $4.2 \%$ of the total) that failed the capture and range test out of a total of 30,703,924 gas flow records in twelve AGR-3/4 capsules and the leadout. Note that the total failed data does not include 1,674,344 slightly negative gas flow rates during ATR cycles between $151 \mathrm{~A}$ and 154B because they are replaced with zero sccm and flagged as Qualified records as reported in the previous document EXT-14-31186. 
Table 11. Number of capsule gas flow rates failed the range tests (exclude FPM flow).

\begin{tabular}{lllllll}
\hline ATR Cycle & Total \# Records & Negative & Too High & Missing & Total \# Failed & \%Failed \\
\hline 151A & 779,020 & 0 & 0 & 0 & 0 & $0.0 \%$ \\
151B & $1,544,708$ & 0 & 2 & 20,588 & 20,590 & $1.3 \%$ \\
152A & $4,099,260$ & 0 & 274 & $1,057,295$ & $1,057,569$ & $25.8 \%$ \\
152B & $3,462,990$ & 0 & 0 & 214,516 & 214,516 & $6.2 \%$ \\
154A & $4,018,006$ & 0 & 0 & 894 & 894 & $0.0 \%$ \\
154B & $4,988,272$ & 0 & 0 & 0 & 0 & $0.0 \%$ \\
155A & $5,845,620$ & 0 & 13 & 0 & 13 & $0.0 \%$ \\
155B & $5,966,048$ & 0 & 1 & 0 & 1 & $0.0 \%$ \\
\hline Total $=$ & $\mathbf{3 0 , 7 0 3 , 9 2 4}$ & $\mathbf{0}$ & $\mathbf{2 9 0}$ & $\mathbf{1 , 2 9 3 , 2 9 3}$ & $\mathbf{1 , 2 9 3 , 5 8 3}$ & $\mathbf{4 . 2 \%}$
\end{tabular}

\subsubsection{Out-of-Range Flow Rates}

Because the gas flow rates range from 0 to $102 \mathrm{sccm}$, the negative flow rates and flow rates exceeding $102 \mathrm{sccm}$ are assigned a Failed data status as a result of the NDMAS capture range testing. According to Table 11, there are no negative flow rates, and only 290 high flow rates out of a total of 30,703,924 capsule gas flow data records.

Negative Gas Flow Rates: Originally, there were 1,674,344 slightly negative gas flow rate records ranging between -0.000183 and $-1.139953 \mathrm{sccm}$. These values were recorded when the actual flow rates were near zero. They can be considered as valid measurements because they are still within the measurement uncertainty range. According to the DRC decision during their meeting on February 12, 2014 (Pham 2014), 800,420 slightly negative gas flow rates were replaced with $0 \mathrm{sccm}$ and flagged as Qualified records. There are 873,924 additional negative flow rates that occurred from ATR Cycle 155B data and some fill-in irradiation data for ATR Cycles 151A, 151B, and 152B. These additional negative flow rates will be replaced with $0 \mathrm{sccm}$ and flagged as Qualified records as well. Consequently, there is no negative flow failure listed in Table 11.

DRC recommendation: Qualify 1,603,453 negative sweep gas flow data received during the last two cycles (ATR Cycles 155A and 155B) and replace them with $0 \mathrm{sccm}$.

Excessive Gas Flow Rates: There were 290 gas flow rates (274 of these occurred during low power Cycle 152A) which are higher than the upper limit of $102 \mathrm{sccm}$ for AGR-3/4 flow meters. These excessive flow rates occurred for the period of testing of the gas flow system during cycle outages. However, because these flow rates are higher than the upper limit of the flow meters, they are not reliable, and therefore, they should be flagged as Failed.

DRC recommendation: Fail 290 high sweep gas flow rate records.

\subsubsection{Missing Flow Rates}

Data are classified as missing only if there is no record present for an existing time stamp in the raw data files provided by the data generators. There are 1,293,293 missing flow rates out of a total of $30,703,924$ flow data records, representing $99.98 \%$ of all the failed capsule flow data. Table 11 breaks down the number of missing data into cycles showing that most of the missing data are during the ATR low power cycle 152A, followed by ATR Cycle 152B. The majority of the missing values occurred during the ATR outage periods, when the impact of bad flow data is not critical to the test objectives. However, there are missing neon flow rate records in Capsules 7 and 8 for the period November 27, 2013 12:00 to November 29, 2013 22:35, immediately after power-up for Cycle 152B, as shown by the pink 
lines in Panels 5 and 6 in Figure 44. These missing neon flow rates prevent capsule neon fraction calculation, which are crucial inputs to the thermal models used for fuel temperature prediction. Figure 44 also shows that during that time helium flows in all capsules (including Capsules 7 and 8) were consistently near $30 \mathrm{sccm}$, indicating pure helium flow. Therefore, the missing neon gas flow data for Capsules 7 and 8 can be filled in with $0 \mathrm{sccm}$ or the difference between the helium flow rate and $30 \mathrm{sccm}$, whichever is larger.

DRC recommendation: (1) Fill in missing neon flow records in Capsules 7 and 8 for the periods November 27, 2013 12:00 to November 29, 2013 22:35 (152B) with whatever is higher, 0 sccm or the difference between $30 \mathrm{sccm}$ and the helium flow rate, and (2) Fail all other missing records.

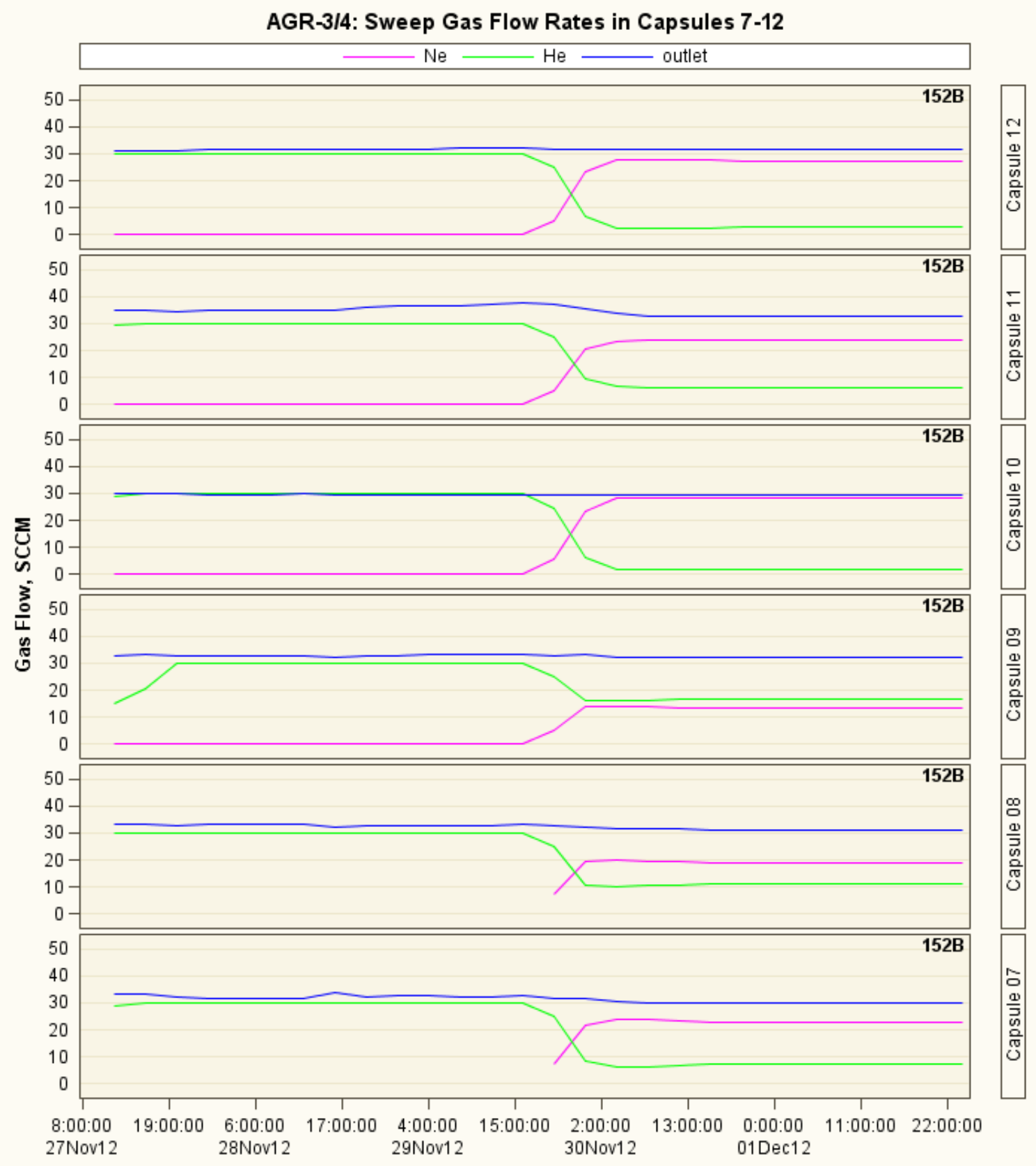

Figure 44. Gas flow rates for Capsules 7-12 during the period November 27, 2013 12:00 to November 29, 2013, 22:35. 


\subsubsection{Testing for Downstream Gas Flow Rates}

The outlet lines transport mixed gas together with any fission products released from the capsules to the FPMS, which is capable of measuring fission product release activities and detecting individual fuel particle failures. A relief valve was installed before each detector to maintain the required gas pressure in each capsule. If this valve lifts, then the mixed gas will leak out before reaching the detector, preventing it from correctly counting the isotope activities of fission products released from the capsule. In order to detect and prevent valve lifting in a timely manner, fourteen additional gas flow meters were installed during the outage phase of ATR Cycle 155A at the outlets of the fourteen FPMS detectors to measure downstream gas flow rates from these detectors. FPMS gas flow meters 7 and 14 are connected to the spare detectors, which are used in the event of a detector failure. The first record of downstream flow data received by NDMAS was on October 29, 2013. When the relief valves are closed, the downstream gas flow rates (labelled "FPM") should ideally be equal to the outlet flow rates measured at the capsule outlets, allowing all mixed gas from the capsules to flow to their corresponding FPMS detectors. This feature will be used to assess the quality of the downstream data. Figure 45 and Figure 46 show hourly averaged flow rates of downstream (purple line) and outlet (blue line) flows for the twelve AGR-3/4 capsules from the time when the downstream data were first captured in the NDMAS database. A summary of FPM gas flow rates during AGR-3/4 irradiation is presented in Table 12. Note that there are no missing values among the FPM flow rates.

The following data trends of downstream gas flow rates are observed from the plots in Figure 45 and Figure 46 and the data summary in Table 12:

1. Consistent flow rates: For all twelve capsules, downstream flow rates and outlet flow rates are consistent relative to each other during ATR Cycle 155A and for only a few weeks of ATR Cycle 155B (when the purple lines are close to the corresponding blue lines).

\section{Out-of-range flow rates:}

- Too high flow rates: there are no excessively high flow rates recorded for the downstream gas flows. The highest recorded flow rate was $62.86 \mathrm{sccm}$ (Column 4 in Table 12), which is significantly lower than the gas flow rate upper limit of $102 \mathrm{sccm}$.

- Negative flow rates: From the beginning of ATR Cycle 155B, the downstream flow rates are negative for Capsules 7 and 8. For the remaining capsules, the downstream flow rates were also negative for most of ATR Cycle 155B, with the exception of a few weeks in February 2014. Column 5 in Table 12 presents number of negative FPM flow rates recorded for ATR Cycle 155A and $155 \mathrm{~B}$. Slightly negative flow rates were recorded by the spare detectors during ATR Cycle 155A (bottom panels of Figure 45 and Figure 46); all downstream flow meters recorded negative flow rates during ATR Cycle 155B. These negative downstream flow rates during ATR Cycle 155B indicate instrumentation failure, because during that time outlet flow rates are still at normal rates (around $15 \mathrm{sccm}$ during outage or $30 \mathrm{sccm}$ during full power) as seen in Figure 45 and Figure 46.

Table 12. Summary of FPM gas flow rates during AGR-3/4 irradiation.

\begin{tabular}{ccccc}
\hline & No. of Records & $\begin{array}{c}\text { Minimum Value } \\
(\mathrm{sccm})\end{array}$ & $\begin{array}{c}\text { Maximum Value } \\
(\mathrm{sccm})\end{array}$ & $\begin{array}{c}\text { No. of Negative } \\
\text { FPM Flow Rates }\end{array}$ \\
\hline 155A & $1,607,844$ & -0.242 & 62.86 & 2,070 \\
$155 \mathrm{~B}$ & $1,898,288$ & -61.322 & 41.75 & $1,456,003$ \\
\cline { 2 - 5 } Total $=$ & $\mathbf{3 , 5 0 6 , 1 3 2}$ & & & $\mathbf{1 , 4 5 8 , 0 7 3}$
\end{tabular}


DRC recommendations: (1) All non-negative FPM flow rate records during ATR Cycles 155A and 155B are Qualified data, and (2) All 1,458,073 negative FPM flow rate records during Cycles 155A and 155B are Failed data.

\section{AGR-3/4: FPM and Outlet Gas Flow Rates in Capsules 7-12}

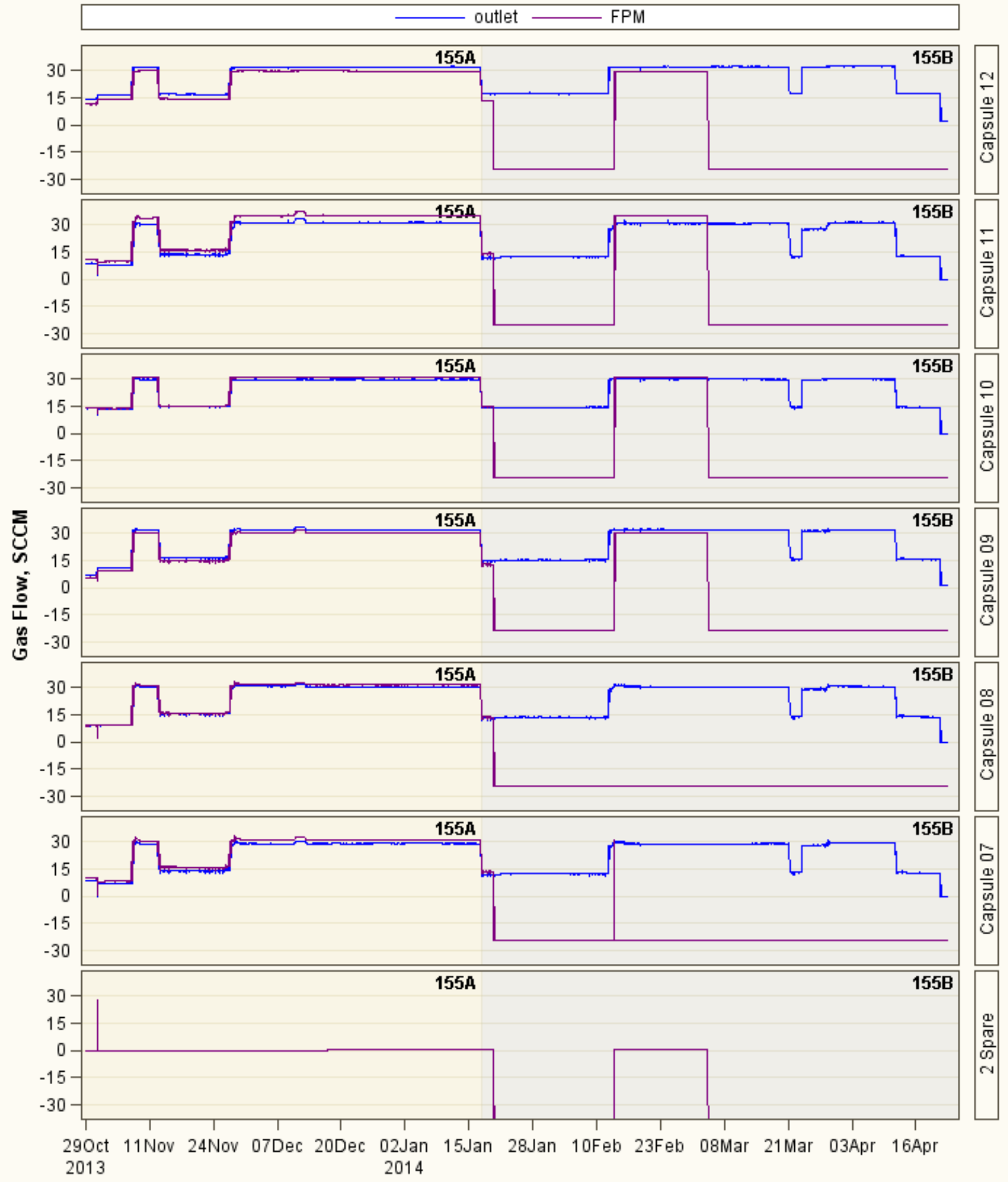

Figure 45. Downstream and outlet gas flow rates for capsules 7-12. 


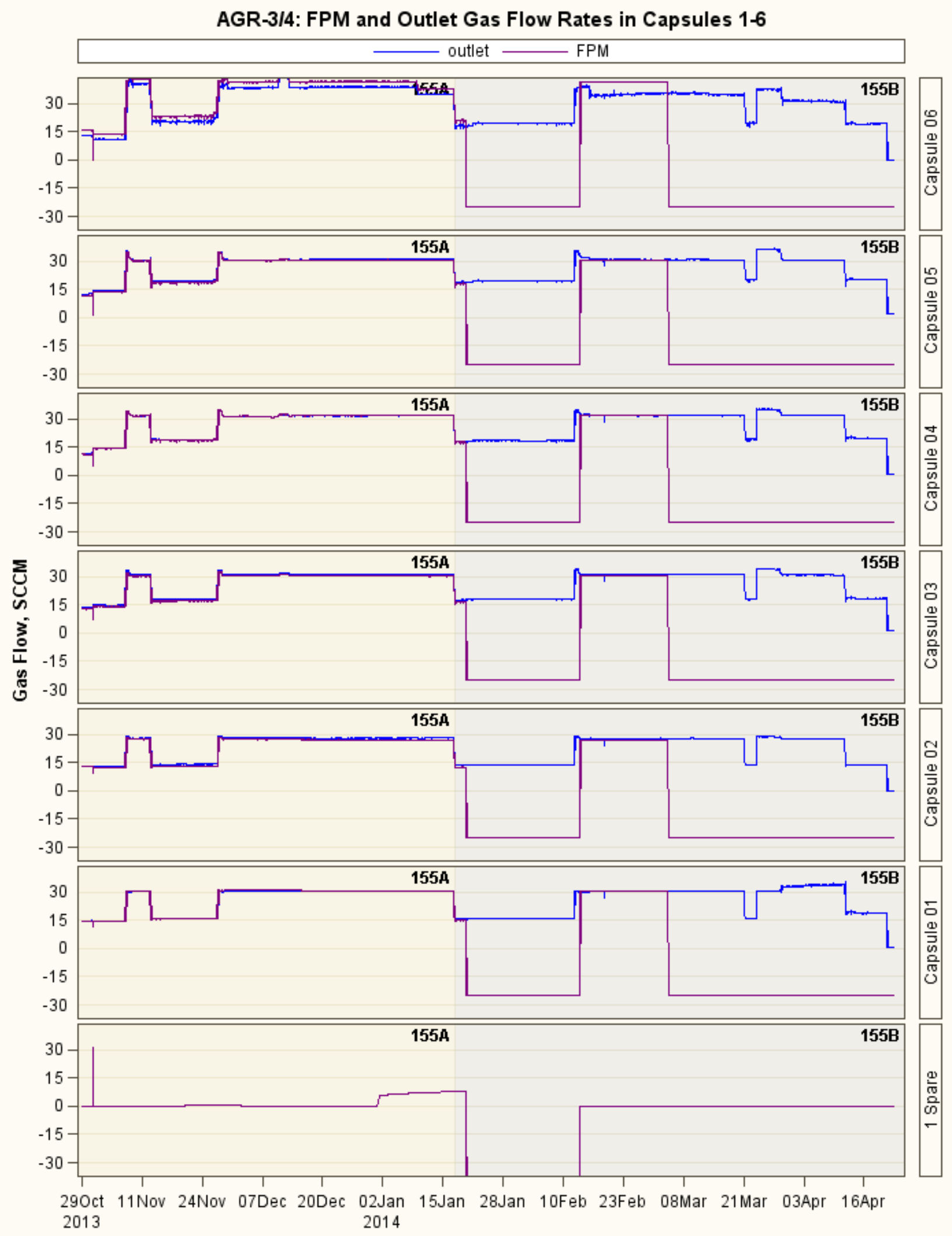

Figure 46. Downstream and outlet gas flow rates for capsules 1-6. 


\subsubsection{Sweep Gas Flow Data Analysis for Neon Fraction Calculation}

As designed, the variation of neon fraction in the sweep gas mixture is used to maintain target fuel temperatures. The accuracy of the calculated neon fraction is critical for the capsule thermal model to correctly predict test fuel temperature. This section examines the actual neon/helium gas flow rates passing through each capsule, taking into account the portion from the leadout flow and measurement bias of the outlet flow meter. For each AGR-3/4 capsule, the inlet flow consists of neon, helium, and impure gas (for Capsules 7 - 12) administered by individual mass flow controllers. When ATR is at full power, the Irradiation Test Vehicle controller delivers a mixture of neon and helium at a total flow rate of 30 $\mathrm{sccm}$; an additional controller delivers $0.5 \mathrm{sccm}$ of impure gas whenever needed to the selected capsule (currently to Capsule 11). In addition to the inlet flows, an unknown portion of the flow in the leadout might also pass through a capsule. The total flow at the capsule outlet is measured by a flow meter. The gas flow rate in the leadout is usually maintained at the same level in each cycle $(12 \mathrm{sccm}$ of pure helium for cycles $151 \mathrm{~A}$ to $154 \mathrm{~B}$ and $24 \mathrm{sccm}$ of a mix of neon and helium for cycles $155 \mathrm{~A}$ and $155 \mathrm{~B}$ ). Ideally, the total outlet flow in one capsule exactly equals the sum of all inlet flows Eq. (1) as in Eq. (2):

$Q_{\text {inlet }}=Q_{N e}+Q_{H e}+Q_{\text {contam }}$

$Q_{\text {outlet }}=Q_{\text {inlet }}+Q_{\text {lo }_{\text {portion }}}=Q_{N e}+Q_{H e}+Q_{\text {contam }}+Q_{\text {lo } \text { portion }}$

where Q represents the gas flow rates in sccm: outlet, inlet, neon, helium, impure, and portion of leadout gas flows. Thus, the unknown portion of the leadout flow passing through capsule can be expressed as:

$Q_{\text {lo }_{\text {portion }}}=Q_{\text {outlet }}-Q_{\text {inlet }}=Q_{\text {outlet }}-\left(Q_{N e}+Q_{H e}+Q_{\text {contam }}\right)$

However, Figure 47 shows that the total outlet flows (blue line) are consistently lower than the sum of inlet flows from the twelve capsules and the leadout (red line) indicating some measurement biases of the outlet flows because the total inlet flows are stable at $30 \mathrm{sccm}$ for all twelve capsules. The possible existence of outlet flow measurement bias prevents exact determination of that portion of leadout gas flows passing through each capsule using Eq. (3), which is needed in the capsule neon fraction calculation. Thus a series of two tests were performed to experimentally determine the amounts of the leadout flow passing through each capsule and the bias of outlet flow measurement.

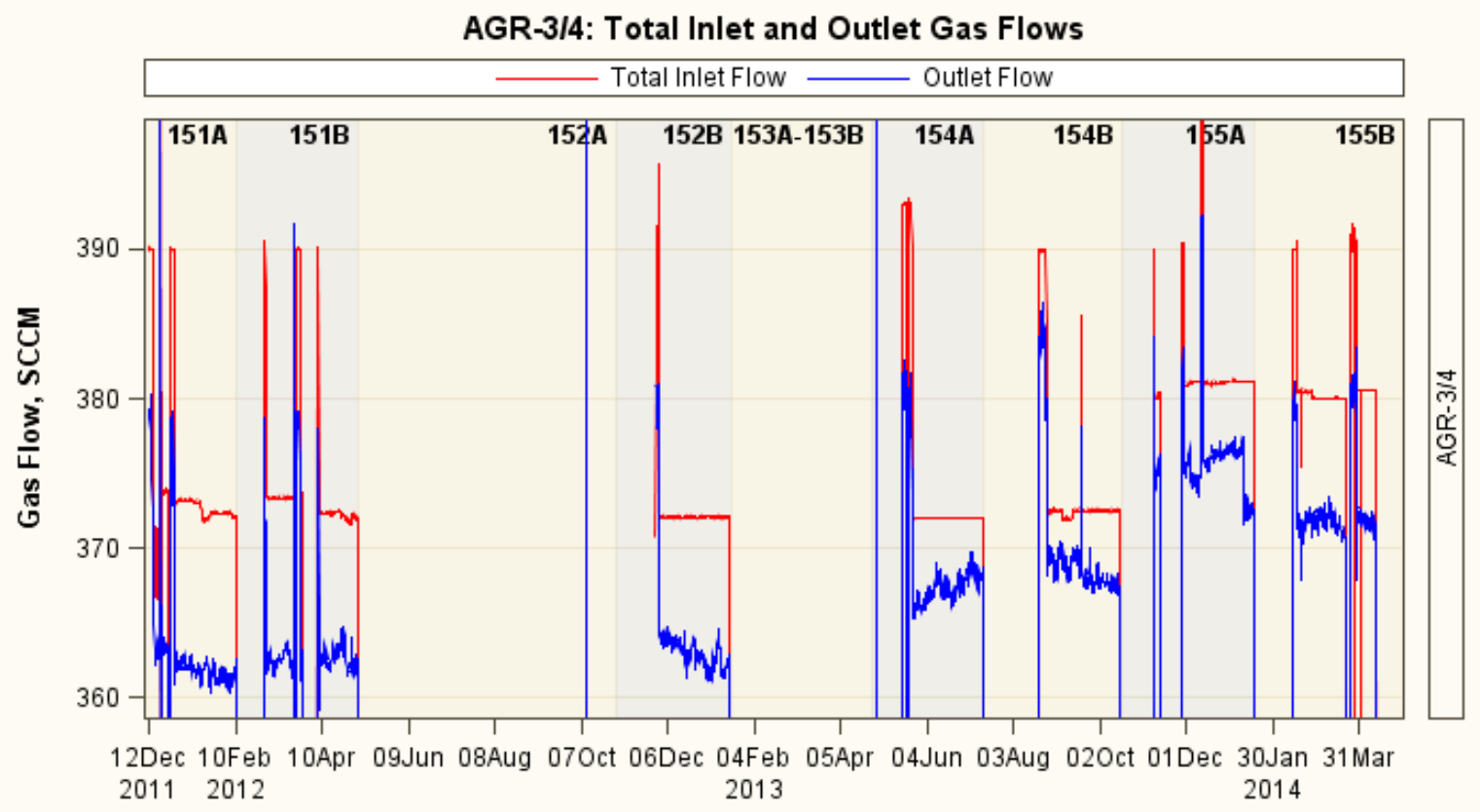

Figure 47. Total inlet and outlet gas flows of the whole AGR-3/4 test train. 


\subsubsection{Leadout flow tests}

Two leadout flow tests were performed in September and December 2013 to determine the amount of leadout flow passing through each of the 12 capsules. During these tests, the flow rate in the leadout was increased to double its normal rate while maintaining the same levels of inlet flows in all capsules. In the first test in September, the leadout flow was increased from 12 to $24 \mathrm{sccm}$ for 24 hours, and in the second test in December the leadout flow was increased from 20 to $40 \mathrm{sccm}$ for 48 hours. As a result, the outlet flows in 8 out of 12 capsules increased as shown in Figure 48.

\section{Amounts of the leadout flow passing through AGR-3/4 capsules.}

Table 13 shows the estimated amount of the leadout flow passing through each capsule equal to the increase in outlet flow when the leadout flow increased from $20 \mathrm{sccm}$ to $40 \mathrm{sccm}$ (Eq. 3).

\section{Outlet flow measurement bias}

After the amount of the leadout flow portion is experimentally determined, the biases of the outlet flows relative to their inlet flows can be calculated as the difference between inlet flow (including the leadout portion) and outlet flow. The outlet measurement bias relative to inlet is calculated as:

$B_{\text {outlet }}=Q_{\text {outlet }}-\left(Q_{\text {inlet }}+Q_{\text {lo }_{\text {portion }}}\right)$

Only three capsules $(2,7$, and 12) had significant outlet measurement bias ( $\sim 2 \mathrm{sccm})$.

Table 13. Summary of the leadout flow portions and the outlet flow measurement biases for all capsules.

\begin{tabular}{l|cccccccccccc}
\hline Capsule & 1 & 2 & 3 & 4 & 5 & 6 & 7 & 8 & 9 & 10 & 11 & 12 \\
\hline $\begin{array}{l}\text { Portion of leadout } \\
\text { flow (sccm) }\end{array}$ & 0 & 0 & 0.5 & 0.5 & 0.5 & 8.5 & 1 & 0.5 & 1.5 & 0 & 1.5 & 0 \\
\hline $\begin{array}{l}\text { Outlet bias relative } \\
\text { to inlet (sccm) }\end{array}$ & 0 & -2 & 0 & $\sim 0$ & 0 & 0 & -2 & 0 & $\sim 0$ & 0 & 0 & +2
\end{tabular}

\subsubsection{Neon fractions for AGR-3/4 capsules including portion of leadout flow}

According to Table 13, the twelve AGR-3/4 capsules can be divided into three categories: (1) capsules with added flow from the leadout and significant outlet measurement bias, which only includes Capsule 7 (purple column); (2) capsules with added flow from the leadout but negligible outlet measurement bias, which are Capsules 3, 4, 5, 6, 8, 9, and 11 (black columns); and (3) tight capsules, which do not have added flow from the leadout which are Capsule 1, 2, 10, and 12 (red columns). The neon fraction $\left(F r_{N e}\right)$ formula for each category is expressed as:

- For Category 1, capsule with added flow from the leadout and outlet measurement bias:

$$
F r_{N e}=\frac{Q_{N e}+\left(Q_{\text {outlet }}-B_{\text {outlet }}-Q_{\text {inlet }}\right) * \frac{Q_{\text {Neleadout }}}{Q_{\text {Ne }}+\text { He leadout }}}{Q_{\text {outlet }}-B_{\text {outlet }}}
$$

- For Category 2, capsules with added flow from leadout but negligible outlet measurement bias

$$
\left(B_{\text {outlet }}=0\right) \text { : }
$$

$$
F r_{N e}=\frac{Q_{N e}+\left(Q_{\text {outlet }}-Q_{\text {inlet }}\right) * \frac{Q_{\text {Ne leadout }}}{Q_{\text {Ne+He leadout }}}}{Q_{\text {outlet }}}
$$

- For Category 3, tight capsules $\left(Q_{l_{\text {portion }}}=0\right)$, neon fraction is equal to inlet neon fraction:

$$
F r_{N e}=\frac{Q_{N e}}{Q_{\text {inlet }}}
$$




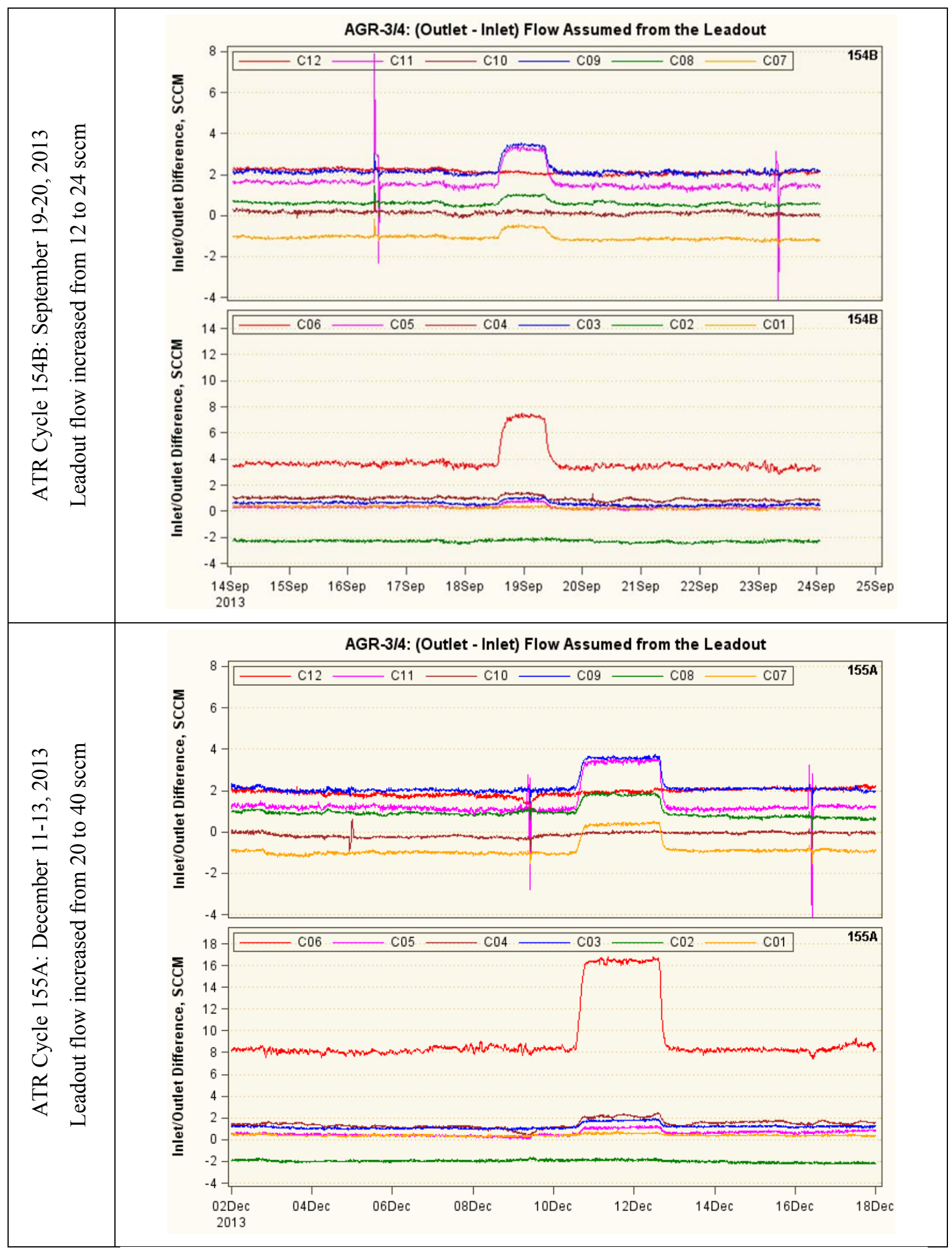

Figure 48. Differences between outlet and inlet flows increased in response to the leadout flow increase. 


\section{DATA RECORD QUALIFICATION SUMMARY}

This section summarizes the data qualification decisions made by the DRC for the AGR-3/4 irradiation data received by NDMAS from December 12, 2012 (start of ATR Cycle 151A) through April 22, 2014 (10 days after the end of ATR Cycle 155B). Detailed information on the data and the technical basis for data record qualification can be found in Sections 2 and 3.

\subsection{Irradiation Monitoring Data}

From the beginning of ATR Cycle 152A, the new automatic data transfer from the CDCS provides NDMAS with 1-minute instantaneous irradiation monitoring data every 2 hours instead of the weekly 5-minute averaged data provided during earlier cycles (ATR Cycles 151A and 151B). The new data delivery method provides NDMAS with significantly more irradiation data and, therefore, required implementation of a more flexible data structure and online database testing. A total of 53,608,130 TC temperature and gas flow rate records for the entire AGR-3/4 irradiation is included in this report.

\subsubsection{Data Qualification Results}

This section presents qualification status of irradiation monitoring data basing on the DRC decisions after reviewing the results of NDMAS database online testing and analysis presented in Sections 2 and 3. Except for a few missing values, there are no Failed gas pressure or moisture measurements because there was no range test or analysis performed for these data. Consequently, qualification results presented in the following subsections are only for TC readings and sweep gas flow measurements.

\subsubsection{TC Readings}

A total of 19,398,074 TC temperatures recorded from 27 TCs installed in twelve capsules were captured in the NDMAS database during the entire AGR-3/4 irradiation. This total does not include irrelevant TC readings received when the experiment was outside of the reactor core during two excluded ATR Cycles (153A and 153B) and 17 days at the start of ATR Cycle 154A. Contrary to AGR-1 and AGR-2 experiments, where most of the TCs had failed by the end of irradiation, only five TCs in AGR-3/4 capsules failed toward the end of irradiation. This is likely because most of the AGR-3/4 TCs are located in the graphite rings, away from experiment fuel compacts, so they are exposed to a lower temperature range $\left(600-800^{\circ} \mathrm{C}\right)$. In addition, only Capsule 3 lost both TCs after ATR Cycle $154 \mathrm{~B}$, so the neon fraction in this capsule was kept at the same level estimated to maintain the projected peak fuel temperature within specified bounds. There was also one TC drift failure (TC3 in Capsule 10) detected using the control charting methodology applied to temperature differences between a TC pair in the same capsule, as described in Subsection 3.2.3.3.

The evidence for TC instrument failures was presented in Section 3.2.1. These five TC failures contributed to 1,480,546 Failed TC readings. Results of the range tests show no TC readings exceeding the upper temperature limit of $1400^{\circ} \mathrm{C}$. There are only 4,275 negative and 16,448 missing $\mathrm{TC}$ readings received during AGR-3/4 irradiation (Table 14). Most of the negative TC readings occurred during the last cycle (ATR Cycle 155B/155B-1). Among them, there are 1,724 negative readings recorded from TC2 in Capsule 10 more than a week after power-down and 2,428 readings recorded from TC1 in Capsule 6 after its failure date. The majority of the missing TC readings occurred during the low-power cycle 152A, when the ATR core was down. The 1,116 missing values from TC3 in Capsule 12 during the power-up phase of ATR Cycle 154A were caused by an error in the data transfer script, which was promptly fixed. 
The DRC members reviewed the results of database range testing and data analysis as described in Section 3.2. As a result, their decisions on qualification statuses for AGR-3/4 TC readings are listed as follows:

1. Fail 16,448 missing and 4,275 negative TC records.

2. Fail all temperatures readings recorded after failure time of five TCs. The established failure times are:
a. TC2 in Capsule 2 starting on 04/26/2013 at 08:45 (Cycles 154A)
b. TC1 in Capsule 3 starting on 05/17/2013 at 03:15 (Cycles 154A)
c. TC2 in Capsule 3 starting on 10/09/2013 at 12:15 (Cycles 154B)
d. TC1 in Capsule 5 starting on 01/11/ 2014 at 08:30 (Cycles 155A)
e. TC1 in Capsule 6 starting on 02/13/2014 at 14:00 (Cycles 155B).

3. Set the qualification state to Trend for 305,742 temperature readings of TC3 in Capsule 10 recorded after September 20, 2013 (middle of ATR Cycle 154B) due to the TC drift failure as described in Subsection 3.2.3.3 (Figure 31).

4. Delete all irrelevant TC readings recorded between January 24, 2013, at 12:41 and April 29, 2013, at 8:50 because the AGR-3/4 experiment was removed from reactor core.

Table 14 summarizes the data qualification statuses of TC temperature records by ATR cycle for the AGR-3/4 experiment. According to this table, the majority of TC temperatures $(90.7 \%$ of the total) are Qualified records. There are 1,498,841 Failed TC temperature records (7.7\% of the total TC readings) mostly due to TC instrument failures. There are 305,742 Trend records (1.6\% of the total TC readings) taken from TC3 in Capsule 10 after September 20, 2013 due to TC drift failure (see Table 9). All irrelevant TC records during ATR Cycles 153A and 153B and at the beginning of ATR Cycle 154A were deleted from the NDMAS database. Therefore, they are not included in Table 14.

Table 14. Summary of TC temperature failures during AGR-3/4 irradiation.

\begin{tabular}{ccccccccc} 
ATR & Total \# of & \multicolumn{7}{c}{ Total \# of } \\
Cycle & Records & Negative & Missing & TC Failures & Failed & \% Failed & \% Qualified** & Note \\
\hline 151A & 478,035 & 0 & 0 & 0 & 0 & $0.0 \%$ & $100.00 \%$ & \\
151B & 946,269 & 95 & 19 & 0 & 114 & $0.0 \%$ & $100.00 \%$ & \\
152A & $2,515,455$ & 5 & 15,252 & 0 & 15,257 & $0.6 \%$ & $99.4 \%$ & \\
152B & $2,288,601$ & 0 & 61 & 0 & 61 & $0.0 \%$ & $100.0 \%$ & \\
154A & $2,780,327$ & 0 & 1,116 & 187,292 & 188,408 & $6.8 \%$ & $93.2 \%$ & a,b \\
154B & $3,157,981$ & 0 & 0 & 246,499 & 246,499 & $7.8 \%$ & $91.0 \%$ & a,b,c \\
155A & $3,570,422$ & 0 & 0 & 407,605 & 407,605 & $11.4 \%$ & $84.9 \%$ & a,b,c,d \\
155B & $3,660,984$ & 4,175 & 0 & 639,150 & $640,897 *$ & $17.5 \%$ & $78.8 \%$ & a,b,c,d,e \\
\cline { 2 - 6 } Total $=$ & $\mathbf{1 9 , 3 9 8 , 0 7 4}$ & $\mathbf{4 , 2 7 5}$ & $\mathbf{1 6 , 4 4 8}$ & $\mathbf{1 , 4 8 0 , 5 4 6}$ & $\mathbf{1 , 4 9 8 , 8 4 1}$ & $\mathbf{7 . 7 \%}$ & $\mathbf{9 0 . 7 \%}$ &
\end{tabular}

a. TC2 in Capsule 2 failed on 04/26/2013 at 08:45 (Cycles 154A)

b. TC1 in Capsule 3 failed on 05/17/2013 at 03:15 (Cycle 154A).

c. TC2 in Capsule 3 failed on 10/09/2013 at 12:15 (Cycle 154B).

d. TC1 in Capsule 5failed on 01/11/2014 at 08:30 (Cycle 155A).

e. TC1 in Capsule 6 failed on 02/13/2014 at 14:00 (Cycle 155B).

* Total number of Failed records for Cycle 155B does not include 2,428 negative readings from TC1 in Capsule 6 because they are already included in the number of Failed records due to this TC failure.

** Qualified percentage does not include 305,742 Trend records received from TC3 in Capsule 10 after September 20, 2013 due to TC drift failure. 


\subsubsection{Sweep Gas Flow Rates}

A total of 34,210,056 gas flow rate records for twelve capsules, the leadout, and fourteen additional flow meters installed downstream from the FPMS detectors were captured in the NDMAS database for the AGR-3/4 irradiation. This total does not include irrelevant flow rate records received when the experiment was outside of the reactor core during ATR Cycles 153A and 153B and 17 days after the start of ATR Cycle 154A. The qualification status of the gas flow rate records is set based on examination of the range test results, which are discussed in detail in Sections 3.3.1 and 3.3.2.

The range test identified 1,674,344 slightly negative flow rates for capsule inlet (neon, helium, and impure) and outlet gas flows, which are in a [-1.1399 to $-0.00018 \mathrm{sccm}]$ range. However, the re-examination of these flow rate records shows that they occurred when the actual flow rates were at/or near zero flow. These negative flow rates are well within flow meter measurement uncertainty. Therefore, they can be qualified and replaced with $0 \mathrm{sccm}$; consequently, they are not included as Failed records in Table 15. In contrast, the range test also identified 1,458,073 negative FPM flow rates, which occurred when the actual flow rates were around $30 \mathrm{sccm}$; therefore, they are clearly Failed records due to flow meter failures. For subsequent AGR experiments, it is recommended that the lower limit for gas flow rates should be changed to $-2.0 \mathrm{sccm}$ instead of the current $0 \mathrm{sccm}$ value, so the slightly negative flow rates recorded at near zero flow could be qualified. The treatment of these qualified negative flow rates (e.g., replace them with $0 \mathrm{sccm}$ ) are up to the end-user judgment.

The range test also identified 290 excessively high gas flow rates and 1,293,293 missing gas flow rates (see Table 15). The high gas flow rates were recorded during testing of the capsule sweep gas system during cycle outages, when the gas flow rates could be much higher than normal. Most of the missing gas flow rates occurred during cycle outages due to equipment maintenance activities, so they have no impact on the experiment objectives. However, some of the missing gas flow rates occurred during the ATR full power period of Cycle 152B (Figure 44). In order to calculate neon fractions of the gas mixture in each capsule, which are essential inputs in the thermal models to predict fuel temperature, these missing gas flow rates were calculated and qualified as described in Section 3.3.1.2. Therefore, they are not included in the total of missing gas flow rate records in Table 15.

The DRC members reviewed these testing results and made decisions on the quality of sweep gas flow rate records, which can be summarized as follows:

1. Qualify and replace all 1,674,344 slightly negative capsule gas flow rates with $0 \mathrm{sccm}$.

2. Fail 1,458,073 negative FPM flow rates recorded during ATR Cycles 155A and 155B.

3. Fill-in missing neon flow records in Capsules 7 and 8 for the period November 27, 2013 12:00 to November 29, 2013 22:35 (when ATR was at power during Cycle 152B) with whatever is the higher of $0 \mathrm{sccm}$ or the difference between $30 \mathrm{sccm}$ and the helium flow rate.

4. Fail all the remaining 1,293,293 missing records.

5. Fail 290 high sweep gas flow rates.

6. Delete all sweep gas flow rates recorded between January 24, 2013, at 12:41 and April 29, 2013 at 08:50 when AGR-3/4 was outside the reactor core.

Table 15 summarizes the data qualification status of neon, helium, impure, outlet, and FPM flow rate records by ATR cycle for the AGR-3/4 experiment as a result of the DRC decisions. The majority of gas flow rates $(92.0 \%$ of the total flow rates) are Qualified records. There are 2,751,656 Failed gas flow rates ( $8.0 \%$ of the total flow rates). It is worth mentioning that the Failed negative gas flow rates are from downstream flow meters and the Failed high and missing flow rates occurred during outages, therefore all Failed flow rates have no impact on AGR-3/4 fuel temperature prediction and FPMS data calculation. 
Table 15. Summary of gas flow rate failures during AGR-3/4 irradiation.

\begin{tabular}{|c|c|c|c|c|c|c|c|c|}
\hline $\begin{array}{l}\text { ATR } \\
\text { Cycle }\end{array}$ & $\begin{array}{c}\text { Total \# } \\
\text { Records }\end{array}$ & Negative & Too High & Missing & $\begin{array}{l}\text { Total \# } \\
\text { Failed }\end{array}$ & $\%$ Failed & $\begin{array}{c}\% \\
\text { Qualified }\end{array}$ & Note \\
\hline $151 \mathrm{~A}$ & 779,020 & 0 & 0 & 0 & 0 & $0.0 \%$ & $100.0 \%$ & $\mathrm{a}$ \\
\hline $151 \mathrm{~B}$ & $1,544,708$ & 0 & 2 & 20,588 & 20,590 & $1.3 \%$ & $98.7 \%$ & $\mathrm{a}$ \\
\hline $152 \mathrm{~A}$ & $4,099,260$ & 0 & 274 & $1,057,295$ & $1,057,569$ & $25.8 \%$ & $74.2 \%$ & $\mathrm{a}$ \\
\hline $152 \mathrm{~B}$ & $3,462,990$ & 0 & 0 & 214,516 & 214,516 & $6.2 \%$ & $93.8 \%$ & $\mathrm{~b}$ \\
\hline $154 \mathrm{~A}$ & $4,018,006$ & 0 & 0 & 894 & 894 & $0.0 \%$ & $100.0 \%$ & $\mathrm{a}, \mathrm{c}$ \\
\hline $154 \mathrm{~B}$ & $4,988,272$ & 0 & 0 & 0 & 0 & $0.0 \%$ & $100.0 \%$ & $\mathrm{a}$ \\
\hline $155 \mathrm{~A}$ & $7,453,464$ & 2,070 & 13 & 0 & 2,083 & $0.0 \%$ & $100.0 \%$ & $\mathrm{~d}$ \\
\hline $155 \mathrm{~B}$ & $7,864,336$ & $1,456,003$ & 1 & 0 & $1,456,004$ & $18.5 \%$ & $81.5 \%$ & $\mathrm{a}, \mathrm{d}$ \\
\hline Total $=$ & $34,210,056$ & $1,458,073$ & 290 & $1,293,293$ & $2,751,656$ & $8.0 \%$ & $92.0 \%$ & \\
\hline
\end{tabular}

a. 1,674,344 slightly negative capsule flow rates were replaced with $0 \mathrm{sccm}$ and were flagged as Qualified records; therefore they are also not included in the total of failed records.

b. Some missing data during ATR Cycle 152B full power phase were replaced with 0 sccm and flagged as Qualified records, which was described in Subsection 3.3.1.2.

c, All irrelevant data at the beginning of Cycle 154A were deleted from NDMAS database.

d. All Failed negative flow rates are the FPM flow rates.

\subsubsection{Data Qualification Summary}

NDMAS received a total of 53,608,130 TC temperature and gas flow rate records for the entire AGR-3/4 irradiation. A summary of the qualification status of these data is presented in Table 16. Of these data, $91.5 \%$ of the total met the requirements for Qualified records, $7.9 \%$ were Failed records, and $0.6 \%$ were Trend records. These numbers were counted after all irrelevant irradiation monitoring data recorded during the period of January 24, 2013, at 12:41 (6 days after 152B power-down and the AGR-3/4 test was removed from the ATR core) to April 29, 2013, at 8:50 (when actual measurements began after AGR-3/4 was inserted back into the ATR core) were deleted. All the pressure and moisture (humidity) sweep gas data were classified as Qualified by the DRC without discussion in this report.

There were $1,498,841$ TC records ( $2.8 \%$ of the total) that were Failed mostly because of five TC instrument failures (see Section 3.2.1 for details) indicating good AGR-3/4 TC performance compared to AGR-1 and AGR-2 TC performance. Only temperature control in Capsule 3 was affected because both TCs failed after ATR Cycle 154B. There were also 305,742 TC records $(0.6 \%$ of the total) that were labelled Trend due to one TC drift failure (TC3 in Capsule 10).

For sweep gas flow rates, there were 2,751,656 gas flow records (5.1\% of the total) that were Failed mostly because of the negative and missing values. The largest Failed count during ATR Cycle 155B is due to negative FPM flow rates. The second largest Failed count occurred during the low power cycle (ATR Cycle 152A) due to missing values when ATR was down. Remarkably, no gas line or valve issues occurred during the AGR-3/4 irradiation. It is worth noting that all Failed capsule gas flow rate records (neon and helium, and outlet flows) had no impact on AGR-3/4 fuel temperature prediction and FPMS data calculation because they occurred during reactor outages. 
Table 16. Qualification status of TC temperatures and sweep gas flow rates for AGR-3/4 experiment.

\begin{tabular}{|c|c|c|c|c|c|c|c|}
\hline $\begin{array}{l}\text { ATR } \\
\text { Cycle }\end{array}$ & $\begin{array}{c}\text { Total \# } \\
\text { Records }\end{array}$ & $\begin{array}{c}\text { Failed } \\
\text { TC }\end{array}$ & $\begin{array}{c}\text { Failed Gas } \\
\text { Flow } \\
\end{array}$ & $\begin{array}{l}\text { Total \# } \\
\text { Failed } \\
\end{array}$ & $\begin{array}{c}\% \\
\text { Failed } \\
\end{array}$ & $\begin{array}{c}\% \\
\text { Qualified* }\end{array}$ & Notes \\
\hline $151 \mathrm{~A}$ & $1,257,055$ & 0 & 0 & 0 & $0.0 \%$ & $100.0 \%$ & $\mathrm{a}$ \\
\hline $151 \mathrm{~B}$ & $2,490,977$ & 114 & 20,590 & 20,704 & $0.8 \%$ & $99.2 \%$ & $\mathrm{a}$ \\
\hline $152 \mathrm{~A}$ & $6,614,715$ & 15,257 & $1,057,569$ & $1,072,826$ & $16.2 \%$ & $83.8 \%$ & $\mathrm{a}$ \\
\hline $152 \mathrm{~B}$ & $5,751,591$ & 61 & 214,516 & 214,577 & $3.7 \%$ & $96.3 \%$ & \\
\hline $154 \mathrm{~A}$ & $6,798,333$ & 188,408 & 894 & 189,302 & $2.8 \%$ & $97.2 \%$ & $a, b, c$ \\
\hline 154B & $8,146,253$ & 246,499 & 0 & 246,499 & $3.0 \%$ & $96.5 \%$ & $\mathrm{a}, \mathrm{c}, \mathrm{d}$ \\
\hline $155 \mathrm{~A}$ & $11,023,886$ & 407,605 & 2,083 & 409,688 & $3.7 \%$ & $95.1 \%$ & $\mathrm{c}, \mathrm{d}, \mathrm{e}$ \\
\hline $155 \mathrm{~B}$ & $11,525,320$ & 640,897 & $1,456,004$ & $2,096,901$ & $18.2 \%$ & $80.6 \%$ & $\mathrm{a}, \mathrm{c}, \mathrm{d}, \mathrm{e}, \mathrm{f}$ \\
\hline Total $=$ & $53,608,130$ & $1,498,841$ & $2,751,656$ & $4,250,497$ & $7.9 \%$ & $91.5 \%$ & \\
\hline
\end{tabular}

a. 1,674,344 slightly negative capsule flow rates were replaced with $0 \mathrm{sccm}$ and flagged as Qualified records; therefore they are not included in the total of Failed records.

b. 1,197,696 irrelevant TC and gas flow records at the beginning of ATR Cycle 154A were deleted.

c. Cycles 154A two TC failures: TC2 in Capsule 2 on 04/26/2013 and TC1 in Capsule 3 on 05/17/2013.

d. Cycles 154B one TC failure: TC1 in Capsule 3 on 10/09/2013.

e. Cycles 155A one TC failure: TC1 in Capsule 5 on 01/11/2014.

f. Cycles 155B one TC failure: TC1 in Capsule 6 on 02/13/2014.

* Qualified percentages do not include 305,742 Trend TC readings ( $0.6 \%$ of the total records) from TC3 in Capsule 10 recorded after September 20, 2013 (ATR Cycle 154B), when it started drifting.

\subsection{FPMS Data}

For the AGR-3/4 irradiation, NDMAS has received and processed into its database release rate and $\mathrm{R} / \mathrm{B}$ data for ATR cycles 151A, 151B, 152B, 154A, 154B, 155A, and 155B/155B-1. This consisted of 259,896 (mostly nominal 8-hour) release rate records and 259,896 $\mathrm{R} / \mathrm{B}$ records for twelve reported radionuclides (Kr-85m, Kr-87, Kr-88, Kr-89, Kr-90, Xe-131m, Xe-133, Xe-135, Xe-135m, Xe-137, $\mathrm{Xe}-138$, and $\mathrm{Xe}-139)$. Each release rate or $\mathrm{R} / \mathrm{B}$ record is accompanied by an estimated uncertainty using knowledge about the FPMS measurement. NDMAS also received 732 records of weekly particle failure counts for each of the twelve capsules throughout the AGR-3/4 irradiation. Each failure count record contains the best-estimate, maximum, and minimum failure counts. All of these data have been capture passed, stored in the NDMAS database, and made available on the NDMAS Web portal (as shown in Figure 16 through Figure 19). The qualification status of all FPMS data has been set to In-process. The report that documents all events impacting quality of the AGR-3/4 FPMS fission product release rate and $\mathrm{R} / \mathrm{B}$ data is being issued as an ECAR that will be used to determine the data quality. Once the ECAR is issued the qualification statuses of FPMS data will be updated accordingly. The latest version of R/B is calculated using the isotope daily birthrate; therefore, these R/Bs are named daily R/B. The daily R/B data replace the earlier version of $\mathrm{R} / \mathrm{B}$ data calculated using a four point isotope birthrate, which have been flagged as Obsolete data in the NDMAS database. These data are available upon special request. The Qualified daily FPMS data are used for display on the NDMAS web pages and are available for data download. 


\section{DATA ACCESS}

The irradiation monitoring data and data qualification status are available on the NDMAS Web portal for secure access by ART Program participants. Currently, the NDMAS website is undergoing a major revision to expand display capacity and access speed as the database grows. Figure 49 shows the home page for fuel development and qualification site (https:/htgr.inl.gov/hprr/agrSite/). All content pages are currently under construction.

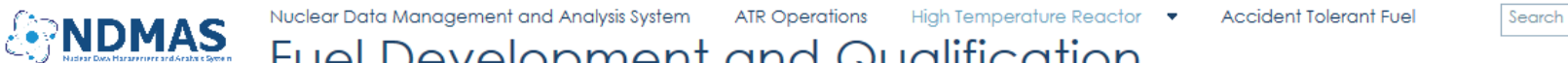

Fuel Development and
Qualification
Site Pages
Fuel Fabrication
Fuel Irradiation
Fuel Post-irradiation
Examination
AGR Data
Qualification Status
AGR-1
Graphite Technology
Development
High Temperature
Materials
HTR Program Data
Qualification Status
Site Contents

\section{TRISO Fuel Development and} Qualification Program

Fuel development and qualification R\&D consists of eight test trains that will be built, irradiated, examined, and tested to provide a baseline fuel form qualification data set to support the licensing and operation of the NGNP hightemperature gas-cooled reactor (HTGR). The first experiment (Advanced Gas Reactor [AGR]-1) using laboratory-scale produced uranium oxycarbide (UCO) fuel has been assembled, and the instrumented test train has been irradiated in the ATR at INL. AGR-1 is currently undergoing post-irradiation examination (PIE) in the MFC Hot Fuel Examination Facility (HFEF) main cell, Analytical Laboratory, and Electron Microscopy Laboratory. The second experiment, AGR-2, using large-scale coater produced $\mathrm{UCO}$ and uranium dioxide (UO2) fuel from the United States (U.S.) and UO2 fuel provided from France and South Africa, was irradiated from June 2010 through midOctober 2013. PIE will follow in Fiscal Year (FY)-14. The third and fourth experiments, AGR-3/4, have been combined in an effort to save money and reduce the overall program schedule. These two experiments presently being irradiated in ATR, and contain designed-to-fail (DTF) fuel particles that will be used to measure fission product transport data and qualification of source terms. The fifth, sixth, and seventh experiments, AGR-5/6/7 will also be combined and are expected to begin irradiation in abou FY-17. These experiments will contain UCO fuel fabricated by a United States-based commercial vendor using production-scale equipment. These experiments will be used for fuel qualification and validation of the preferred fuel design. The eighth experiment, AGR-8, will use the same UCO fuel as $5 / 6 / 7$, with some DTF fuel particles to validate the fission-product transport results of earlier experiments. It is expected to begin irradiation in about FY-1

The Fuel Development and Qualification Control Account includes the following data collection activities:

- Fabrication

- Irradiation

Post-iradiation Examination

- Fuel-performance Modeling

- Fission-product Transport

These activities are integral to the AGR Fuel Development and Qualification Program established by DOE in late 2002.

HTR Fuels point-of-contact: Dave Petti, 208.526.7735

Web page point-of-contact: Nancy Lybeck, 208.526.1033
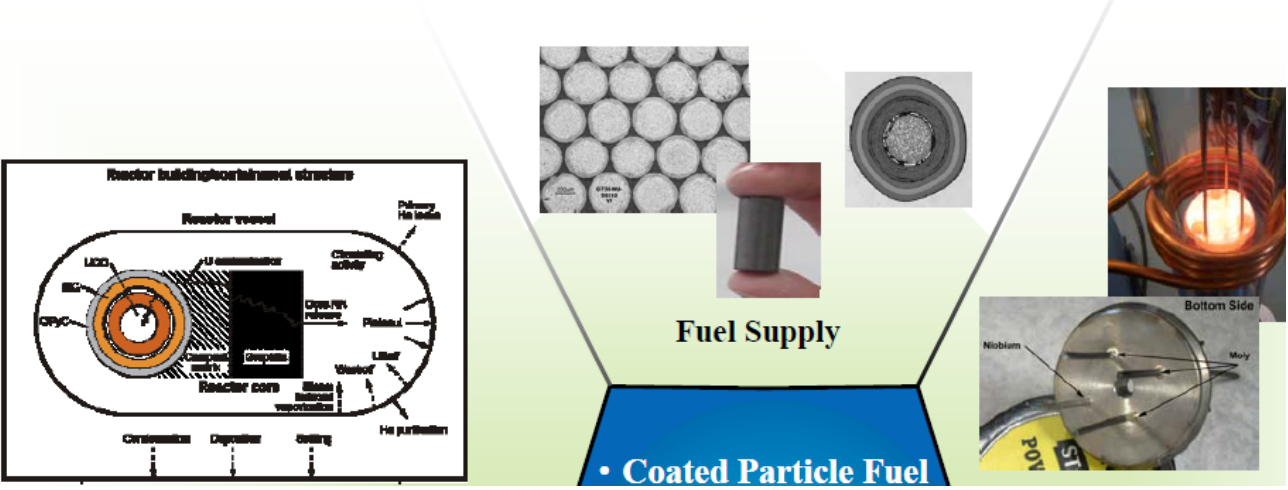

Figure 49. Example of Fuel development and qualification web pages on the NDMAS SharePoint site. 
The Web pages for the AGR-3/4 fuel irradiation will include plots and links for downloading data. The displayed information was built to assist with experiment monitoring and control, summarize data, and provide data for the program's data analysts and modelers. The irradiation experimental data (i.e., gas flow rates, TC temperatures, etc.) accessible here include only Qualified records and the calculated data (i.e., physics, fuel temperatures, and R/B etc.) are from the latest calculation. A special request is required if the need for different data tables (new formats, special period of time, older versions, etc.) and plots arises.

\section{REFERENCES}

ASME NQA-1, “Quality Assurance Requirements for Nuclear Facility Applications,” 2008, 1a 2009 addenda.

GDE-503, “Users' Guide for the Fission Product Monitoring System,” Rev. 1, Idaho National Laboratory, Idaho Falls, ID.

Hawkes, G. L. et al., 2014, "Thermal Predictions of the AGR 3/4 Experiment with Time Varying Gas Gaps,” 2014 ASME International Mechanical Engineering Congress \& Exposition, Paper IMECE2014 36943, November 2014, Montreal, Canada.

Hawkes, G. L., "NDMAS AGR-3/4 Calculated Temperatures; Calculated As-Run Daily Thermocouple and Peek Fuel Temperatures for Agr-3/4," FRM-241.21, Idaho National Laboratory, Idaho Falls, ID, 2015.

Hull, L., "NDMAS System and Process Description," INL/EXT-12-27594, Idaho National Laboratory, Idaho Falls, ID, 2012.

IAS121679, "Review of INL QA Program Execution for NDMAS ATR Data Source Streams," Idaho National Laboratory, 2012.

LWP-13621, "Software Quality Assurance for Research and Development Activities," Rev. 1, Idaho National Laboratory, Idaho Falls, ID.

MCP-2691, “Data Qualification,” Rev. 3, Idaho National Laboratory, Idaho Falls, ID.

PDD-13000, “Quality Assurance Program Description,” Rev. 4, Idaho National Laboratory, Idaho Falls, ID.

Pham, B.T., "AGR-3/4 Data Qualification Report for ATR Cycles 151A, 151B, 152A, 152B, 154A, and 154B,” INL/EXT-14-31186, Idaho National Laboratory, Idaho Falls, ID, 2014.

PLN-2690, "Idaho National Laboratory Advanced Reactor Technologies Technology Development Office Quality Assurance Program Plan,” Rev. 13, Idaho National Laboratory, Idaho Falls, ID.

PLN-2709, "Nuclear Data Management and Analysis System Plan,” Rev. 4, Idaho National Laboratory, Idaho Falls, ID.

PLN-3319, "Records Management Plan for the INL ART Technology Development Office," Rev. 3, Idaho National Laboratory, Idaho Falls, ID.

PLN-3551, "Fission Product Monitoring System Operability Test Plan for the AGR Experiment Series," Rev. 1, Idaho National Laboratory, Idaho Falls, ID.

PLN-3636, "Technical Program Plan for the Advanced Reactor Technologies Technology Development Office/Advanced Gas Reactor Fuel Development and Qualification Program," Rev. 3, 2014.

PLN-3867, “AGR-3/4 Irradiation Experiment Test Plan,” Idaho National Laboratory, Idaho Falls, ID, Rev. 0, 2011.

Q15807901, “Engineering Work Instructions for Assembling the AGR-3/4 Experiment,” Idaho National Laboratory, Idaho Falls, ID, December 6, 2011. 
SPC-1345, “AGR-3/4 Irradiation Test Specification,” Rev. 0, Idaho National Laboratory, Idaho Falls, ID, 2011.

TFR-630, “Advanced Gas Reactor AGR-3/4 Experiment Test Train,” Technical and Functional Requirements, TFR-630, January 27, 2011.

TFR-656, “Temperature Control and Off Gas Monitoring Systems for Advanced Gas Reactor Experiment AGR-3/4,” Technical and Functional Requirements, TFR-656, Rev. 1, July 21, 2011.

TFR-729, “Advanced Gas Reactor AGR-3/4 North East Flux Trap Irradiation Housing,” Technical and Functional Requirements, TFR-729, January 27, 2011.

TFR-747, "RDAS-CDCS Data Transfer to NDMAS," Technical and Functional Requirements, TFR-747 Rev. 3, July 21, 2011. 


\section{APPENDIX A}

\section{Credentials of Technical Reviewer}




\section{APPENDIX A}

\section{Credentials of Technical Reviewer}

\section{Credentials for Blaise Collin}

Blaise Collin is a senior nuclear physicist and engineer with more than 10 years of experience in modeling, simulation, and data analysis. His past fields of interest and expertise include intermediate energy nuclear physics, particle astrophysics, neutronics and nuclear reactor core physics. His current focus is on the modeling and assessment of TRISO fuel performance, especially for its use in the AGR experiments. In his different activities, he performed experimental modeling, ran simulations, and analyzed the subsequent results and output data. As a member of the AGR Fuel Development and Qualification Program team, he has a sound knowledge of the AGR-3/4 experiment, for which he wrote the Irradiation Experiment Test Plan. 